\author{
UNIVERSIDADE DE SÃO PAULO - USP \\ INSTITUTO DE PSICOLOGIA \\ DEPARTAMENTO DE NEUROCIÊNCIAS E COMPORTAMENTO
}

THAÍS FERNANDES ALVIM COELHO

RELAÇÃO ENTRE SENSIBILIDADE AO CONTRASTE E JULGAMENTO DE EXPRESSÕES FACIAIS DE EMOÇÕES EM CRIANÇAS DE 6 A 14 ANOS

SÃO PAULO 


\title{
RELAÇÃO ENTRE SENSIBILIDADE AO CONTRASTE E JULGAMENTO DE EXPRESSÕES FACIAIS DE EMOÇÕES EM CRIANÇAS DE 6 A 14 ANOS
}

\author{
Versão Original
}

\author{
Dissertação apresentada ao Instituto de Psicologia \\ da Universidade de São Paulo para obtenção do \\ título de Mestre em Ciências. \\ Área de Concentração: Neurociências e \\ Comportamento \\ Orientador: prof. Dr. Marcelo Fernandes da Costa
}


Fernandes Alvim Coelho, Thaís

Relação entre sensibilidade ao contraste e julgamento de expressões faciais de emoções em crianças de 6 a 14 anos / Thaís Fernandes Alvim Coelho; orientador Marcelo Fernandes da Costa. -- São Paulo, 2019.

$70 \mathrm{f}$.

Dissertação (Mestrado - Programa de Pós-Graduação em Neurociências e Comportamento) -- Instituto de Psicologia, Universidade de São Paulo, 2019.

1. Sensibilidade ao Contraste. 2. Desenvolvimento. 3. Percepção de Faces. 4. Julgamento de Emoções. I. Fernandes da Costa, Marcelo, orient. II. Título. 
FOLHA DE APROVAÇÃO

Thaís Fernandes Alvim Coelho

Relação entre sensibilidade ao contraste e julgamento de expressões faciais de emoções em crianças de 6 a 14 anos

Dissertação apresentada ao Instituto de Psicologia da Universidade de São Paulo para obtenção do título de Mestre em Ciências.

Área de Concentração: Neurociências e Comportamento

Orientador: prof. Dr. Marcelo Fernandes da Costa

Aprovada em:

11

Banca Examinadora:

Prof.(a) Dr.(a):

Julgamento: Assinatura:

Prof.(a) Dr.(a):

Julgamento: Assinatura:

Prof.(a) Dr.(a):

Julgamento: Assinatura: 
Ao Celso, meu querido sogro, que desde o início me apoiou e encorajou a conquistar este objetivo, e que certamente me iluminou após sua partida deste plano, me dando força e com suas palavras doces me incentivou "você é capaz, norinha!" Obrigada!

À Deus, que me deu a oportunidade de encarar novos desafios, descobrindo forças e capacidades que eram desconhecidas, e reforçando laços de afeto com aqueles que estão e estarão para sempre ao meu lado. 


\section{AGRADECIMENTOS}

Ao Marcelo da Costa Fernandes, meu orientador, que teve paciência comigo durante esses anos, me auxiliando, orientando, guiando, ensinando, me ajudando no meu crescimento e na conquista do meu objetivo, obrigada!

Ao pessoal do Lab Visual que me apoiou, escutou, auxiliou, orientou, e aguentou durante esses anos. À Elis, que com seus abraços reconfortantes me trouxe paz no meio do caos. À Heydi, que com seu sorriso trouxe luz aos meus dias. À Andréa que foi a peça inicial nessa história, que me incentivou e auxiliou durante esses árduos anos.

Ao Conselho Nacional de Desenvolvimento Científico e Tecnológico (CNPQ), pela concessão da bolsa de mestrado e pelo apoio financeiro para a realização desta pesquisa.

Ao meu marido, que com muita paciência, carinho e amor, esteve ao meu lado a todo instante, me apoiando e incentivando. Acreditando em mim quando eu mesma não acreditei, obrigada! Sem você, essa conquista seria impossível!

Aos meus pais que me deram a oportunidade de trilhar os caminhos desde o início, me orientando, auxiliando e ensinando valores que levarei para sempre comigo. Amo vocês!

À Silvia, que se tornou uma pessoa essencial, sem a qual eu não teria conseguido ter forças, nem capacidade para alcançar esse ou qualquer objetivo na minha vida. À Célia, que conquistou um espaço importante nessa minha jornada e que tenho muito carinho.

Aos meus irmãos Marcelo e Fernanda, que são um exemplo para mim. Ao meu avô Manuel, exemplo de trabalhador, e minha avó Inês, guerreira que tem ensinado tanto a todos nós, obrigada! 


\section{RESUMO}

Este trabalho teve como objetivo estudar a relação entre sensibilidade ao contraste e o julgamento de expressões faciais de emoções durante o desenvolvimento infantojuvenil, analisando a existência de possíveis correlações entre idade, taxa de acertos nas respostas e nível de contraste testado; além de diferenciar quais expressões emocionais precisam de maior/menor contraste para serem identificadas corretamente. Foram testadas 50 crianças, com idade média de 10,3 anos (desvio padrão= 2,05 anos; mediana = 10,5 anos e variação entre 6 e 14 anos) da Escola Municipal General Liberato Bittencourt (São Paulo/SP). Tivemos um grupo de adultos para comparação de pleno desenvolvimento, que contou com 30 adultos com acuidade visual normal, com idade média de 22,7 anos (desvio padrão=2,7; mediana $=$ 22,0 anos, variação entre 18 e 30 anos). Foi necessário desenvolver um instrumento de testagem que abrangesse todos os aspectos que queríamos abordar. Para isso utilizamos o Programa de Psicofísica Psykinematix. Avaliamos 4 diferentes expressões faciais, sendo neutra, alegria, tristeza e raiva, tanto para face feminina quanto para masculina. A tarefa do participante foi a de julgar o sexo e a emoção de cada imagem apresentada. Testamos 5 níveis de contraste distribuídos logaritmicamente entre $2,5 \%$ e $15 \%(2,5 ; 3,4 ; 5,2 ; 8,5 ; 15)$. O limiar de contraste para julgamento de cada emoção em cada sexo foi obtido por meio de uma medida psicofísica de Estímulos Constantes. Cada um dos níveis de contraste foi apresentado 3 vezes para cada uma das 4 expressões faciais. A imagem de cada face/expressão apareceu na tela do computador por um tempo de 2 segundos. O sujeito realizou um total de 120 julgamentos (60 faces masculinas +60 faces femininas). Uma função psicométrica determinou o limiar de contraste correspondente a $75 \%$ de julgamentos corretos. Como resultado, encontramos um aprimoramento da capacidade de reconhecimento de emoções em faces proporcional ao aumento da idade. Para face Masculina Neutra houveram diferenças estatisticamente significantes $(F=8,63$; $p<$ 0,001) entre os subgrupos: Adulto Masculino e Adulto Feminino; Adulto Masculino e Criança Masculino; Criança Feminino e Criança Masculino; Adulto Feminino e Criança Feminino. Para a face Masculina Alegre $(F=3,08 ; p=0,032)$ houve diferença entre os subgrupos Adulto Masculino e Criança Masculino. Na face Masculina Triste $(F=6,50$; $p=0,002$ ), mantiveram a diferença entre Adulto Masculino e Criança Masculino; e 
entre os subgrupos Adulto Feminino e Criança Feminino. Nas faces Femininas tivemos na Neutra $(F=5,13 ; p=0,003)$, a diferença entre os subgrupos Adulto Masculino e Criança Masculino. Na face Alegre $(F=5,57 ; p=0,002)$ tivemos diferença entre os subgrupos Adulto Feminino e Criança Feminino. A face Feminina Triste ( $F=$ 4,04; $p=0,011$ ) mostrou diferença entre Adulto Masculino e Criança Masculino; e entre os subgrupos Adulto Feminino e Criança Feminino. Foi identificado apenas uma diferença estatisticamente significante entre os subgrupos de mesma idade testados, onde os Homens Adultos necessitaram de um menor limiar de contraste para identificar a face do Homem com expressão Neutra, dentre todos os outros subgrupos, e sexo/expressões, não houve diferença estatisticamente significante. Como conclusão: o contraste de luminância afeta o julgamento de expressões faciais quando comparamos adultos e crianças, independente da emoção expressada.

Palavras-chave: Sensibilidade ao contraste; julgamento de emoções; desenvolvimento; percepção de faces. 
ABSTRACT

This work aimed to study the relationship between sensitivity to contrast and the judgment of facial expressions of emotions during the development of children and adolescents, analyzing the existence of possible correlations between age, rate of correct answers and level of contrast tested; in addition to differentiating which emotional expressions need greater / lower contrast to be correctly identified. 50 children were tested, with a mean age of 10.3 years (standard deviation $=2.05$ years, median $=10.5$ years and variation between 6 and 14 years) of Escola Municipal General Liberato Bittencourt (São Paulo / SP). We had a group of adults for comparison of full development, who had 30 adults with normal visual acuity, mean age of 22.7 years (standard deviation $=2.7$, median $=22.0$ years, variation between 18 and 30 years). It was necessary to develop a testing instrument covering all the aspects we wanted to address. For this we use Psykinematix Psychophysics Program. We evaluated 4 different facial expressions, being neutral, joy, sadness and anger, both for the female and male faces. The participant's task was to judge the sex and emotion of each presented image. We tested 5 levels of contrast distributed logarithmically between $2.5 \%$ and $15 \%(2.5,3.4,5.2,8.5,15)$. The contrast threshold for the judgment of each emotion in each sex was obtained by means of a psychophysical measure of Constant Stimuli. Each of the contrast levels was presented 3 times for each of the 4 facial expressions. The image of each face / expression appeared on the computer screen for 2 seconds. The subject performed a total of 120 judgments (60 male faces + 60 female faces). A psychometric function determined the contrast threshold corresponding to $75 \%$ of correct judgments. As a result, we find an improvement in the ability to recognize emotions in faces proportional to the increase in age. There were statistically significant differences between the subgroups for Male Neutral Face ( $F=$ 8.63, $p<0.001)$ : Male and Female; Adult Male and Child Male; Child Female and Child; Adult Female and Child Female. For the Joy Male $(F=3.08, p=0.032)$ there was a difference between the Male and Female subgroups. In the sad male face ( $F=6.50$, $p=0.002$ ), they maintained the difference between male and female; and among the subgroups Adult Female and Female Child. In the Female Faces we had in Neutral ( $F=5.13, p=0.003$ ), the difference between the subgroups Adult Male and Male Child. In the Joy face $(F=5.57, p=0.002)$ there was difference between the subgroup Adult 
Female and the subgroup Child Female. The sad female $(F=4.04, p=0.011)$ showed difference between male and female; and among the subgroups Adult Female and Female Child. Only a statistically significant difference was identified among the subgroups of the same age tested, where Adult Men required a lower contrast threshold to identify the Neutrally Man face, among all the other subgroups, and sex / expressions, there was no difference statistically significant. As a conclusion: the luminance contrast affects the judgment of facial expressions when comparing adults and children, regardless of the emotion expressed.

\section{Keywords:}

Contrast sensitivity; judgment of emotions; development; perception of faces. 


\section{LISTA DE FIGURAS}

Figura 1: O olho humano e suas principais estruturas anatômicas.............................

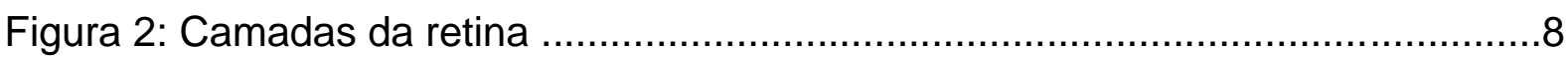

Figura 3: Principais estruturas do sistema visual humano, corte lateral...................10

Figura 4: Campos receptivos das células ganglionares .....................................13

Figura 5: Figura ilustrativa sobre a definição de ângulo visual.................................20

Figura 6: Letra de Snellen ilustrando a medida do ângulo visual.............................20

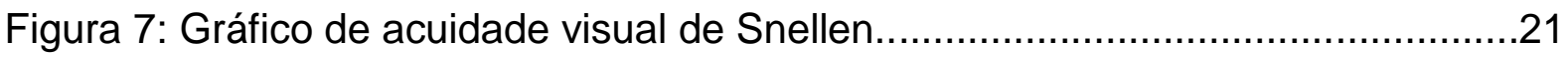

Figura 8: Estímulos utilizados para a medida de acuidade visual............................21

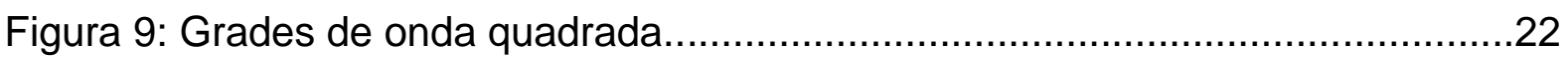

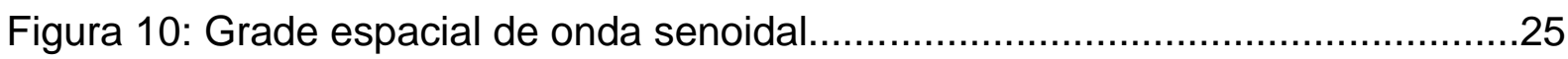

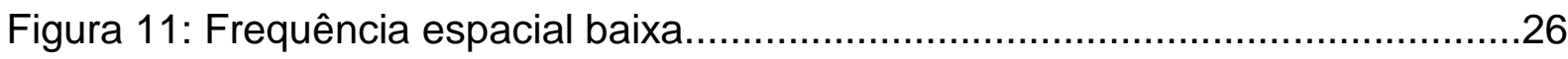

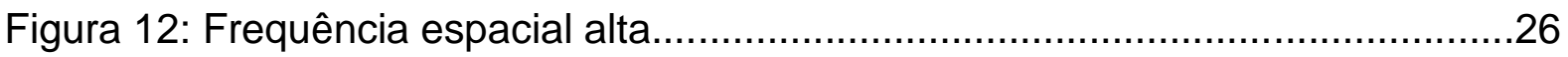

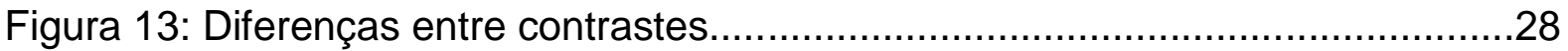

Figura 14: Ilustração mostrando a relação entre freq. esp. e contraste......................29

Figura 15: Experiência de incremento de limiar...................................................31

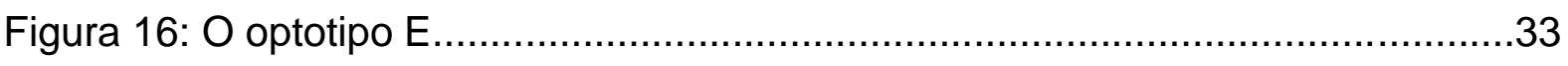

Figura 17: Filtragem de componentes espectrais espaciais de face neutra..............35

Figura 18: Ilustração das imagens utilizadas no experimento..................................48

Figura 19: Imagens utilizadas no experimento deste projeto...................................49 


\section{LISTA DE TABELAS}

Tabela 1: Valores Médios (desvio padrão) de Limiares de Contraste.........................50

Tabela 2: Análises Intragrupos.......................................................................58 


\section{LISTA DE GRÁFICOS}

Gráfico 1. Face do Homem com expressão Neutra .............................................51

Gráfico 2. Face do Homem com expressão Alegre.............................................52

Gráfico 3. Face do Homem com expressão Raiva...............................................52

Gráfico 4. Face do Homem com expressão Triste...............................................53

Gráfico 5. Face da Mulher com expressão Neutra.............................................54

Gráfico 6. Face da Mulher com expressão Alegre..................................................54

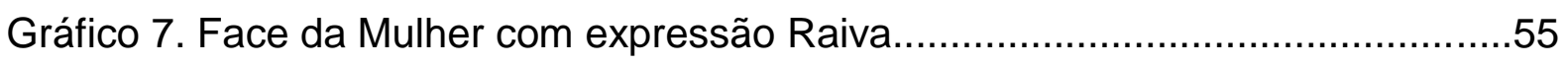

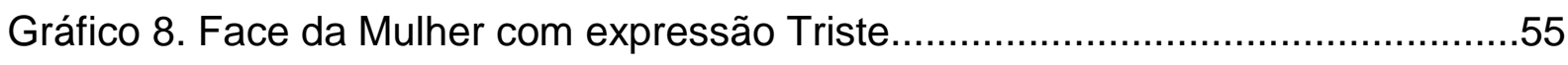

Gráfico 9. Análise Intragrupo subgrupo Adulto Homem .........................................56

Gráfico 10. Análise Intragrupo subgrupo Adulto Mulher .......................................56

Gráfico 11. Análise Intragrupo subgrupo Criança Homem (Meninos) .......................57

Gráfico 12. Análise Intragrupo subgrupo Criança Mulher (Meninas) .......................57 


\section{LISTA DE SIGLAS}

$\begin{array}{ll}\text { AV } & \text { Acuidade Visual } \\ \text { Área IT } & \text { Córtex Inferotemporal } \\ \text { Área MT } & \text { Área Médio-temporal } \\ \text { Área V1 } & \text { Área visual 1 } \\ \text { BASC } & \text { Behavior Assessment System for Children } \\ \text { C/face } & \text { Ciclos por Face } \\ \text { Cone S } & \text { cone Short / curto } \\ \text { DAP } & \text { Diferença Apenas Perceptível } \\ \text { FSC } & \text { Função de Sensibilidade ao Contraste } \\ \text { IE } & \text { Inteligência Emocional } \\ \text { LD } & \text { Limiar de Diferença } \\ \text { Lmax } & \text { Luminância Máxima } \\ \text { Lmin } & \text { Luminância Mínima } \\ \text { MAR } & \text { Mínimo Ângulo de Resolução } \\ \text { MSCEIT-YV } & \text { Mayer-Salovey-Caruso Emotional Intelligence Test - Youth Version } \\ \text { NGL } & \text { Núcleo Geniculado Lateral } \\ \text { OP } & \text { Olhar Preferencial } \\ \text { PVE } & \text { Potencial Visual Evocado } \\ \text { SV } & \text { Sistema Visual }\end{array}$




\section{SUMÁRIO}

I. INTRODUÇÃO

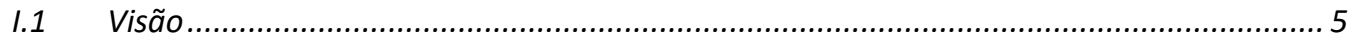

I.1.1 Estruturas Oculares..................................................................................... 5

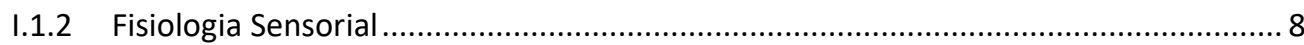

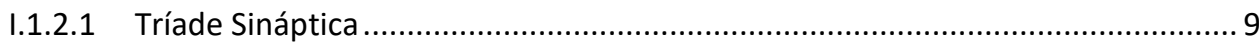

I.1.2.2 Campos Receptivos das Células Ganglionares ............................................ 12

I.1.2.2.1 Tipos de Células Ganglionares ............................................................ 14

I.1.2.3 Campos Receptivos do Núcleo Geniculado Lateral (NGL) ............................. 14

I.1.2.3.1 Divisão Parvocelular e Visão de Cores........................................................ 15

I.1.2.4 Campos Receptivos do Córtex Visual ......................................................... 16

I.1.2.4.1 Organização do Córtex Visual ............................................................... 17

I.1.2.5 Córtex Visual e Detecção de Características ..................................................... 18

I.1.2.6 Inibição lateral........................................................................................... 18

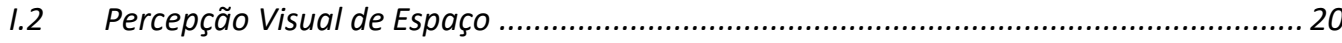

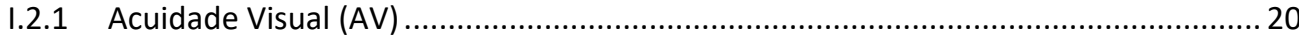

I.2.2 Visão de Contraste de Luminância .............................................................................. 24

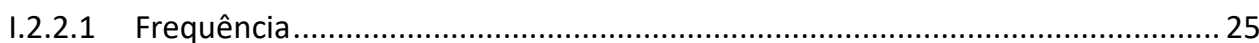

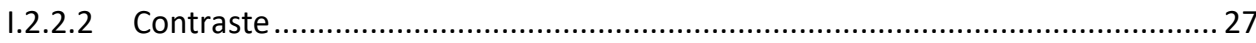

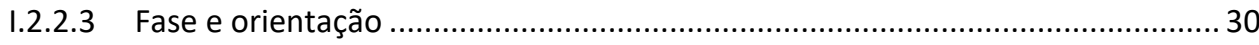

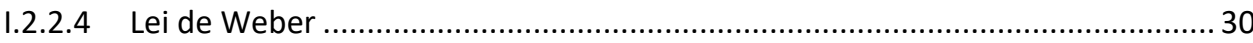

I.2.3 Frequências Espaciais e Reconhecimento de Faces ............................................. 33

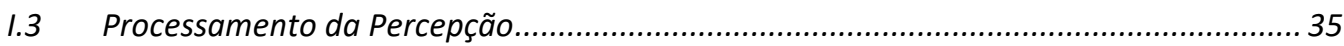

I.4 Desenvolvimento da Percepção de Faces................................................................... 36

I.4.1 Julgamento de Faces e Emoções........................................................................ 38

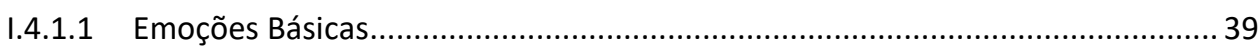

I.4.1.2 Processamento da Informação Facial ......................................................... 41

I.4.1.3 Alterações no Processamento da Informação Facial ........................................ 42

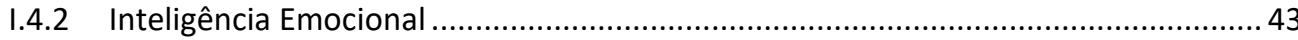

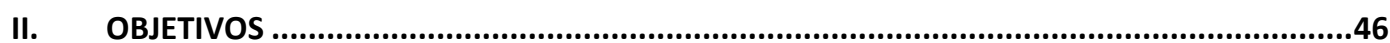

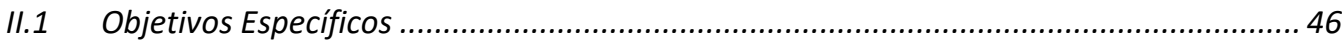

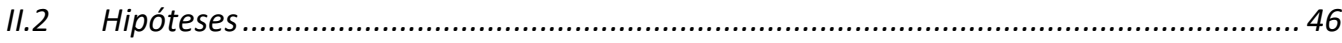

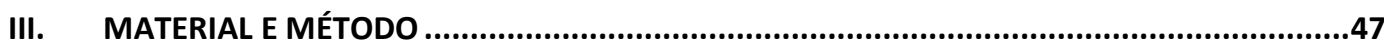




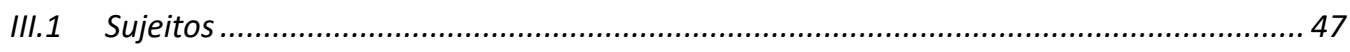

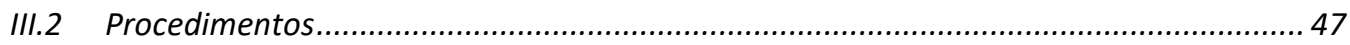

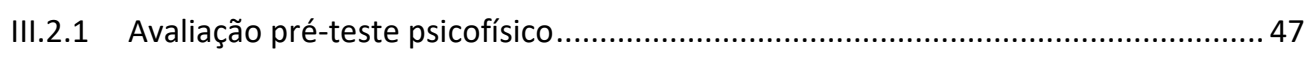

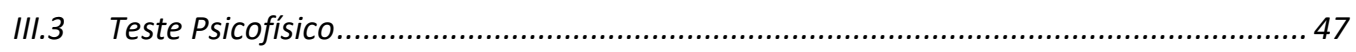

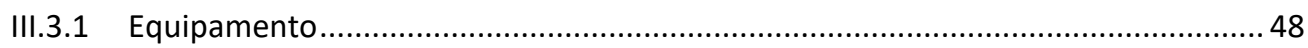

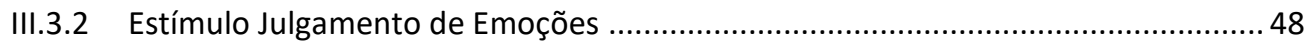

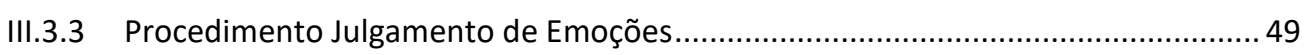

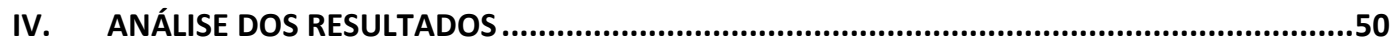

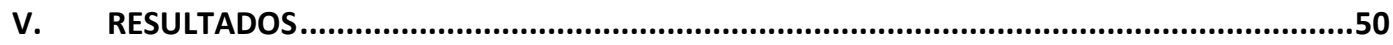

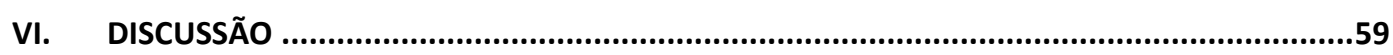

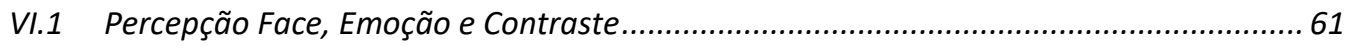

VII. CONCLUSÃO

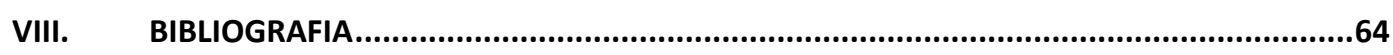




\section{INTRODUÇÃO}

Os sentidos são as estruturas fundamentais para a percepção do mundo. O mundo físico estimula e interage com os sentidos, levando o sistema nervoso a transformar, integrar e processar os estímulos, viabilizando a percepção do ambiente. A visão é o sistema sensorial predominante e mais significativo para os seres humanos. No nível biológico, isso se verifica pelo fato de que cerca de metade do córtex cerebral se destina ao processamento visual (Schiffman, 2005).

O reconhecimento de emoções em faces é uma habilidade essencial à interação social humana (Rocca et al., 2009), fornecendo informações interpessoais relevantes, permitindo predizer comportamentos e intenções de outras pessoas e, assim, adaptando nossas próprias ações (Calvo \& Lundqvist, 2008; Maxim \& Nowicki, 2003; Meletti, 2016).

Para estudarmos a relação entre sensibilidade ao contraste e julgamento de expressões faciais de emoções em crianças, precisaremos abordar um ponto específico dos sentidos, a visão, e pontos da percepção, que podem interferir direta e indiretamente na maneira como essas crianças julgam emoções durante seu desenvolvimento.

A sensação é o processo inicial de detecção e codificação da energia ambiental. $O$ ambiente emite sinais de energia potencial através da luz, pressão, calor, substâncias químicas, etc. e os órgãos dos sentidos recebem essa energia, e a transformam em um código neural bioelétrico que é enviado ao cérebro. As células receptoras são o primeiro passo para se sentir o mundo, e elas reagem a tipos específicos de energia. As células do olho reagem à energia luminosa e fazem parte de uma estrutura complexa que nos permitem enxergar o mundo detalhadamente (Schiffman, 2005).

\section{I.1 Visão}

\section{I.1.1 Estruturas Oculares}

Embora não seja o foco de nosso estudo, apresentamos uma brevíssima introdução sobre a anatomia do sistema visual. Nosso foco maior será na fisiologia e nas funções visuais. Segundo Simões e Tiedemann (1985), a sensação de cores, da claridade, da escuridão e do brilho dos objetos nos é proporcionada por um conjunto de células receptoras que revestem o interior do globo ocular. $O$ olho é um órgão 
complexo, composto de diversas partes (figura 1), algumas das quais são transparentes como a córnea, o humor aquoso contido na câmara anterior do globo ocular, o cristalino e o humor vítreo, substância gelatinosa que ocupa toda a câmara posterior.

Depois que passou por estes elementos, a luz atinge e atravessa todas as camadas da retina, uma vez que os fotorreceptores se encontram na última, adjacente à membrana da coróide. Esta é constituída por uma rede de vasos sanguíneos e encontra-se entre a retina e a esclera, que é a estrutura mais externa, de tecido fibroso, responsável pela sustentação e forma característica do globo ocular. A córnea e o cristalino formam, junto com o humor vítreo e o humor aquoso, o sistema óptico responsável pela focalização da imagem sobre a fóvea, a região mais delgada da retina. A fóvea também é conhecida como mancha amarela ou mácula lútea, devido à pigmentação causada pelo acúmulo de luteína, dando esta característica escurecida à área.

Há na região posterior do globo ocular um pequeno orifício, por onde penetram vasos sanguíneos e fibras do nervo óptico, em direção aos centros nervosos. Funcionalmente, esta região é conhecida como ponto cego, no qual não há receptores e, portanto, não tem representação perceptual. A córnea é uma grande lente com poder dióptrico de, aproximadamente, 60 graus de dioptrias esféricas, sendo a lente de maior poder do olho humano.

O cristalino apresenta uma característica de mudar seu poder dióptrico e apresenta menor poder dióptrico, em torno de 20 graus. O cristalino fica encapsulado em uma estrutura membranosa e é mantido na sua posição por um conjunto de delicadas fibras que partem de sua borda e se inserem no músculo ciliar; são as fibras da zônula, estruturas responsáveis pela acomodação (mudança do poder dióptrico) do cristalino. Logo à frente do cristalino encontra-se o conjunto de músculos que formam a íris e a pupila, que é o orifício pelo qual a luz penetra no olho. 


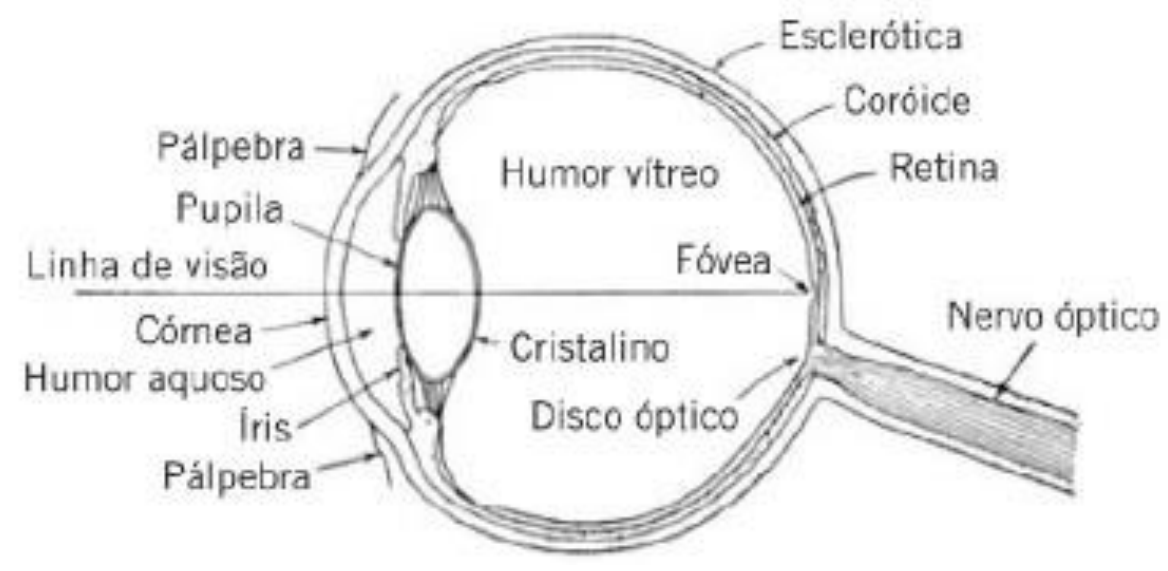

Fonte: Schiffman (2005)

Figura 1: O olho humano e suas principais estruturas anatômicas.

A retina é uma projeção do sistema nervoso central para fora da calota craniana. Esta peculiaridade faz com que grande atenção seja dada a esta estrutura, uma vez que ao observar a retina, estamos observando parte do sistema nervoso central. $\mathrm{Na}$ retina encontram-se diversos tipos de células neurais como fotorreceptores, células da glia e neurônios bipolares. A camada de fotorreceptores é formada pelas células nervosas sensíveis à luz. Após atravessar todas as estruturas transparentes do olho, a luz atinge finalmente a retina; porém, antes de ser absorvida pelos fotorreceptores, terá que atravessar também todas as camadas de células da própria retina, já que os receptores estão localizados na última camada e virados para trás, apontando seus receptores para a camada do epitélio pigmentado.

A camada mais interna, em oposição à mais externa dos fotorreceptores, corresponde a fibras nervosas que darão origem ao nervo óptico. A seguir, a luz atravessa a camada das células ganglionares, amácrinas, região plexiforme interna, células bipolares, região plexiforme externa e células horizontais. Finalmente, na última camada da retina, a luz é absorvida pelos fotorreceptores que ali se encontram. A organização destas camadas pode ser verificada na figura 2. 
A)

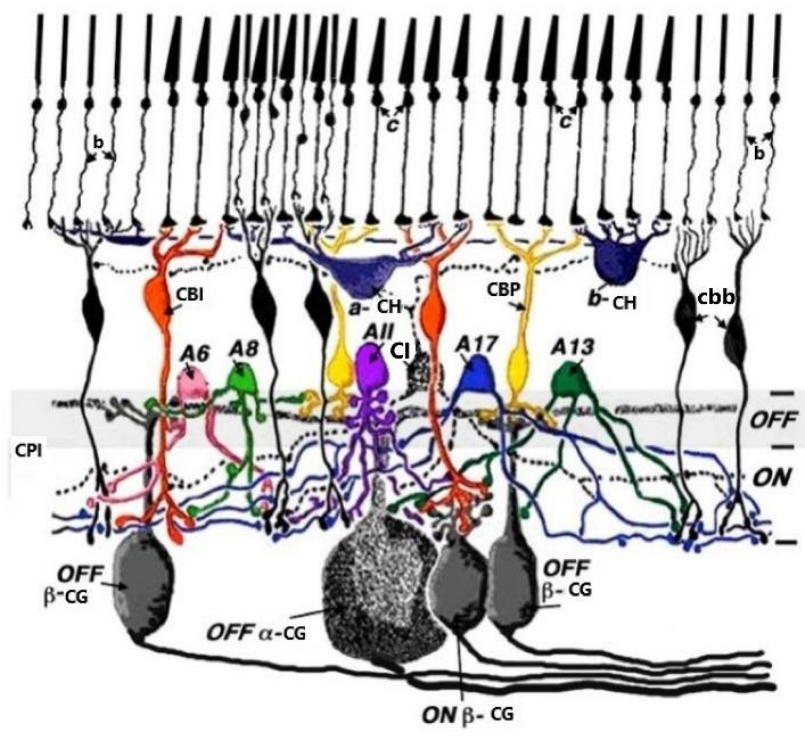

B)

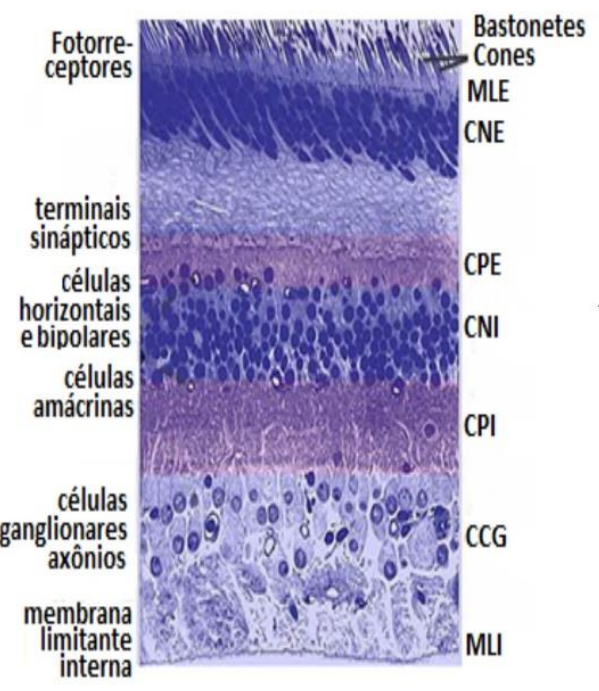

Fonte: Adaptado de Kolb (2011)

Figura 2. Camadas da retina. A) Reprodução de lâmina de histologia mostrando diferentes marcações para as diferentes estruturas retinianas. B) Temos uma reprodução esquemática, simplificada, dos principais grupos celulares da retina. Legendas: $b$ - bastonete; $c$ - cone; $\mathrm{CBI}$ - Célula Bipolar Invaginante; a-CH - a-Célula Horizontal; CBP - Célula Bipolar Plana; b-CH - b-Célula Horizontal; cbb - células bipolares dos bastonetes; A6/A8/All/A17/A13 - Células amácrinas; CL - Células interplexiformes; $\mathrm{CPI}$ - Camada Plexiforme Interna; $\beta$-CG - $\beta$-Célula Ganglionar; $\alpha-C G$ - $\alpha$-Célula Ganglionar; MLE - Membrana Limitante Externa; CNE - Camada Nuclear Externa; CPE - Camada Plexiforme Externa; CNI - Camada Nuclear Interna; CCG - Camada de Células Ganglionares; MLI Membrana Limitante Interna.

Outros dois grupos celulares presentes na retina são as células amácrinas e horizontais, que proporcionam a comunicação entre neurônios de uma mesma camada, permitindo uma sofisticada elaboração da informação captada pelos receptores.

A reação fotoquímica dos receptores dá origem a uma resposta neural, que é transmitida às células bipolares. Estas, por sua vez, transmitem seus sinais às células ganglionares, cujos axônios se agrupam e, formam, assim, o nervo óptico, o qual levará os impulsos nervosos ao sistema nervoso central. Esta atividade neurofisiológica é a base da construção das informações sensoriais, apresentadas a seguir.

\section{I.1.2 Fisiologia Sensorial}

De acordo com Simões e Tiedemann (1985) a percepção de brilho é a capacidade de perceber a luz que emana ou reflete dos objetos no ambiente. Como 
os objetos fornecem luz, são chamados fontes luminosas, e podem ser de dois tipos: fontes emissoras e fontes refletoras.

As fontes emissoras, como lâmpadas, velas, vaga-lumes e o sol, emitem luz própria. As fontes refletoras são todos os objetos capazes de refletir parte, ou a totalidade, da luz que incide sobre eles. A intensidade da luz de fontes emissoras é medida em termos de iluminância, enquanto que no caso de fontes refletoras falamos em medida de luminância. A percepção de luminosidade, aparentemente, é uma capacidade perceptiva inata, que pouco depende da aprendizagem para ser aprimorada. A percepção de luminosidade em crianças é muito semelhante à dos adultos.

Fotorreceptores são receptores sensoriais responsáveis pela visão. São células que captam a luz que chega à retina e transmitem para o cérebro um impulso nervoso correspondente à qualidade dessa luz, permitindo assim que o cérebro reconheça imagens (do Valle, 2008). Apresentam um nível muito alto de atividade metabólica e isso determina sua localização na retina externa, perto do suprimento de sangue da coróide. Os fotorreceptores se dividem em dois grupos: bastonetes, que são a base da visão escotópica, e cones, que fornecem a base para a visão fotópica.

A visão escotópica ocorre sob condições de iluminação fraca (noturno). É caracterizada por sensibilidade maior a luzes muito fracas, pouca acuidade visual e a ausência de discriminação de cores, e é mediada por bastonetes. A visão fotópica, que ocorre sob condições de iluminação intensa (diurna), apresenta pouca sensibilidade a luzes fracas; no entanto, é caracterizada por excelente acuidade visual e discriminação de cores. Os cones medeiam a visão fotópica. A existência de duas classes de fotorreceptores, cada uma operando sob diferentes condições de iluminação, leva ao que foi chamado de retina duplex. Em condições crepusculares (mesópicas), tanto os bastonetes quanto os cones contribuem para a visão (Schwartz, 2009).

\section{I.1.2.1 Tríade Sináptica}

Os três principais locais onde ocorrem o processamento e as conexões sinápticas do sistema visual humano são a retina, o Núcleo Geniculado Lateral (NGL) e o córtex visual do lobo occipital, destacados na figura 3. 


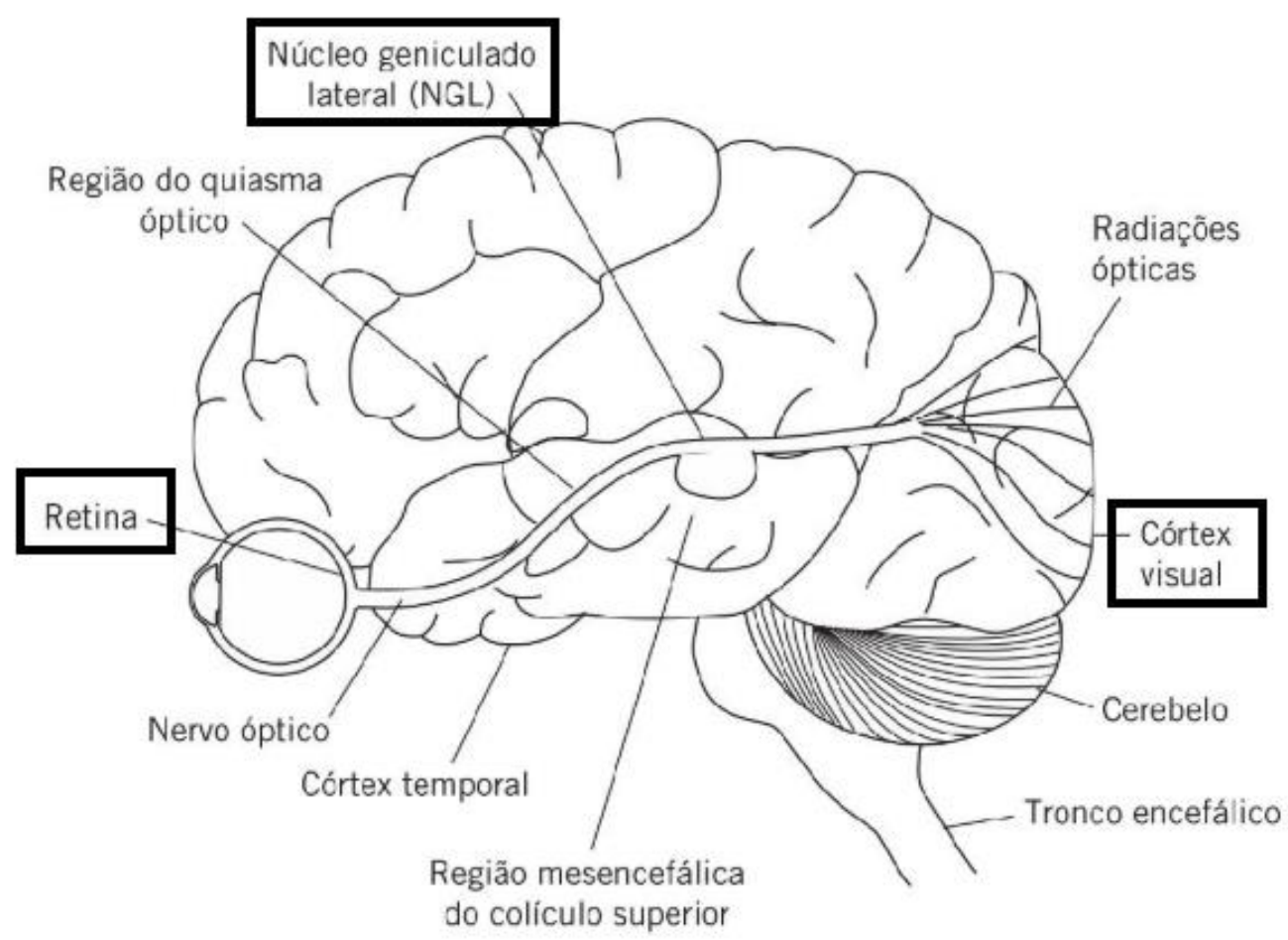

Fonte: Adaptado de Schiffman (2005)

Figura 3: Principais estruturas do sistema visual humano, corte lateral. São destacados os três principais locais onde ocorrem o processamento e as conexões sinápticas: a retina, o Núcleo Geniculado Lateral (NGL) e o córtex visual do lobo occipital. Também aparecem a localização do colículo superior do mesencéfalo, o córtex temporal e algumas estruturas colaterais, como a região do quiasma óptico e o tronco encefálico.

Segundo Schiffman (2005), o NGL serve como um centro sensorial importante para a visão. Os axônios das células ganglionares da retina formam sinapse com as células do NGL de maneira ordenada e sistemática. Quando os axônios saem do NGL, distribuem-se como um grupo de fibras chamado radiações ópticas. Essas radiações fazem sinapse com um aglomerado específico de neurônios do lobo occipital do córtex cerebral, situado na parte posterior do cérebro. Essa região é chamada córtex estriado, ou córtex visual primário (ou área visual 1 - Área V1).

O processamento neural executado pelo córtex visual primário está em um nível relativamente básico, servindo para registrar inicialmente as características locais de estímulos, como bordas e orientação. Da Área V1 as mensagens são encaminhadas a várias outras áreas anatômica e funcionalmente distintas do córtex, que coletivamente formam o córtex extra-estriado, ou córtex secundário. 
Essas áreas que formam o córtex extra-estriado são nomeadas em sequência com números baseados em sua localização relativa ao córtex visual primário (Área V1), de modo que a mais próxima seja V2, depois V3 e assim por diante. Funcionalmente, as Áreas V2 e V3 estão relacionadas à forma e à orientação, a Área V4 parece ser especializada no processamento das informações sobre cores, enquanto a Área V5 parece ser especializada na análise da estimulação de movimento.

Além dessas regiões corticais, outra região do lobo temporal do córtex (Área IT, córtex inferotemporal) e uma região do lobo parietal do córtex (Área 7 de Brodmann) também recebem mensagens neurais iniciadas no nível da Área V1. Possivelmente, as análises de forma e cor são integradas na área do IT, permitindo assim a percepção espacial.

Mishkin et al., (1983) identificaram dois caminhos relativamente independentes, mas paralelos, através dos quais as mensagens são enviadas da Área V1 para áreas distintas dos córtices extra-estriado, temporal e parietal, que representam aspectos complexos da nossa experiência visual. Um caminho (chamado de via dorsal, ou caminho parietal), importante para a localização espacial, estendese do córtex visual primário, fazendo conexões intermediárias com as Áreas V2, V3 e V5 (MT - área médio-temporal), ao lobo parietal. O segundo caminho (chamado de via ventral, ou caminho temporal), importante para a identificação de objetos, estendese da Área V1, com conexões intermediárias com as Áreas V2 e V4, e termina na Área IT.

Schiffman (2005) conclui que a estimulação recebida do ambiente e projetada na retina é processada e transmitida a três níveis do sistema visual. As células ganglionares da retina enviam a maior parte dos axônios ao NGL do tálamo, cujos axônios alcançam a área de projeção cortical primária do lobo occipital. $O$ córtex visual primário encaminha mensagens neurais a partes do córtex extra-estriado, inclusive a regiões específicas dos lobos temporal (MT, IT) e parietal do córtex. A seguir estudaremos como as células de cada um desses níveis reagem à estimulação ambiental projetada na retina. 


\section{I.1.2.2 Campos Receptivos das Células Ganglionares}

O campo receptivo de determinada célula receptora é a região do campo visual ou a região correspondente da retina que, quando adequadamente estimulada, excita ou inibe o padrão de disparo da célula (Schiffman, 2005). As células ganglionares possuem campos receptivos centro-periféricos. Seus campos receptivos são pequenos e aproximadamente circulares. Dependendo da parte estimulada, a luz altera o disparo da célula ganglionar de variadas formas, como vemos na figura 4 .

Em uma determinada célula ganglionar, o campo receptivo consiste em uma pequena área circular " $O N$ ', na qual a taxa de impulso da célula aumenta quando estimulada pela luz. Quando essa estimulação é feita em uma área periférica "OFF" da célula, ocorre a inibição da atividade neural, que produz uma sequência rápida de impulsos ao cessar o estímulo luminoso.

Também existe outro tipo de célula ganglionar, uma com forma reversa de campo receptivo, a qual consiste em uma região inibitória centro-OFF e uma região excitatória periferia- $O N$. Se a periferia- $O N$ estiver iluminada, a taxa de disparo das células aumenta; se a região centro-OFF estiver iluminada, a taxa de disparo é suprimida. Contudo, quando a iluminação do centro-OFF acaba, há uma vigorosa descarga de reação (Schiffman, 2005). 


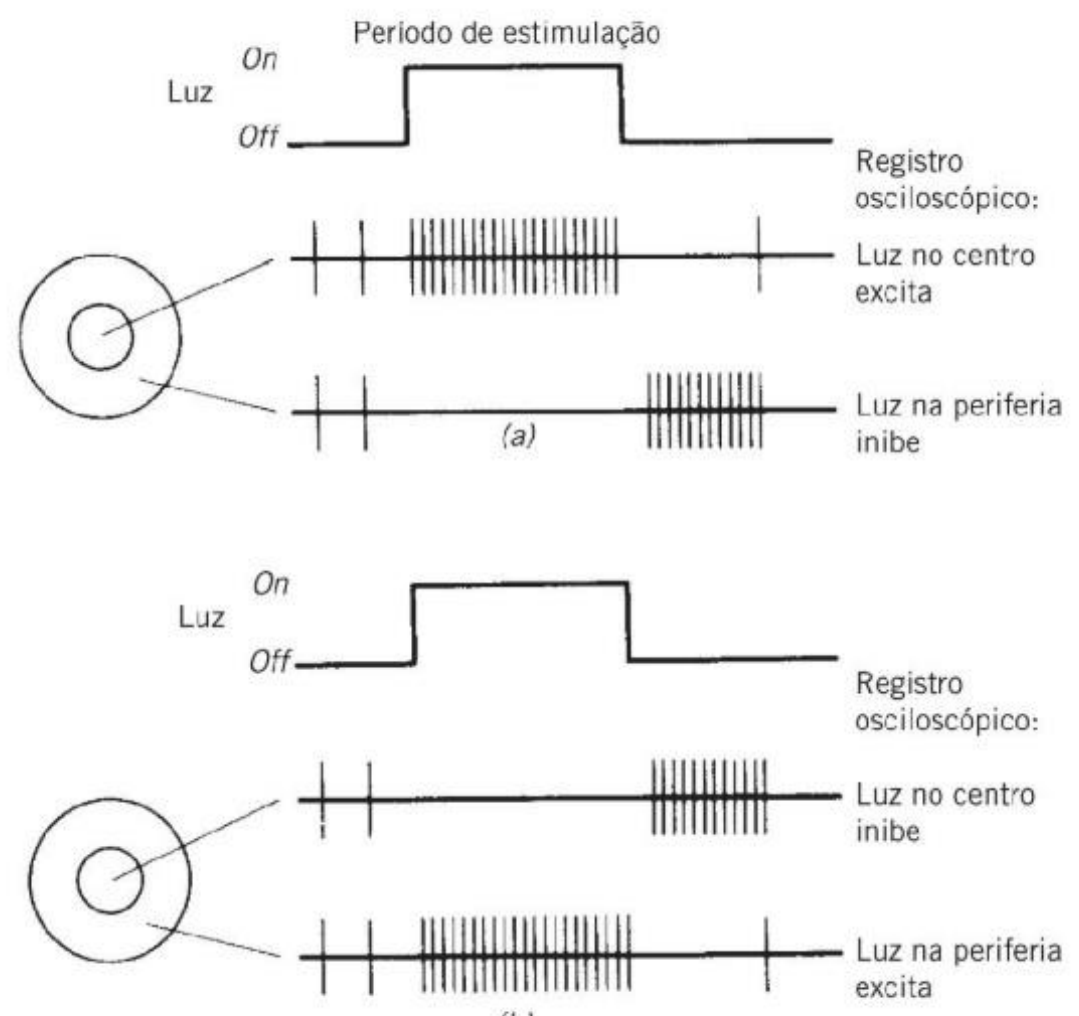

(b)

Fonte: Schiffman (2005)

Figura 4: Campos receptivos das células ganglionares a) Registro osciloscópico mostrando o disparo intenso de uma célula ganglionar na região centro-ON quando um ponto circular de luz atinge 0 centro do campo. Se o ponto de luz atingir a área anular periferia-OFF, o disparo é suprimido até a luz ser desligada. Essa célula tem, pois, um campo receptivo centro-periférico. b) Registro osciloscópico de uma célula ganglionar com uma região inibitória centro- $O F F$ e uma região excitatória periferia-ON.

Se a luz atingir o centro do campo, a taxa de disparo é suprimida, porém há uma descarga forte quando a luz deixa de brilhar.

As regiões $O N$ e OFF são antagônicas, portanto ao iluminar ambas ao mesmo tempo, teremos efeitos opostos, se neutralizando e resultando em respostas ON e OFF muito fracas. Sendo assim, a iluminação uniforme da retina, que afeta simultaneamente todos seus receptores, não afeta uma única célula ganglionar tanto quanto um ponto pequeno de luz que cubra apenas o campo receptivo excitatório desta célula. Os campos receptivos centro-periféricos são melhores na detecção de contrastes do que na iluminação geral por não responderem muito a alterações na iluminação quando estas incluem tanto o centro do campo receptivo quanto a periferia (Schiller, 1992). 


\section{I.1.2.2.1 Tipos de Células Ganglionares}

Além das características gerais do campo receptivo citadas acima, as células ganglionares também se dividem em dois tipos, células $P$ (do latim parvum, pequeno) e células $M$ (magnum, grande), se diferenciando em número, tempo de reação a sinais neurais, tamanho dos campos receptivos e localização. É necessário distingui-las, pois elas processam diferentes tipos de informações, transmitindo-as a diversas áreas do NGL.

Schiffman (2005) nos relata que as células $P$ são as células ganglionares mais numerosas, apresentam baixa velocidade de condução, reagindo de maneira estável e sustentada aos estímulos. Possuem campos receptivos centro-periféricos pequenos e, por este motivo reagem a detalhes precisos e minuciosos de estímulos estacionários. Estão localizadas na fóvea (região retiniana responsável pela acuidade visual), e também estão envolvidas no processamento de informação das cores.

As células $M$ têm uma velocidade de condução mais rápida e respondem abruptamente com reações transitórias, exibindo uma rápida explosão de atividade com a estimulação e voltando rapidamente a ficar inativas. Comparadas às células $P$, as células $M$ têm campos receptivos centro-periféricos grandes e estão localizadas na periferia retiniana, por serem menos capazes de contribuir com a acuidade visual. Sua principal propriedade é responder ao movimento, por apresentar reações rápidas aos estímulos.

Com essas informações, o autor acima citado nos permite concluir que a retina não apenas transforma a energia luminosa e transmite sinais neurais, mas que além disso, dentro da retina já pode ser percebido um processamento preliminar, porém complexo, do estímulo.

\section{I.1.2.3 Campos Receptivos do Núcleo Geniculado Lateral (NGL)}

A maioria dos axônios das células ganglionares retinianas transmite sinais às células do NGL no tálamo (Schiffman, 2005). As diferenças entre as células $\mathrm{P}$ e $\mathrm{M}$ também são mantidas no NGL. Seus campos receptivos são similares, tendo centro$O N$ e periferia- $O F F$, ou inverso, além de diferenças anatômicas e funcionais.

Livingstone \& Hubel (1987) estudam e descrevem essas diferenças entre duas divisões distintas dentro do NGL. Uma divisão de células pequenas no NGL, chamada de divisão parvocelular, recebe sinais das células ganglionares retinianas $\mathrm{P}$, 
com campos receptivos pequenos, e uma divisão de células grandes, chamada de divisão magnocelular, recebe sinais das células ganglionares retinianas $M$, com campos receptivos relativamente grandes.

As células da divisão parvocelular do NGL são sensíveis à cor, têm campos receptivos pequenos (capacitando-as distinguir detalhes visuais finos), dão uma resposta lenta, relativamente prolongada, e são relativamente pouco responsivas a estímulos de baixo contraste.

As células da divisão magnocelular são insensíveis à cor, apresentam campos receptivos grandes e baixa resolução para características visuais pequenas, respondem depressa, de maneira transitória, e são relativamente sensíveis a estímulos de baixo contraste. As principais diferenças entre as duas divisões implicam que elas são responsáveis por aspectos muito diferentes da visão. Concluindo assim, que a divisão magnocelular lida com movimento e localização da imagem visual, enquanto a divisão parvocelular está ligada à cor, à forma e ao detalhe da imagem visual. Muitas vezes as divisões magnocelular e parvocelular são referidas pelos neurocientistas como divisões onde e o quê, respectivamente.

\section{I.1.2.3.1 Divisão Parvocelular e Visão de Cores}

O cientista inglês Thomas Young propôs a Teoria Tricromática, em 1802, que foi retomada e ampliada por Herman von Helmholtz em 1866. Essa teoria postula a existência de três tipos de células com fotopigmentos sensíveis a comprimentos de onda, cada qual com um pico de absorção em uma região particular do espectro de luz. Sua nomenclatura é derivada das suas sensibilidades máximas, sendo chamados de cones $\mathrm{S}$, por absorverem comprimentos de onda curta (cone $\mathrm{S}$ - Short), correspondentes ao azul, cones $\mathrm{M}$, que realizam a absorção de ondas médias, correspondentes ao verde, e os cones $\mathrm{L}$, que absorvem porções de luz de comprimento de onda longa, correspondente ao vermelho.

Os cones $L$ e $M$ estão concentrados no centro da fóvea, enquanto os cones $S$ concentram-se na sua borda, sendo escassos no centro. Os fotopigmentos dos cones $M$ e $L$ são sensíveis ao longo da maior parte do espectro visível, enquanto os cones $S$ respondem a menos da metade do espectro. Devido a essa distribuição, vários comprimentos de onda estimulam mais de um tipo de cone (Schiffman, 2005). 
Uma segunda importante teoria da visão colorida foi postulada por Ewald Hering em 1920, chamada Teoria do Processo Oponente. Ele propõe três mecanismos independentes, cada qual composto por um par de processos cromáticos ou de sistemas neurais oponentes: os processos oponentes amarelo-azul, vermelhoverde e preto-branco. Cada um desses processos pode fornecer apenas dois tipos de respostas sensoriais, que são antagônicas uma à outra.

Só se pode enxergar o vermelho ou o verde, o amarelo ou o azul, mas não o vermelho e o verde, nem o amarelo e o azul ao mesmo tempo. Se ambos os membros de um par de receptores forem igualmente estimulados, eles se cancelam mutuamente, resultando na sensação de cinza, ou ausência de cor.

Hurvich e Jameson (1955, 1957 e 1974), propuseram que a codificação de cor é feita em dois estágios. As informações sobre os comprimentos de onda são processadas pelos três tipos diferentes de receptores no nível dos cones, e então essas informações passam a alimentar os processos oponentes que ocorrem posteriormente em nível neural.

\section{I.1.2.4 Campos Receptivos do Córtex Visual}

Diferentemente dos campos receptivos das células ganglionares e do NGL, as células do córtex visual exigem um arranjo óptico mais preciso para que sejam excitadas. Hubel e Wiesel realizaram vastas pesquisas sobre o funcionamento do cérebro visual dos mamíferos, nos trazendo alguns esclarecimentos a respeito dos campos receptivos do córtex visual primário.

Uma das descobertas de Hubel e Wiesel (1962), foi que, em vez de campos receptivos circulares, com regiões $O N$ e OFF concêntricas, como nas células ganglionares retinianas e nas células do NGL, os campos receptivos dos neurônios do córtex visual apresentam propriedades lineares. Ou seja, a maioria dos estímulos efetivos é formada de linhas, barras e variados segmentos retangulares com bordas definidas. Esses neurônios variam de diversos modos, alguns possuem campos receptivos extremamente pequenos, e outros têm campos relativamente grandes, especialmente os que estão ligados às regiões retinianas periféricas.

Schiffman (2005) apresenta que algumas dessas células possuem, comparativamente, campos receptivos simples; um pequeno segmento alongado de reta, uma borda ou uma barra de luz desencadeará uma resposta enérgica. Os 
campos receptivos dessas células corticais também exigem que o estímulo esteja em determinada localização e em certa orientação. Por responderem a características ambientais simples, porém seletivas, Hubel e Wiesel as denominaram como células simples.

Outra classe de células identificadas por Hubel e Wiesel são chamadas células complexas. Estas são unicamente para orientação, ou seja, reagem a estímulos que estejam em uma orientação específica, ao movimento do estímulo em uma direção específica e seus campos receptivos são geralmente maiores do que os das células simples.

Uma terceira classe de células corticais foi denominada como células hipercomplexas, são semelhantes às células complexas, respondendo ao movimento e aos estímulos especificamente orientados, porém, sua característica é que sua resposta será melhor ajustada de acordo com o comprimento específico do estímulo, respondendo a alterações nos limites. Essas células são especificamente úteis para detecção de bordas, cantos e divisas.

Schiffman (2005) relata que algumas células corticais simples e complexas também respondem com mais força se o estímulo em seu campo receptivo tiver um comprimento específico, sendo chamadas de células end-stopped. Segundo o autor acima citado, a organização estrutural e funcional dos campos receptivos do córtex visual se dá através de colunas de orientação, hipercolunas e ampliação cortical.

\section{I.1.2.4.1 Organização do Córtex Visual}

Colunas de orientação são células alinhadas com seus campos receptivos, dentro de uma dada coluna, que reagem melhor a uma única orientação de estímulo. Essas colunas também estão organizadas com relação ao olho estimulado, mesmo as células do córtex recebendo informações de ambos os olhos, as colunas de orientação são mais receptivas e mostram maior resposta à estimulação de um dos olhos. Essa preferência das células corticais a responder melhor ao estímulo em um dos olhos chama-se dominância ocular.

Hubel e Wiesel (1977) notaram que a superfície do córtex é composta de séries alternadas de colunas de dominância ocular, com cada coluna reagindo melhor à estimulação recebida tanto do olho esquerdo, quanto do direito. Sendo assim, o córtex se organiza em colunas de dominância ocular e em colunas de orientação. 
Chama-se hipercoluna um conjunto de colunas adjacentes que inclui todas as orientações possíveis, bem como colunas de dominância ocular.

As hipercolunas se repetem regularmente na superfície do córtex visual primário, realizando assim a análise e o processamento das informações que caem em um ponto específico do campo visual. Essas hipercolunas estão distribuídas, servindo cada uma delas a uma região local precisa da retina, e são dezenas de milhares. Porém elas não se ligam de maneira igual a todas as áreas retinianas.

A área retiniana próxima à fóvea abrange mais espaço cortical, e com isso mais hipercolunas do que outra área de um mesmo tamanho na periferia da retina (Anstis, 1998). Essa distribuição desigual, mas funcionalmente importante da representação cortical da área foveal relativa à periferia retiniana, chama-se ampliação cortical (Schiffman, 2005).

\section{I.1.2.5 Córtex Visual e Detecção de Características}

Nos itens acima pudemos observar que o processamento de informações ocorre em diversas regiões do sistema visual, incluindo o nível ganglionar retiniano, o NGL, o córtex visual primário, onde as células disparam em resposta a características específicas de orientação, movimento e tamanho. Em áreas situadas fora do córtex visual primário, podemos encontrar células que reagem à características ainda mais específicas.

Nosso instrumento de estudo é a face, e alguns estudos em macacos (Desimone et al., 1984; Desimone, 1991; Rolls e Tovee, 1995; Young e Yamane, 1992) identificaram células no córtex inferotemporal (IT) que alternavam o padrão de atividade, respondendo com mais força a perfis de faces de macacos do que a outros estímulos. Gross, Rocha-Miranda e Bender (1972) identificaram um grupo de células corticais no córtex IT de macacos, cujos campos receptivos eram sensíveis especificamente a tamanho, forma, movimento, orientação e características cromáticas.

\section{I.1.2.6 Inibição lateral}

A percepção de bordas e margens é parte integrante da percepção de contornos e formas, e essa percepção de limites é necessária para a percepção de formas. A inibição lateral resulta da estimulação dos receptores retinianos, interagindo 
entre si. A atividade neural de um fotorreceptor é afetada não somente pela iluminação que recebe, mas também pela estimulação de fotorreceptores vizinhos.

A presença da luz em um fotorreceptor diminui a atividade de reação à luz nos receptores próximos. Quando dois fotorreceptores vizinhos recebem iluminação simultaneamente, cada um descarrega menos impulsos do que acontece quando somente um recebe a mesma quantidade de luz. Quanto maior a iluminação dos fotorreceptores vizinhos e quanto mais próximo estiverem, mais forte será o efeito inibidor lateral (mútuo).

As células ganglionares da retina costumam disparar de maneira não isolada, garantindo assim com que haja muitas células disparando e uma grande ocorrência de interações laterais. Dessa maneira, tendo em mente a inibição lateral, podemos compreender que as células da retina humana afetam a atividade umas das outras, intensificando a percepção de bordas e limites.

Toda esta organização fisiológica é a base da nossa percepção visual que, ao caminhar dentro do sistema nervoso central, ganha aspectos de maior complexidade e menor seletividade para atributos sensoriais. A percepção de estímulos espaciais complexos, como as faces que são os objetos de nosso estudo, tem como base o processamento espacial de elementos simples como tamanho e contraste. 


\section{I.2 Percepção Visual de Espaço}

\section{I.2.1 Acuidade Visual (AV)}

Uma das habilidades mais elementares do sistema visual é a de perceber estímulos no espaço, isto é, poder detectá-los, separá-los e discriminar diferenças entre eles. Uma das maneiras mais frequentes de se estudar esta habilidade é pela avaliação da Acuidade Visual (AV). A AV é definida como a habilidade do sistema visual em distinguir detalhes finos de objetos apresentados no espaço, ou seja, a medida do menor ângulo formado entre os detalhes de um determinado objeto, e sua imagem na retina. Esse ângulo é chamado de Mínimo Ângulo de Resolução (MAR) (figuras 5 e 6 ).
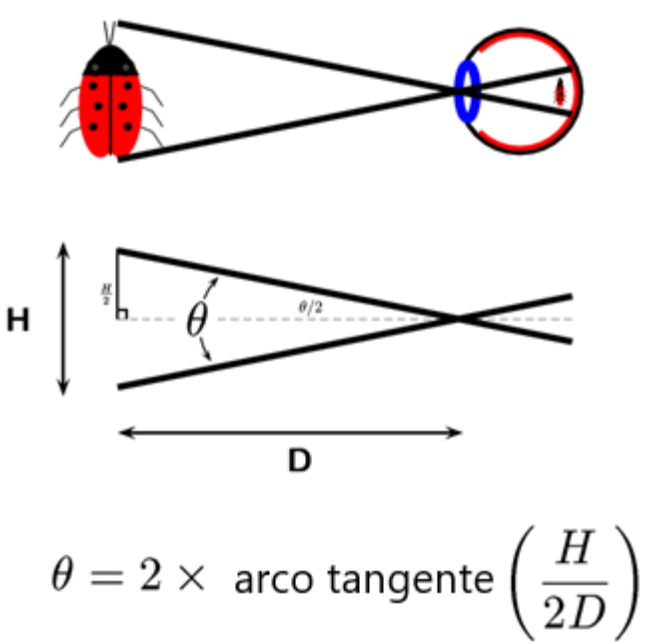

Fonte: Adaptado de http://www.gta.igs.net/ bgbauer/trentweb/366W04/images/visualangle.html

Figura 5: Figura ilustrativa sobre a definição de ângulo visual.

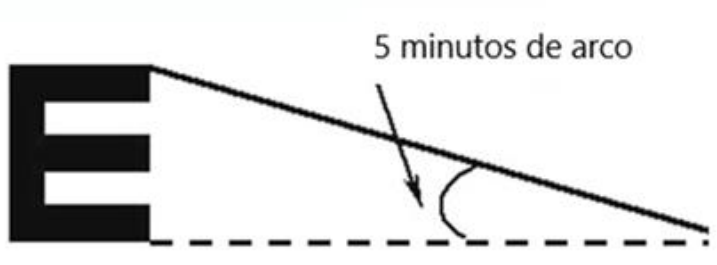

Distância de teste de 6 metros

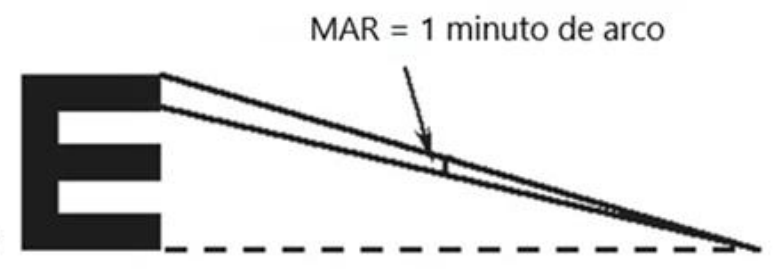

Distância de teste de 6 metros

Fonte: Adaptado de https://webvision.med.utah.edu/book/part-viii-psychophysics-of-vision/visualacuity/

Figura 6: Letra de Snellen ilustrando a medida do ângulo visual. 
Segundo Salomão (2007), a medida da acuidade visual em adultos ou em indivíduos que conseguem informar o quanto enxergam é simples e direta, independente do modelo de tabela que se empregue. Existem diferentes tipos de acuidade visual. O mais conhecido de todos é a acuidade de reconhecimento, a habilidade de identificar corretamente letras, que se mede tipicamente com uma tabela, como a conhecida tabela de Snellen (figura 7), ou formas como os exemplos da figura 8.

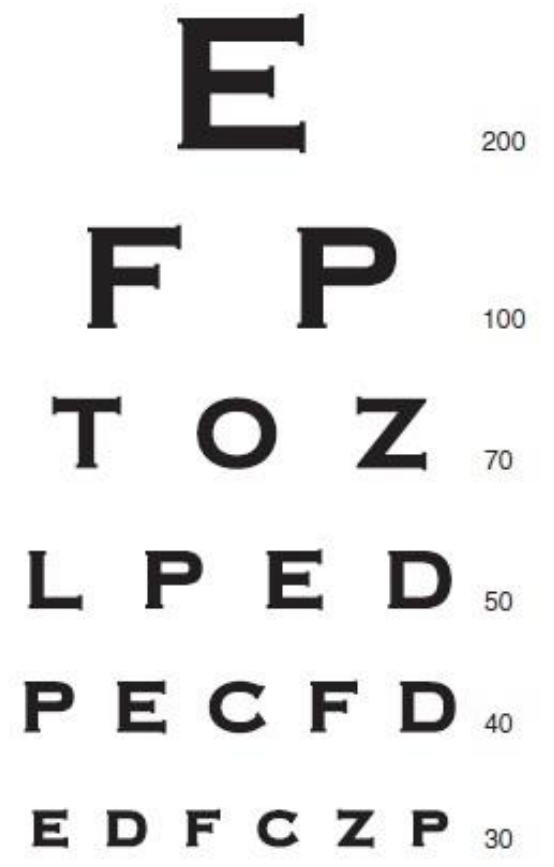

Fonte: Schwartz (2009)

Figura 7: Gráfico da Tabela de acuidade visual de Snellen.
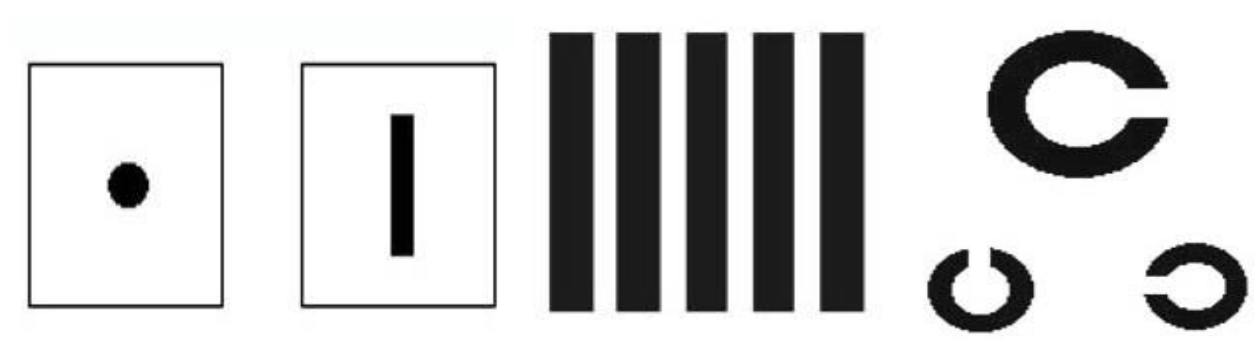

Fonte: Adaptado de https://webvision.med.utah.edu/book/part-viii-psychophysics-ofvision/visual-acuity/

Figura 8: Exemplos de Estímulos utilizados para a medida de acuidade visual. As duas figuras da esquerda são estímulos simples utilizados frequentemente para a medida de acuidade de detecção. As barras presentes no estímulo central são utilizadas para a medida de acuidade visual de resolução. Já os estímulos em forma de letra $\mathrm{C}$ de Landolt, são utilizados para a medida de acuidade visual de identificação e reconhecimento. 
A acuidade de grades, que leva em conta a resolução de variações de luminância no espaço, se desenvolve nos primeiros anos de vida, e seus valores podem ser obtidos por duas diferentes técnicas: Olhar Preferencial (OP) e Potencial Visual Evocado (PVE). Tanto o método comportamental (OP) como o método eletrofisiológico (PVE) de medida da acuidade visual se baseiam na habilidade do sujeito em resolver padrões listrados ou em formato de tabuleiro de xadrez. Essa tarefa visual é chamada de acuidade de resolução de grades. As grades usadas como estímulos de acuidade podem ser listras pretas e brancas com bordas marcadas (grades de onda quadrada) (figura 9) ou grades senoidais - aquelas com perfil de luminância de onda senoidal, que parecem listras com bordas graduadas (figura 10), que veremos no próximo item. Em ambos os casos, o "ciclo de trabalho" das grades é 1:1, ou seja, as barras escuras e as claras têm a mesma largura.

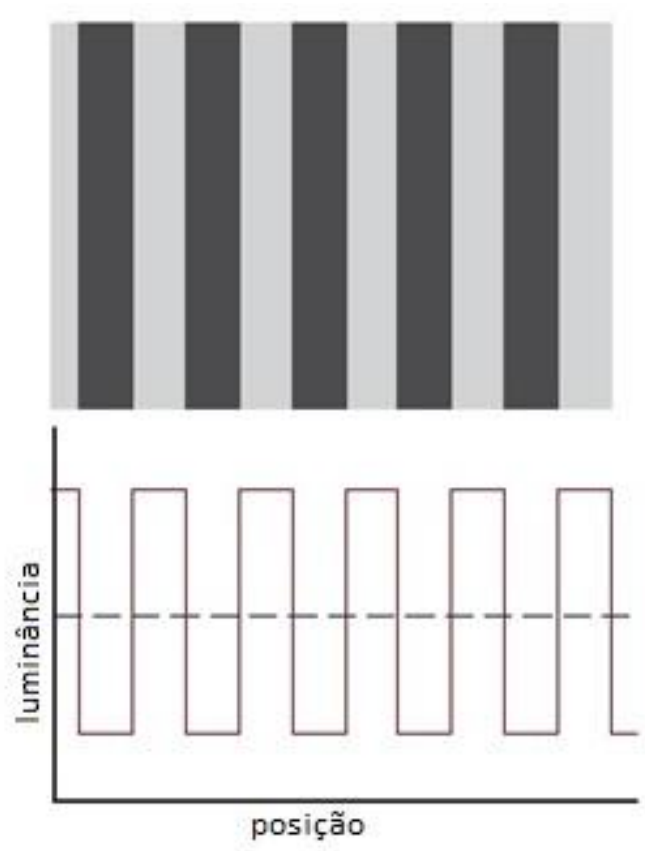

Fonte: Adaptado de Schwartz (2009)

Figura 9: Grades de onda quadrada e abaixo seu perfil de luminância. O pontilhado está representando o valor da luminância média da onda.

A unidade de AV mais comumente usada é a notação de Snellen, que define a acuidade adulta normal como 20/20. Schiffman (2005) esclarece que essa unidade é definida comparando a visão do sujeito avaliado com o desempenho de uma pessoa com visão teoricamente normal. $O$ valor é expresso como uma razão 
entre a distância em que a pessoa começa a enxergar uma fileira de letras (da tabela de Snellen) e a maior distância em que uma pessoa hipotética, típica, com visão normal, ainda consegue enxergar a mesma linha. A razão 20/20 indica que a pessoa reconhece corretamente, à distância de 20 pés (aproximadamente 6 metros), as letras que uma pessoa de visão média consegue reconhecer a essa distância (20/20 = 1 min de arco).

Uma pessoa que enxerga uma razão 20/15 tem uma média de acuidade melhor, e uma pessoa com razão 20/30, enxerga a 20 pés as letras com tamanho suficiente para serem lidas por uma pessoa de visão média a 30 pés (pouco mais de 9 metros), sendo mais fraco do que a média de acuidade. A "cegueira legal" é definida como a acuidade visual de 20/200, ou menos. Os valores de Snellen são comumente usados para determinar a acuidade de reconhecimento, mas outras duas unidadesmínimo ângulo de resolução e ciclos por grau de ângulo visual - são mais adequadas e utilizadas para medir a acuidade de grades.

Todas essas unidades são baseadas ao definir o ângulo visual subentendido pelo menor estímulo que o sistema visual pode "resolver". Sem considerar as unidades usadas, os valores de acuidade dependem criticamente da distância do estímulo de acuidade em relação ao observador. À medida que aumenta a distância de um dado estímulo, seu ângulo visual diminui; ao contrário, um estímulo pequeno próximo do observador subentenderá o mesmo ângulo visual que um estímulo duas vezes maior no dobro da distância.

Para grades de onda quadrada, o ângulo mínimo de resolução é definido como a menor separação detectável entre as linhas na grade que, dado um ciclo de 1:1, iguala-se à menor largura de listra detectável. Abaixo do limiar de resolução, as listras não podem ser individualmente percebidas e se juntam num cinza homogêneo.

O mínimo ângulo de resolução é expresso em minutos de arco de ângulo visual, com 1 minuto de arco representando a acuidade adulta normal. Grades senoidais e quadradas podem ser definidas em termos de sua frequência espacial, medida pelo número de ciclos da grade dentro de um grau de ângulo visual. Um ciclo equivale a uma barra escura mais uma barra clara da grade, ou duas vezes a largura de uma única barra usada para definir o mínimo ângulo de resolução. Sendo assim, um ângulo de resolução de 1 minuto de arco corresponde a uma frequência espacial de 30 ciclos por grau de ângulo visual ( 1 ciclo $=2$ minutos de arco; 1 grau $=60$ minutos 
de arco; 1 grau = 30 ciclos/grau). Portanto, a acuidade crescentemente melhor é representada por valores progressivamente menores do mínimo ângulo de resolução, mas por frequências espaciais maiores.

As medidas de acuidade visual obtidas por essas técnicas podem alterar a verdadeira capacidade do sujeito de executar a tarefa visual pedida. Isto se deve à presença inevitável de "ruído" nos testes (comportamentais ou eletrofisiológicos). Existem muitas fontes de "ruído" que podem interferir nas medidas de desempenho visual: ruído comportamental - cooperação, mudanças no estado geral, fatores de atenção; ruído óculo-fisiológico - acomodação imprecisa, imaturidade no controle da movimentação dos olhos; ruído externo - interferência elétrica em registros eletrofisiológicos em função da atividade muscular, ruído inerente ao estímulo luminoso em si e ruído neurofisiológico - ruído inerente à transmissão dos sinais visuais ao longo da via visual a partir dos fotorreceptores até o local em que a resposta visual está sendo medida (Hamer \& Mayer, 1994).

\section{I.2.2 Visão de Contraste de Luminância}

A visão espacial também está relacionada com variações da luminância no espaço. Para facilitar a compreensão dos processos complexos da visão espacial, os estudos utilizam estímulos simples que servem para formar estímulos mais complexos. Assim, com base nos princípios evidenciados pela análise de Fourier, na qual qualquer onda complexa pode ser dividida em uma série de ondas senoidais com diferentes frequências, amplitudes, fases e orientações, utilizam-se para estes estudos, grades de onda senoidal.

Com base nos princípios de Fourier, para descrever completamente uma grade de onda senoidal, é necessário especificar sua frequência, contraste (amplitude), fase e orientação (Schwartz, 2009). Em nosso texto, apresentaremos apenas as dimensões frequência e contraste, por estarem mais intimamente relacionadas com nosso estudo. Uma grade de onda senoidal é dada na figura 10, juntamente com seu perfil de luminância. 


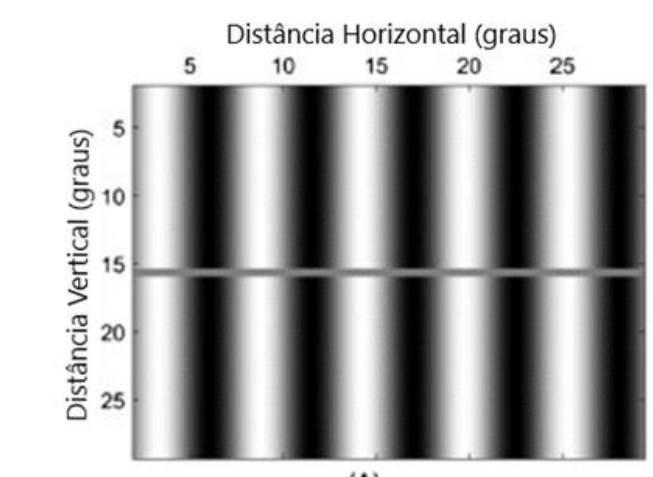

(A)

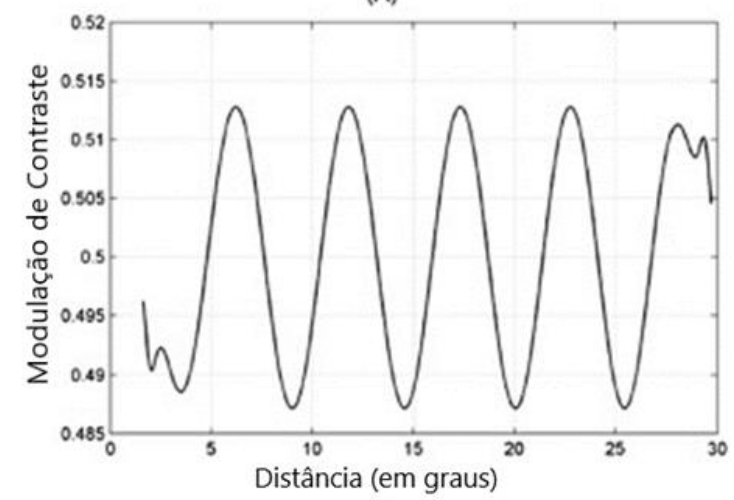

(B)

Fonte: Adaptado de Schwartz (2009)

Figura 10: Grade espacial de onda senoidal (A) e seu perfil de luminância (B). As barras claras representam a luminância máxima, enquanto as barras escuras representam a luminância mínima.

A grade consiste em alternar espacialmente barras claras e escuras. O pico do perfil de luminância corresponde a uma barra clara da grade, enquanto a depressão do perfil corresponde a uma barra escura. A transição de barras claras para barras escuras é uma transição gradual (sinusoidal), não uma transição abrupta.

\subsubsection{Frequência}

Frequência é o número de ciclos (alternância entre pico e vale) por unidade dimensional (espaço, tempo etc.). As frequências espaciais são o número de alternâncias de luminosidade em determinado espaço, tornando possível a análise de um cenário visual consistente de áreas claras e escuras. Quanto mais alternâncias de barras claras e escuras por unidade de área de um padrão, mais alta será a sua frequência espacial (Schiffman, 2005). A figura 11 exemplifica frequência espacial baixa, tendo menos alterações entre as faixas claras e escuras, compondo elementos largos. 


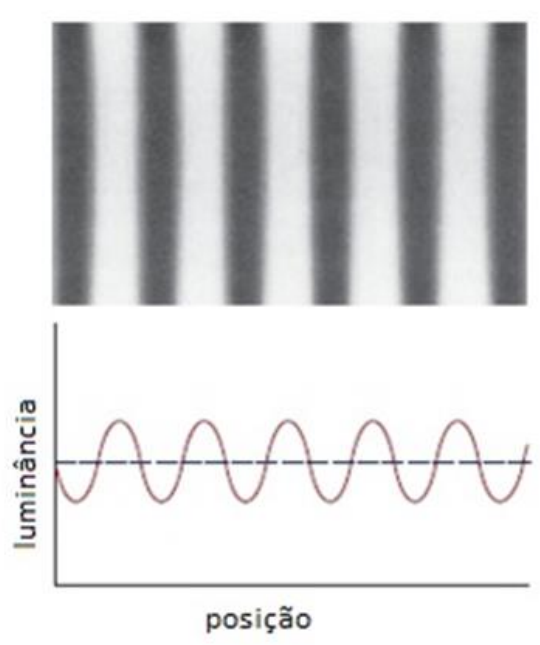

Fonte: Adaptado de Schwartz (2009)

Figura 11: Frequência espacial baixa, apresentando menos alterações entre as barras.

A figura 12 apresenta frequência espacial alta, contendo mais alterações entre as faixas claras e escuras. Comparado com as frequências baixas esta frequência consiste em detalhes mais finos.

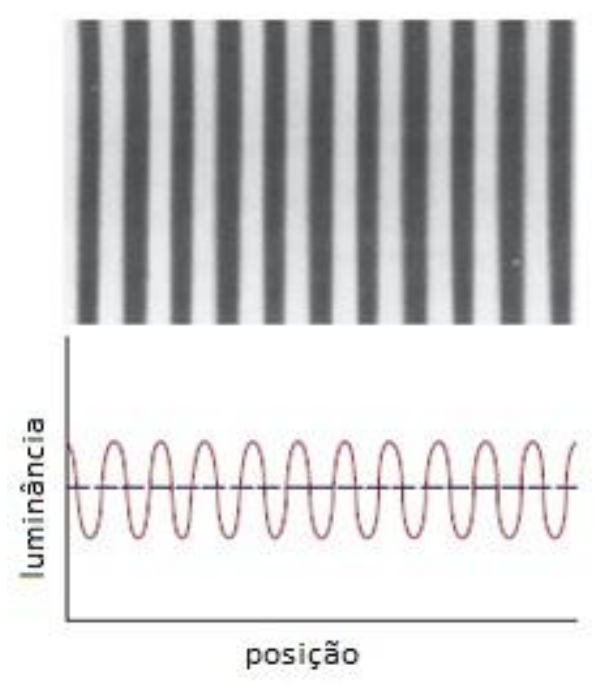

Fonte: Adaptado de Schwartz (2009)

Figura 12: Frequência espacial alta, apresentando mais alterações entre as barras.

Segundo Schiffmann (2005) “(...) a frequência espacial se refere ao número de ciclos de alterações luminosas por grau de ângulo visual (ciclos por grau). Isso liga a unidade de frequência espacial a um tamanho específico de imagem retiniana - o ângulo visual, excluindo, assim, a necessidade de especificar o tamanho de áreas individuais contrastantes e a distância da qual cada uma delas é vista". Isto significa 
que o número de ciclos por grau de ângulo visual é uma medida relativa, já que leva em conta a distância entre o estímulo e o observador, enquanto o número de ciclos por imagem é uma medida absoluta de informação que não muda independente da distância do observador (Perilla, 2008).

\subsubsection{Contraste}

A habilidade do homem e outros animais perceberem os detalhes dos objetos ou de uma cena visual é determinada basicamente pela capacidade de seus sistemas visuais em distinguir contraste, isto é, diferenças de brilhos de áreas adjacentes (Campbell \& Maffei, 1974). Isso leva a alguns autores a dizer que um objeto só consegue ser identificado caso haja contraste entre ele e o ambiente ao seu redor (Souza et al., 2013).

A figura 13.A mostra uma grade de onda senoidal de baixo contraste, juntamente com seu perfil de luminância, enquanto a figura 13.B mostra uma grade da mesma frequência espacial, mas de contraste mais alto. As linhas tracejadas ao longo dos perfis de luminância representam as luminâncias médias das grades (a média dos picos e depressões). Enquanto a luminância média ( $\left.l_{m e d}\right)$ é a mesma para ambas as grades, a da figura 13.B tem uma diferença maior entre seu pico e o valor médio de luminância, indicativo de maior contraste (Schwartz, 2009). 
A)

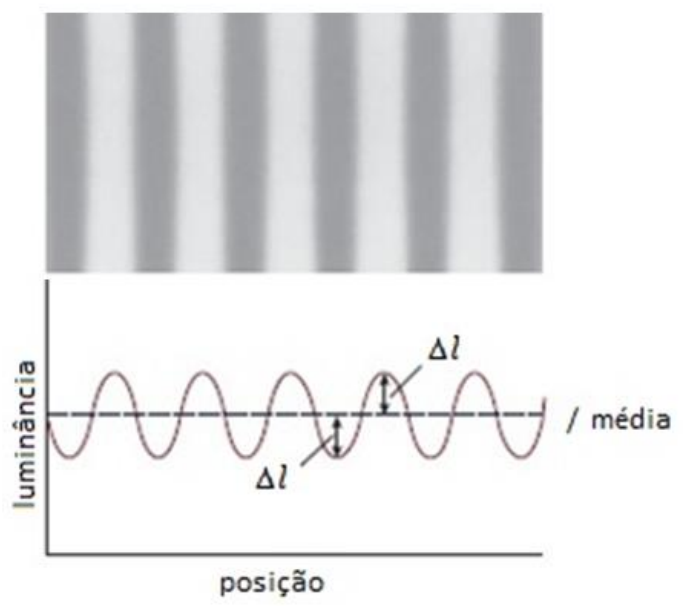

B)

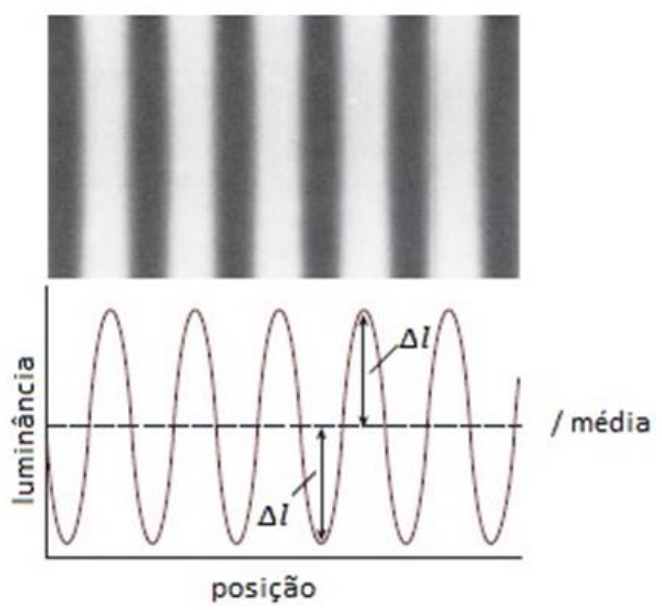

Fonte: Adaptado de Schwartz (2009)

Figura 13: Diferenças entre contrastes A) Frequência espacial de baixo contraste, $\Delta l$ indica uma diferença pequena entre seu pico e o valor médio de luminância. B) Frequência espacial de alto contraste, $\Delta l$ indica uma diferença maior entre seu pico e o valor médio de luminância.

A sensibilidade ao contraste é definida na literatura como a recíproca da quantidade mínima de contraste necessária para detectar uma grade de uma frequência espacial específica (Cornsweet, 1970). Quando se mede a capacidade de detectar contrastes para diferentes frequências espaciais, tem-se a possibilidade de se construir uma função que relacione estas duas unidades, a Função de Sensibilidade ao Contraste (FSC), figura 14.

A FSC é o inverso da curva de limiar de contraste $(1 / \mathrm{Cl})$. O Sistema Visual (SV) possui alta sensibilidade quando um padrão precisa de pouco contraste para ser detectado e, baixa sensibilidade, quando o SV precisa de alto valor de contraste para detectar o estímulo. A FSC estima a sensibilidade ao contraste de grades (ou qualquer padrão) como uma função de sua frequência espacial (Schwartz, 2009). 


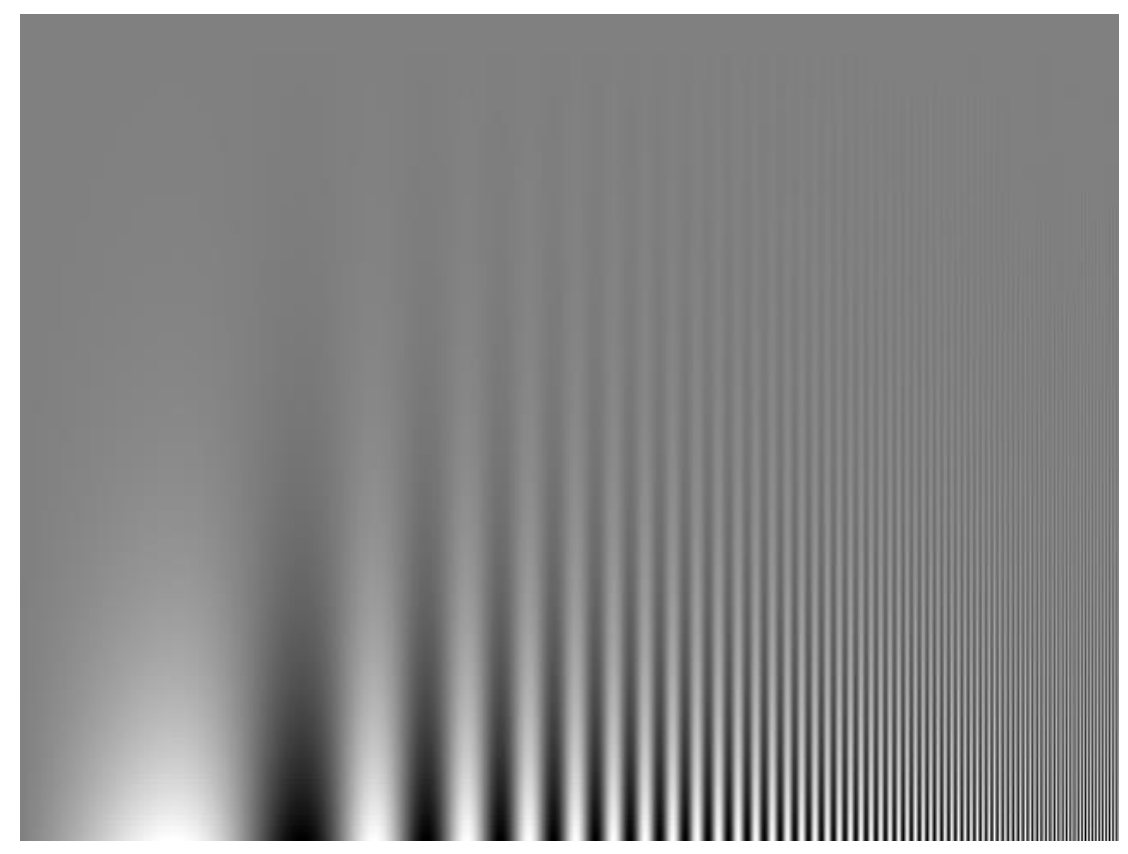

Fonte: Schwartz (2009)

Figura 14: llustração mostrando a relação entre frequência espacial (eixo horizontal) e contraste (eixo vertical). As frequências espaciais aumentam da esquerda para direita e o nível de contraste diminui de baixo para cima. Claramente observamos que nossa percepção de contraste nos permite discriminar menores níveis de contraste para as frequências espaciais médias.

A sensibilidade ao contraste está relacionada à diferença existente entre picos e depressões das ondas senoidais. Essa diferença traduz o valor de contraste necessário para que o sistema visual humano possa distinguir um estímulo de frequência espacial daquele com um campo uniforme de luminância média. Para realizar a medição do contraste é necessário medir a luminância máxima (Lmax) e a luminância mínima (Lmin) e, a partir desses valores, calcular o contraste. A fórmula usada (equação de Michelson) é:

$$
\text { Contraste }=\frac{\operatorname{Lmax}-\operatorname{Lmin}}{\operatorname{Lmax}+\operatorname{Lmin}}
$$

Uma característica marcante da FSC advém do fato que ela descreve o desempenho do sistema visual em níveis diferentes de contrastes. Isso a difere de medidas clássicas como $\mathrm{AV}$, que geralmente descreve o desempenho do SV em contraste muito alto (letras pretas sobre um fundo branco).

A forma e a dinâmica com que a FSC interage com as condições visualizadas permite fortes inferências sobre processos comportamentais e 
fisiológicos básicos. Os processos fisiológicos relacionados à diminuição do desempenho do SV na percepção de contraste para as baixas frequências está relacionado ao tamanho dos estímulos. Estímulos de frequências espaciais muito baixas são maiores do que as regiões de centro e periferia do campo receptivo das células visuais, reduzindo assim sua resposta.

As reduções de contraste para as altas frequências espaciais são devidas a um componente duplo: óptico e neural. Conforme aumenta-se a frequência espacial há uma limitação óptica para transferência de modulação entre o estímulo e a imagem criada. Quanto maior a frequência espacial, maior é a degradação da imagem. Além disso, há um limite espacial que corresponde ao tamanho dos próprios fotorreceptores na retina. Frequências espaciais muito altas geram estímulos antagônicos para as regiões de centro e periferia do campo receptivo destas células, o que consequentemente reduz a quantidade de contraste e da informação processada.

O contraste varia entre $0 \%$ e $100 \%$. Não pode ser maior que $100 \%$ por causa da impossibilidade física de fazer $\Delta l$ maior do que o $l_{\text {med }}$. (A depressão do perfil de luminância está com luminância zero quando $\Delta l=l_{\text {med }}$. Não é possível ter luminância menor que zero) (Schwartz, 2009).

\subsubsection{Fase e orientação}

Fase refere-se à posição de uma grade de onda senoidal em relação à outra grade de onda senoidal. Por exemplo, se duas grades estão em fase, os picos e depressões de seus perfis de luminância estarão alinhados. Se duas grades estiverem 180 graus fora de fase, o pico de um perfil de luminância será alinhado com a depressão do outro perfil. Orientação descreve o ângulo feito por uma grade em relação a uma referência, como a horizontal (Schwartz, 2009).

\subsubsection{Lei de Weber}

Em 1834, Ernst Weber, um fisiologista alemão, investigou a capacidade de observadores em desempenhar tarefas de discriminação. Ele observou que, para que uma mudança em um estímulo fosse detectada, a quantidade de mudança - ou seja, o aumento ou a diminuição - era proporcional à magnitude do estímulo em comparação. Em resumo, Weber notou que a discriminação entre as magnitudes de dois estímulos é uma questão de julgamento relativo, em vez de absoluto. Descobriu 
que, por exemplo, o ato de se juntar uma vela acesa a 60 outras resultava na percepção de uma diferença de luminosidade, ao passo que o mesmo não ocorria se juntasse uma vela a 120 outras. Para uma Diferença Apenas Perceptível (DAP) na luminosidade de 120 velas, seriam necessárias pelo menos mais duas velas (Schiffman, 2005).

De acordo com Schwartz (2009), em muitos procedimentos psicofísicos, a tarefa é discriminar entre a combinação de estímulo e plano de fundo e apenas o plano de fundo. Isto é exemplificado numa experiência de incremento de limiar, ilustrada na figura 15. A tarefa do observador é detectar o incremento do estímulo, $\Delta I$, que é mostrado no fundo, $I_{b}$. O incremento do limiar é chamado de diferença apenas perceptível (DAP) ou Limiar de Diferença (LD).
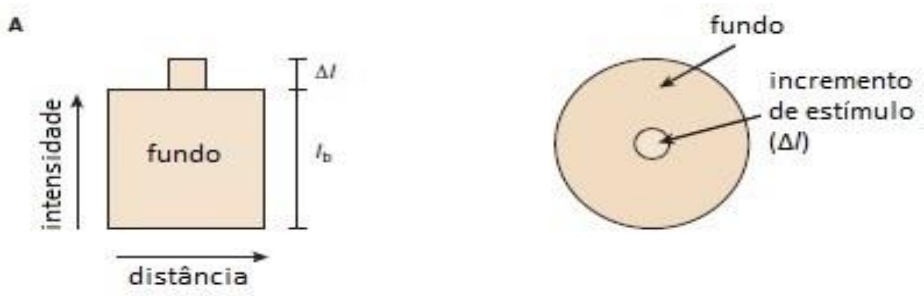

B

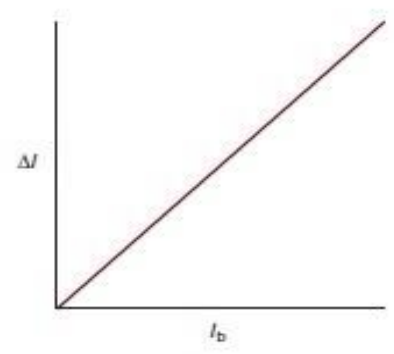

c

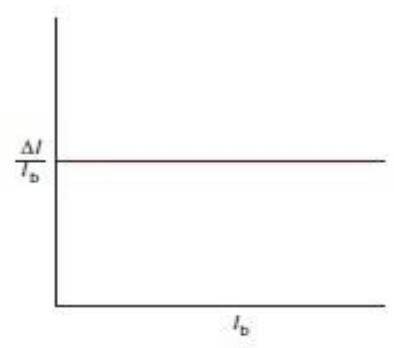

Fonte: Adaptado de Schwartz (2009)

Figura 15: Experiência de incremento de limiar A). Arranjo de limiar de incremento que pode ser usado para demonstrar a lei de Weber. Um perfil de luminância está à esquerda e a visão do observador do estímulo está à direita. B) Representação gráfica da lei de Weber mostrando que a razão entre $\Delta I$ e $I_{b}$ é uma constante. C) Figura B replantada para mostrar $\Delta I / I_{b}$ como uma função de $I_{b}$. 
A DAP não é uma constante, mas muda conforme o plano de fundo é alterado. À medida que a intensidade de fundo aumenta, a DAP também aumenta de tal forma que a relação entre a DAP e a intensidade de fundo permanece constante (veja as figuras 15 B e C). Isso é chamado de lei de Weber, e é expresso matematicamente como:

$$
\Delta I=K I_{b}
$$

$\mathrm{Ou}$

$$
K=\frac{\Delta I}{I_{b}}
$$

Onde, $\Delta I=$ limite de incremento (DAP), $I_{b}=$ iluminação de fundo e $K=$ Constante ou fração de Weber.

O sistema visual segue a lei de Weber em grande parte de sua faixa operacional, com diferentes frações para visão escotópica e fotópica. À medida que o fundo se torna mais intenso, o limite de incremento aumenta. Consequentemente, a sensibilidade absoluta diminui, enquanto a sensibilidade relativa permanece constante. Esse processo - regulação de sensibilidade - resulta em um limiar de contraste constante, independentemente do brilho do plano de fundo. Para visão escotópica, esse limiar de contraste é de 0,14 (ou 14\%); para visão fotópica é 0,015 (ou $1,5 \%$ ).

Um resultado importante da regulação da sensibilidade é ilustrado na figura 16, que mostra um optotipo escuro sobre um fundo cinza sob iluminação fotópica fraca e clara. O optotipo reflete $10 \%$ da luz que incide sobre ele, e o fundo reflete $10,40 \%$; consequentemente, o contraste do optotipo é de aproximadamente $2 \%$. Quando a iluminação aumenta, o contraste permanece constante porque a quantidade de luz refletida nas superfícies escuras e cinzas aumenta na mesma taxa, resultando em uma relação constante entre o optotipo e a luminância de fundo. Como a fração de Weber para visão fotópica é de aproximadamente 0,015 , o optotipo está no limiar (dificilmente detectável) sob ambas as condições de iluminação. $O$ optotipo não se torna mais visível quando mais luz é refletida a partir dele. Pelo contrário, como o 
contraste permanece constante, a aparência permanece a mesma, um fenômeno conhecido como constância de luminosidade.

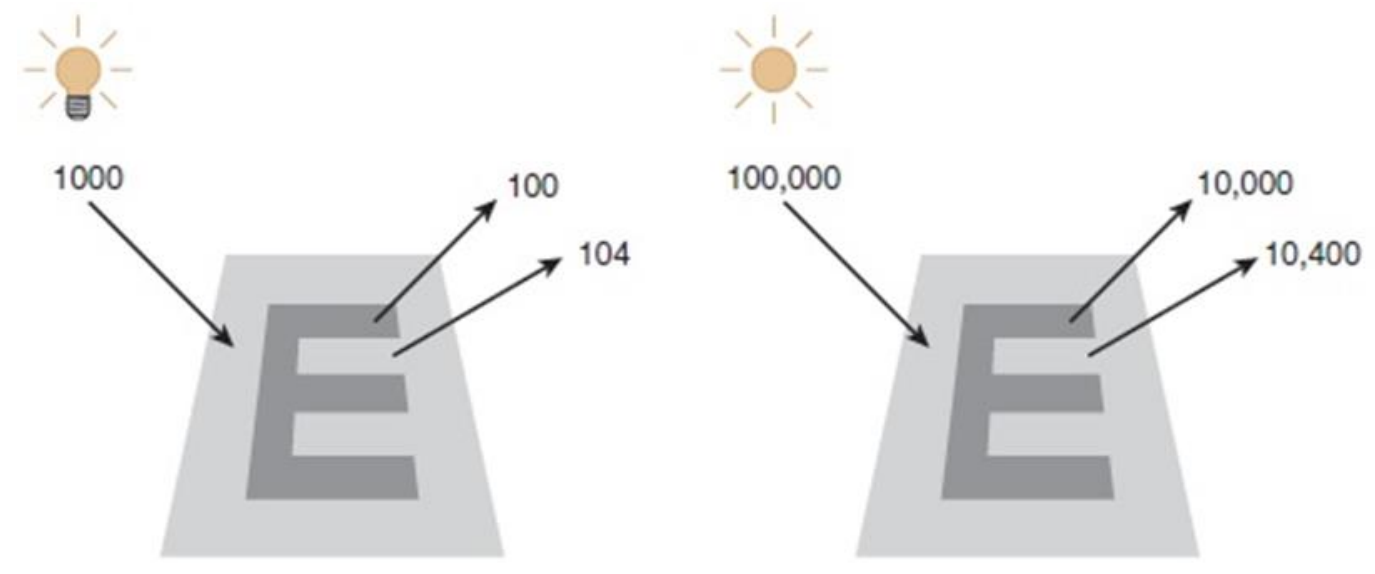

Fonte: Schwartz (2009)

Figura 16: O optotipo E reflete 10\% da luz incidente sobre ele, e o fundo cinza reflete $10,40 \%$. Seja sob iluminação fotópica fraca (1000 unidades de luz) ou iluminação brilhante (100.000 unidades de luz), a relação entre o optotipo e a luminância de fundo (contraste) é a mesma. Como o sistema visual evoluiu para detectar contraste, em vez de luminância absoluta, a aparência do $E$ é a mesma sob condições de iluminação fraca e clara. Este fenômeno é referido como constância de luminosidade.

\subsubsection{Frequências Espaciais e Reconhecimento de Faces}

Vários estudos sugerem que o reconhecimento das imagens faciais depende apenas de uma faixa limitada de frequências espaciais. Fiorentini, Maffei e Sandini (1983) estudaram o reconhecimento de imagens de face filtradas de passagem baixa e passagem alta. Eles descobriram que a precisão do reconhecimento foi pior para as imagens que apenas contêm frequências espaciais abaixo de 5 ciclos por face (c/face) do que para imagens que apenas contêm frequências espaciais acima de $5 \mathrm{c} / \mathrm{face}$. Uma vez que ajustaram as distâncias de visualização de modo que as frequências espaciais acima de $15 \mathrm{c} /$ face não fossem visíveis, o resultado significa que a informação entre 5 e $15 \mathrm{c} /$ face é mais útil para o reconhecimento de faces. Costen, Parker e Craw (1996) estudaram a precisão de identificação para faces filtradas com diferentes frequências de corte. Seus resultados sugeriram que a identificação do rosto preferencialmente depende de frequências espaciais entre 8 e 16 c/face. 
Hayes, Morrone e Burr (1986) estudaram o reconhecimento de imagens de rosto filtradas por banda de passagem de frequências espaciais mostradas a partir de três pontos de vista diferentes. Hayes et al., (1986) usaram um filtro de passagem de banda estreita de 1,5 oitavas para várias frequências espaciais. Os resultados foram expressos na proporção de reconhecimentos corretos em função da frequência espacial central do filtro passa-banda. De acordo com seus resultados, a banda de frequências espaciais mais úteis para o reconhecimento facial está localizada em torno de $20 \mathrm{c} /$ face. Esta descoberta foi independente da distância de visualização. Portanto, a dimensão relevante da frequência espacial para o reconhecimento de objetos é ciclos por objeto em vez de ciclos por grau de ângulo visual.

Estudos psicofísicos em observadores humanos sugerem que faixas de frequência espacial distintas podem ter papéis diferentes no processamento de faces (Sergent, 1985; Costen et al., 1996; Schyns et al., 1999; Nasanen, 1999; Liu et al., 2000). Os componentes de baixa frequência espacial (2-8 ciclos/ face), exemplificado no terceiro quadro da figura 17, transmitem informações de configurações globais (Sergent, 1985; Costen et al., 1996), suficientes para fornecer apenas pistas emocionais grosseiras (Schyns et al, 1999; Calder et al., 2000).

Os componentes de alta frequência espacial (8-16 ciclos/ face), quadro central da figura 17, em contraste, transportam informações de grão fino importantes para o reconhecimento preciso da identidade (Sergent, 1985; Liu et al., 2000; Tieger et al., 1979; Fiorentini et al., 1983; Hayes et al., 1986) e para análise mais detalhada de traços faciais, como idade ou rugas de expressão relacionadas (Schyns et al., 1999; Norman et al., 1987). 

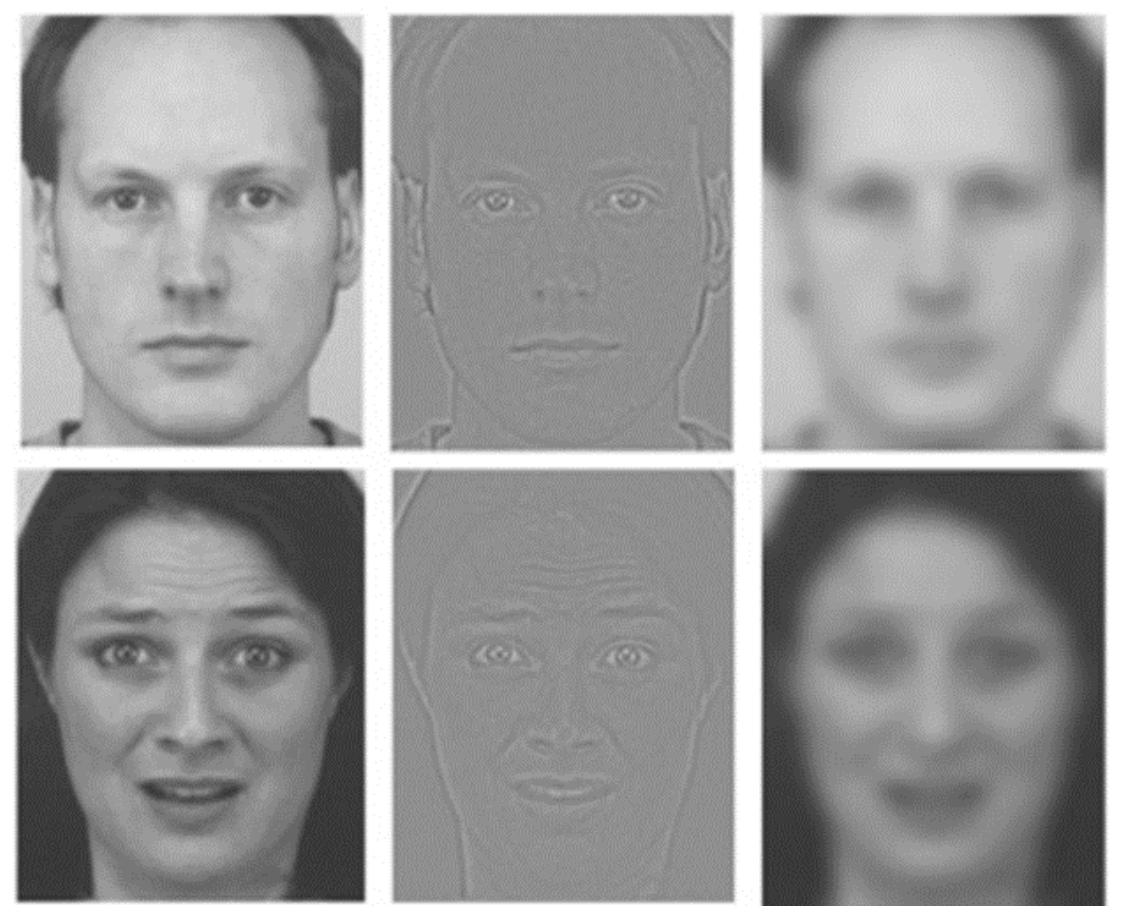

Fonte: Adaptado de Vuilleumier (2003)

Figura 17: llustração de uma filtragem de componentes espectrais espaciais de face neutra (fotos superiores) e de fotos com expressões emocionais (fotos inferiores). Os componentes emocionais globais das faces são principalmente enviados pelas frequências baixas (terceiros quadros), enquanto que as altas frequências informam detalhes visuais finos e componentes emocionais de maior sutileza (quadros centrais).

\section{I.3 Processamento da Percepção}

Simões e Tiedemann (1985) afirmam que os mecanismos de captação de energia do ambiente e a fisiologia da transdução são os mesmos em todos os seres humanos. O que difere de uma pessoa para a outra, diante de uma mesma situação de estímulos, é a percepção. Ou seja, a seleção e interpretação dos dados sensoriais. Todo conhecimento que temos de nosso próprio corpo e do ambiente, constituído tanto de nossos semelhantes quanto de objetos inanimados, é fornecido por nossos órgãos dos sentidos. Eles transformam diferentes tipos de energia (mecânica, térmica, eletromagnética, etc.) em energia eletroquímica, que chega ao nosso cérebro na forma de impulsos nervosos.

No cérebro, serão integradas as informações provenientes dos diversos órgãos sensoriais. Isto, porém, não basta para nossa percepção do ambiente. Ela dependerá também de nossa experiência passada, de nosso estado emocional e motivacional, bem como de nossas atitudes, preconceitos e de nossas expectativas a respeito do futuro. 


\section{I.4 Desenvolvimento da Percepção de Faces}

A percepção da criança é diferente da percepção do adulto, pois o seu sistema nervoso central ainda está em desenvolvimento. Porém nem todas as modificações ocorridas em nossas capacidades perceptivas podem ser diretamente associadas a modificações neurais. Um adulto poderá ter melhor desempenho em uma complexa discriminação porque aprendeu estratégias melhores (Miller, 1962). Reconhecer as faces humanas com rapidez e precisão é uma habilidade crucial para os seres humanos como uma espécie social. O rosto humano é um dos sinais sociais mais importantes e transmite diferentes informações sociais (Wilhelm et al., 2010).

Segundo Miller (1962) a orientação de uma criança pequena, em relação a espaço, bem como a quantidade é caracterizada pela dependência do campo visual, e apresenta pouca capacidade para ir além dele. A sua própria percepção é a única realidade. Crianças na idade de oito anos são fortemente dominadas pelo campo visual. Entre as idades de oito a cerca dos treze anos, verifica-se uma aprendizagem nítida, estão mais aptas a ignorar a aparência visual e a julgar na base de suas referências internas.

A fase final do desenvolvimento intelectual inicia-se quando a criança começa a descrever ou explicar os princípios e operações que aprendera previamente, de maneira tácita e não-verbal. Dos oito aos doze anos, o conhecimento da criança é largamente organizado em termos de operações concretas a serem realizadas sobre objetos concretos. Em muitas situações, a criança obviamente conhece as regras para execução de uma tarefa, dado que a desempenha com êxito constante, contudo, ao mesmo tempo, não consegue explica-las.

O processo de conversão do conhecimento teórico em prático tem início na adolescência e pode prosseguir por toda a vida. Eles começam a codificar os seus conhecimentos, ampliar o que sabem e conhecem por caminhos que só o pensamento formal e abstrato pode sustentar. Essa conversão possibilita que o conhecimento se torne comunicável (Miller, 1962). Autores especializados em comunicação não verbal e expressões faciais de emoções afirmam que os sinais comunicativos são percebidos, analisados e respondidos pelos humanos de maneira fundamentalmente inconsciente ou automática (Davis, 1979; Ekman \& Friesen, 2003). Ekman (1978) relaciona dezoito categorias de características que podem ser percebidas através da face: identidade pessoal, parentesco, etnia, sexo, temperamento, personalidade, 
beleza, atratividade sexual, inteligência, doença, emoção, humor, emblemas, adaptadores, ilustradores, reguladores, idade, vida emocional prévia.

As habilidades de reconhecimento da expressão facial melhoram durante a infância e a adolescência (De Sonneville et al., 2002; Gao \& Maurer, 2009; Herba \& Phillips, 2004), com diferentes trajetórias de desenvolvimento observadas para diferentes emoções (Lawrence et al., 2015; Rodger et al., 2015). Ewing et al., (2017) realizou um estudo referente as mudanças ocorridas na infância e adolescência e o quanto elas afetam a compreensão de expressões faciais. Neste estudo foi utilizada uma nova adaptação do paradigma de correlação reversa de bolhas de Gosselin \& Schyns (2001) O paradigma de Bubbles consiste de uma técnica computadorizada que permite identificar quais os estímulos estão sendo utilizados por nosso sistema visual para identificação e categorização de determinada figura) (Gomes, 2013). As expressões faciais foram também manipuladas com diferentes níveis de frequência espacial. A precisão do julgamento de emoções dos participantes apresentou melhora com a idade, assim como a eficiência de processamento (medida pela quantidade de informações visuais necessárias para alcançar os resultados de desempenho: número de bolhas).

Através das expressões, os participantes mostraram uma consistência de categorização mais forte para as faces felizes, seguidos de medo, tristeza e raiva. Os sujeitos usaram dicas visuais como os olhos arregalados para o medo, sorriso para a felicidade, a boca virada para baixo, para a tristeza e a testa tensa para a raiva. As classificações corretas das expressões faciais básicas são caracterizadas por um subconjunto crítico de informação visual que difere através de emoções (por exemplo, sobrancelha franzida para raiva, olhos abertos por medo) e pode ser otimizado para diferenciar essas categorias (Smith et al., 2005).

O refinamento do uso de informações com a idade e a experiência pode explicar a capacidade de processamento melhorada, ajudando as crianças a aprender a se concentrar nas pistas mais confiáveis para seus julgamentos (Johnston et al., 2011). No trabalho realizado por Caramaschi (1997) foi identificado que os homens tiveram escores ligeiramente melhores do que as mulheres no julgamento de emoções, contrariando informações fornecidas na literatura, onde as mulheres se destacavam (Berenbaum \& Rotter, 1992; Tucker \& Riggio, 1988). 


\subsubsection{Julgamento de Faces e Emoções}

Emoção é um conjunto de processos reguladores vitais do comportamento intra e interpessoal (Bretherton et al., 1986; Denham et al., 1994) que se iniciam num estado de excitação, no momento em que o sistema nervoso autônomo é ativado por uma alteração com origem num evento externo ou interno (Denham, 1998).

A perspectiva de Denham (1998) incide na função e papel central das emoções nas interações sociais ao longo da vida: (a) como fonte significativa de informação tanto para a pessoa que comunica, como para a pessoa que recebe a informação (Halberstadt et al., 2001); (b) como processos dinâmicos que estão embebidos nas interações sociais mas que, também, podem ser produtos destas (Colwell \& Hart, 2006; Halberstadt et al., 2001), com consequências de regulação intra e interpessoais (Campos, Campos, \& Barrett, 1989). A competência emocional tem implicações no desenvolvimento social, acadêmico e afetivo.

De acordo com o trabalho publicado em março de 2016, por Lewis et al., a capacidade de reconhecer as emoções dos outros representa um componente crítico de capacidades sócio-cognitivas humanas (Bruce \& Young, 2012). As emoções, no geral, constituem as respostas do nosso corpo após processar mudanças no ambiente, que nos preparam para a ação (Rodrigues \& Rocha, 2016).

Expressões faciais podem fornecer informações importantes para os observadores. Por exemplo, a expressão do medo indica a percepção potencial de perigo no ambiente; a expressão da raiva representa um comportamento agressivo latente (Keltner et al., 2003). As emoções não apenas refletem os estados mentais das pessoas, mas também aprimoram o processamento facial (Chen, 2014). Por exemplo, D'Argembeau et al., (2003) relataram que as expressões positivas tiveram um efeito facilitador no reconhecimento facial em comparação com a expressão neutra; Bate et al., (2010) descobriram que expressões faciais emocionais poderiam facilitar o reconhecimento facial.

Alguns estudos demonstram um efeito de superioridade da raiva (por exemplo, Hansen \& Hansen, 1988). Pesquisadores apoiando essa ideia propuseram que as expressões negativas aumentam o processamento de faces mais do que as expressões positivas. Eles explicaram esse efeito a partir da perspectiva da psicologia evolutiva: porque expressões emocionais negativas (por exemplo, raiva) são mais ameaçadoras e perigosas em comparação com expressões emocionais positivas (por 
exemplo, felizes), rostos raivosos são mais facilmente detectados ou respondidos como resultado de busca pré-atenta de humanos por sinais de ameaça social. Por exemplo, rostos zangados atraíram mais atenção e estimularam respostas mais rápidas em comparação com rostos felizes ou neutros - as pessoas levaram menos tempo e cometeram menos erros ao reconhecer rostos zangados do que rostos felizes ou neutros (Hansen \& Hansen, 1988). Com base nesses achados, eles sugeriram que a capacidade humana de reconhecer expressões emocionais negativas com precisão e rapidez pode ter valor evolutivamente adaptativo / sobrevivência.

Outros pesquisadores sugeriram que havia um efeito de superioridade da felicidade. Eles argumentavam que as pessoas processam expressões felizes mais prontamente do que expressões negativas ou neutras, porque expressões positivas são mais agradáveis do que outras. Por exemplo, LaBarbera et al., (1976) demonstraram que a preferência de um ser humano pelo processamento de expressões felizes se desenvolve desde a infância: os bebês olham para expressões alegres por um tempo significativamente maior do que olham para expressões zangadas ou neutras. Os resultados indicam que os humanos preferem processar expressões positivas sobre negativas desde os primeiros estágios da vida.

\subsubsection{Emoções Básicas}

Indivíduos de diferentes culturas são capazes de emitir e reconhecer emoções distintas, as quais podem variar. Mas algumas dessas são amplamente reconhecidas, mesmo diante de variedade cultural: são as chamadas "emoções básicas", que compreendem a alegria, a tristeza, a raiva, o nojo, a surpresa e o medo (Ekman, 1992). Atualmente, há um questionamento se existem seis emoções básicas de fato ou somente quatro emoções fundamentais, visto que alguns estudos têm mostrado que as emoções de medo e de surpresa são amplamente confundidas entre si, bem como as expressões de raiva e nojo (Jack, Garrod \& Schyns, 2014). Nesta pesquisa focaremos em 3 dessas emoções: alegria, tristeza, raiva, e a expressão facial neutra.

De acordo com Ekman e Friesen (2003) e Ekman (2011), os padrões musculares presentes na alegria estão demarcados por um sorriso ocasionado pelo músculo facial zigomático maior, gerando o levantar das bochechas, além da separação dos lábios superior e inferior com consequente aparecimento das gengivas 
e enrugamento das pálpebras. A raiva é caracterizada por uma junção das sobrancelhas unidas para o centro ocorrendo o enrugamento entre elas, como consequência há o fenômeno do olhar concentrado. Na parte inferior ocorre a compressão dos lábios deixando-os mais finos.

$\mathrm{Na}$ expressão facial da tristeza, ocorre o levantamento dos cantos internos das sobrancelhas unindo-as. Ocorre também o rebaixamento do olhar, deixando as pálpebras superiores se curvarem ou penderem. Na parte inferior da face, há uma leve abertura da boca, onde os cantos projetam-se para baixo, as bochechas são erguidas aparentando apertar os olhos. Em contrapartida, a face neutra caracterizase pela inexistência de movimentos faciais.

Ainda que algumas expressões faciais sejam consideradas universais, existem algumas diferenças culturais a serem consideradas (Ekman e Friesen, 2003; Matsumoto, 2009). Estas são decorrentes de, pelo menos, dois mecanismos. O primeiro deles refere-se às diferenças culturais nas normas de gestão e regulação da expressão emocional em função das circunstâncias sociais, conhecidas como regras de exibição (Ekman e Friesen, 1969). Estas regras influenciam as expressões emocionais e são apreendidas desde cedo na vida, regendo as formas de gerir ou modificar as demonstrações emocionais, dependendo das circunstâncias emocionais.

O segundo mecanismo envolve diferenças culturais em expressividade em relação aos tipos de eventos que funcionam como gatilhos, onde desta forma eventos diferentes ocorrem em diferentes culturas podendo ou não ter significados diversificados, no qual os indivíduos acabam aprendendo a ter distintas reações emocionais entre as culturas, produzindo expressões díspares (Matsumoto, 2009).

Charles Darwin foi o pioneiro no estudo mais aprofundado das emoções expressas em face e na sugestão de que existiriam algumas emoções universais e independentes da cultura (Ekman, 2003; Feitosa, 1999), mas foi o psicólogo e pesquisador Paul Ekman que retomou tais hipóteses darwinianas e motivou o campo de estudos do reconhecimento de emoções faciais e da análise das micro expressões em face na atualidade (Fasel \& Luettin, 2003).

A face é um dos principais atributos que possuímos para reconhecer outras pessoas e a face humana é um estímulo visual complexo que envolve informações de contraste de brilho, sombreamentos, contornos, figura-fundo e simetrias (Johnston, Hill \& Carman, 2013). Mas mesmo diante desta extensa variabilidade que uma face 
pode ter (incluindo o ângulo observado, a expressão, a idade da face, a familiaridade), o ser humano é eficaz ao reconhecer outro rosto e distinguir faces diferentes (Burton, 2013).

\subsubsection{Processamento da Informação Facial}

A identificação de uma face é resultado de um processo cognitivo de reconhecimento de padrões visuais, na qual existe a comparação do estímulo externo a um padrão mental internalizado (Mendes, Arrais \& Fukusima, 2009). Os humanos desenvolvem precocemente a capacidade de reconhecer tanto faces familiares quanto não familiares, a própria-face e, também, a interpretar emoções expressas por meio da face (Nelson, 2001).

A capacidade de reconhecimento de faces refere-se à capacidade de uma pessoa perceber e reconhecer de forma correta e rápida diferentes estímulos faciais. Essa capacidade inclui três componentes: percepção da face (capacidade de discriminar e comparar diferentes estímulos faciais), memória facial (capacidade de lembrar vários estímulos faciais) e velocidade de reconhecimento facial (quão rapidamente um indivíduo responderá aos estímulos faciais corretamente) (Wilhelm et al., 2010).

O córtex motor primário parece ser o centro de comando consciente da produção de expressões faciais (Adolphs et al., 2005). As expressões emocionais em face têm sido utilizadas para pesquisar as bases neurais da percepção de emoção no ser humano (Huang, Hsiao, Hwu \& Howng, 2012; Phillips et al., 2003). Especificamente para o reconhecimento de emoções faciais, o giro fusiforme é a principal área encefálica estabelecida como responsável por tal função, por isso também chamada de "área da face" (Kawasaki et al., 2011; McCarthy, Puce, Gore \& Allison, 1997; Weiner \& Zilles, 2015). Porém, esta área estabelece conexões com outras partes do encéfalo que também atuam no sistema emocional (Gauthier, Tarr, Anderson, Skudlarski \& Gore, 1999; Haxby et al., 2000).

Alguns estudos apontam que diferentes emoções são identificadas em partes distintas do sistema nervoso central (Dalgleish, Dunn \& Mobbs, 2009; Kesler et al., 2001; Rolls, 2000; Streit et al., 1999; Tettamanti et al., 2012): a amígdala, que está localizada no lobo temporal, opera principalmente nas emoções de medo (LeDoux, 2003); a ínsula, situada no sulco lateral, relacionada ao nojo (Vuilleumier \& Pourtois, 
2007); a ínsula anterior estaria mais conectada à tristeza (Mayberg et al., 2014); os gânglios basais ventrais, especificamente o corpo estriado, pertinentes à emoção de raiva (Calder, Keane, Lawrence \& Manes, 2004); a substância negra, atuando na surpresa (Lee, Youn, O, Gallagher \& Holland, 2006); o córtex pré-frontal medial ventral, envolvido nas expressões de alegria (Lane, Reiman, Ahern, Schwartz \& Davidson, 1997).Resultados de estudos apontam que a alegria é a expressão mais facilmente identificada em quaisquer faixas etárias e que isso advém, provavelmente, por esta ser a única emoção de valência positiva dentre as emoções básicas (Ku et al., 2005).

O conceito de "expressão neutra" desempenha um papel importante na lógica do reconhecimento da emoção através de expressões faciais. Como ponto neutro de um sistema de medição, as expressões neutras permitem aos pesquisadores ilustrar quais faces estão transmitindo emoções básicas e quais não estão (Carrera-Levilain \& Fernandez-Dols, 1994 apud Matsumoto \& Ekman, 1988).

A capacidade de reconhecer uma emoção expressa em face está presente desde a infância e continua a progredir ao longo do desenvolvimento humano (Freitag \& Schwarzer, 2009; Russell \& Fernández-Dols, 1997). Evidências sugerem que o reconhecimento de emoções faciais já está presente ao final do primeiro ano de vida, quando bebês são capazes de discriminar entre várias expressões emocionais (Hess, Jr \& Kleck, 2004).

Tal capacidade está intimamente relacionada à idade (Brody \& Harrison, 1987; Leitzke \& Pollak, 2016), e é durante o desenvolvimento infantil que esta se modifica mais intensamente e quando as mudanças entre diferentes faixas etárias ocorrem mais abruptamente (Haan, Belsky, Reid, Volein \& Johnson, 2004; Malatesta \& Haviland, 1982). No entanto, somente a partir dos três anos é que as crianças começam a reconhecer e a identificar/nomear as emoções faciais, com a distinção e nomeação de todas as emoções básicas por volta dos seis anos, continuando a melhorar tal desempenho com o avanço da idade (Freitag \& Schwarzer, 2009).

\subsubsection{Alterações no Processamento da Informação Facial}

Considerando a relevância da dimensão social em nosso cotidiano, a capacidade de julgar as expressões emocionais consiste em um mecanismo importante para a comunicação interpessoal eficaz (Pelphrey, et al., 2007). Contudo, 
alguns indivíduos com transtorno do espectro do autismo ou com esquizofrenia demonstram déficits na capacidade de reconhecimento das expressões faciais dos outros, enfatizando sua dificuldade de interação social com seus pares e com familiares (Bal et al., 2010; Baron-Cohen et al., 1999; Buitelaar, et al., 1999; Burns, 1999).

Outros estudos ainda sugerem que a dificuldade em reconhecer e nomear expressões de emoções parece ser um marcador diferencial para crianças e adolescentes com transtorno bipolar (Brotman, et al., 2008; Rocca et al., 2009; Shankman, et al., 2013), síndrome de down (Santana \& Feitosa, 2014) e transtorno de déficit de atenção e hiperatividade (Albert, et al., 2008; Dias \& Minervino, 2009; Palma \& Aboitiz, 2012). Ainda, tais dificuldades podem estar envolvidas em crianças com transtornos alimentares, de ansiedade, de humor ou de conduta (Collin, et al., 2013).

Machado et al., (2008) apresentaram diversas repercussões das dificuldades de conhecimento das emoções no desempenho escolar e, consequentemente, no desenvolvimento infantil. De acordo com tais autores, quando as crianças possuem maior conhecimento das emoções, tendem a responder de maneira mais assertiva às solicitações de professores e pares, construindo interações sociais mais ricas, o que afeta sua disposição emocional e motivação para a realização das tarefas acadêmicas, repercutindo positivamente no sucesso escolar e na autoestima da criança (Izard et al., 2001).

Crianças mais hábeis na identificação de emoções têm melhores resultados acadêmicos e aceitação pelos pares (Garner, Jones \& Miner, 1994; Waiden \& Field, 1990), ainda que comparadas a pares com mesma capacidade cognitiva e habilidade de comunicação verbal. Maxim e Nowicki (2003) afirmam que a dificuldade em reconhecer emoções em face pode, de fato, predizer prejuízos na responsividade às demandas sociais em crianças.

\section{I.4.2 Inteligência Emocional}

Inteligência Emocional (IE) foi descrita por Salovey e Mayer (1990) como a capacidade de monitorar as próprias emoções e de outras pessoas, discriminar entre diferentes emoções e rotulá-las apropriadamente, e usar informações emocionais para guiar o pensamento e o comportamento. 
A capacidade de reconhecimento facial pode ser uma habilidade social cognitiva independente que reflete a IE de uma pessoa (Wilhelm et al., 2010). Chen (2014) realizou um estudo referente ao reconhecimento de faces e a inteligência emocional. Primeiramente foi examinada como a capacidade de reconhecimento de face estava associada à IE de um indivíduo; em segundo lugar, foi investigada como a emoção e a etnia afetam a precisão, a latência da resposta, a sensibilidade e o viés de resposta do reconhecimento facial. Para abordar estas questões, a precisão e velocidade dos participantes em uma tarefa de reconhecimento facial foram gravadas. Além disso, a IE de cada participante foi avaliada através do Inventário de Inteligência Emocional de Bar-On (versão resumida).

Faces com expressões positivas resultaram em maior precisão e melhor sensibilidade em comparação com faces neutras ou com expressões negativas. Os participantes apresentaram melhor desempenho com faces de outras etnias do que as da sua própria. Mais importante ainda, observou-se também que a capacidade de reconhecimento facial estava relacionada à pontuação no teste de IE, sugerindo associação entre IE e capacidade social cognitiva.

Rivers et al., (2010) realizaram um teste de validade inicial do Teste de Inteligência Emocional de Mayer - Salovey - Caruso, Versão Jovem (Mayer-SaloveyCaruso Emotional Intelligence Test - Youth Version - MSCEIT-YV) usando relatórios de alunos e professores do funcionamento acadêmico, social e pessoal no Sistema de Avaliação Comportamental para Crianças (Behavior Assessment System for Children - BASC; Reynolds \& Kamphaus, 1992). Os estudantes com pontuação mais alta no MSCEIT-YV tinham menos probabilidade de serem classificados pelos professores como tendo problemas de externalização ( $p$. ex., hiperatividade, agressão, problemas de conduta), problemas de internalização (p. ex., ansiedade, depressão) e problemas escolares. A associação entre os escores do MSCEIT-YV e os problemas escolares foi particularmente alta, indicando que os alunos com maior inteligência emocional podem ter melhor habilidade de atenção e menos problemas de aprendizagem.

A motivação de realizarmos este trabalho está baseada no fato de que, embora a literatura apresente vasto acervo sobre frequências espaciais e julgamentos de expressões faciais de emoções, pouca atenção tem sido dada ao estudo de como a sensibilidade ao contraste influencia o julgamento de faces e de expressões faciais 
em adultos e crianças. Considerando que a sensibilidade ao contraste se desenvolve até 0 final da adolescência, importantes informações sobre diferenças nos julgamentos de emoções ao longo da infância e adolescência podem estar relacionadas aos nossos limites de perceber contraste. 


\section{OBJETIVOS}

Estudar a relação entre sensibilidade ao contraste e o julgamento de expressões faciais de emoções durante o desenvolvimento infanto-juvenil.

\section{II.1 Objetivos Específicos}

- Analisar a existência de possíveis correlações entre idade, taxa de acertos nas respostas e nível de contraste testado;

- Diferenciar quais expressões emocionais precisam de maior/menor contraste para serem identificadas corretamente.

\section{II.2 Hipóteses}

- Esperávamos um aprimoramento da capacidade de reconhecimento de emoções em faces proporcional ao aumento da idade: ou seja, espera-se que a criança de 11 anos obtenha mais acertos para o reconhecimento da emoção facial quando comparada a uma criança mais jovem;

- Acreditávamos que houvesse diferença nos níveis de intensidade de contraste requeridos para cada emoção básica, com necessidade de menor nível de contraste para identificar expressão de alegria. 


\section{MATERIAL E MÉTODO}

\section{III.1 Sujeitos}

Avaliamos 50 crianças, com idade média de 10,3 anos (desvio padrão= 2,05 anos; mediana=10,5 anos e variação entre 6 e 14 anos). As crianças foram recrutadas e examinadas na Escola Municipal General Liberato Bittencourt.

Os critérios de inclusão foram:

- avaliação oftalmológica normal e acuidade visual corrigida melhor ou igual a 20/20;

- desempenho cognitivo que permitiu entender as instruções do teste.

Os critérios de exclusão foram:

- uso de medicamentos de efeito no sistema nervoso central;

- doenças sistêmicas associadas.

Tivemos um grupo de adultos para comparação de pleno desenvolvimento, que contou com 30 adultos com acuidade visual normal, com idade média de 22,7 anos (desvio padrão= 2,7; mediana= 22,0 anos, variação entre 18 e 30 anos).

\section{III.2 Procedimentos}

III.2.1 Avaliação pré-teste psicofísico

Os sujeitos ou responsáveis responderam a uma anamnese completa, contendo dados pessoais, antecedentes familiares e problemas visuais e de saúde geral associados. Em seguida, após a leitura e concordância, assinaram o termo de assentimento livre e esclarecido.

O presente estudo está atualmente em avaliação pelo Comitê de Ética em Pesquisa com Seres Humanos do Instituto de Psicologia da USP.

\section{III.3 Teste Psicofísico}

Para avaliar o reconhecimento de emoção em faces com variação de contraste nas crianças pretendidas, foi necessário construir um instrumento de testagem. 


\section{III.3.1 Equipamento}

Para esse estudo, foi utilizado o Programa de Psicofísica Psykinematix (KyberVisionv.14.3, Tokio, Japan). O programa rodou em um computador IMac OSX (v.10.8.3), um monitor integrado de 21.5" com resolução de 1920X1080, frequência de $60 \mathrm{hz}$, com distância de $60 \mathrm{~cm}$ do teste (compreende um campo de visão de $43 \times 25^{\circ}$ ) e placa gráfica NVIDIA GT 640M. A luminância média foi de $60.4 \mathrm{~cd} / \mathrm{m}^{2}$. O programa utiliza um sistema de bitstilling que permite a geração de 11,6 níveis de contraste (3.104 níveis de contraste) a partir de uma placa gráfica comercial de alta resolução e desempenho (Tyler, 1997). Este nível de contraste está adequado para a utilização em experimentos de sensibilidade ao contraste (Pelli \& Zang, 1991).

\section{III.3.2 Estímulo Julgamento de Emoções}

Avaliamos 4 diferentes expressões faciais, sendo neutra, alegria, tristeza e raiva, tanto para face feminina quanto para masculina. As faces utilizadas pertencem ao Banco de Faces do Karolinska Institute (Karolinska Directed Emotional Faces (Lundqvist, D., et al., 1998), Suécia, e são royallity-free. Usamos faces de humanos com exclusão de orelhas e cabelo (figura 18). As fotos das faces foram modificadas para branco e preto em software específico (Photoshop), preservando as características originais de luminância e contraste.
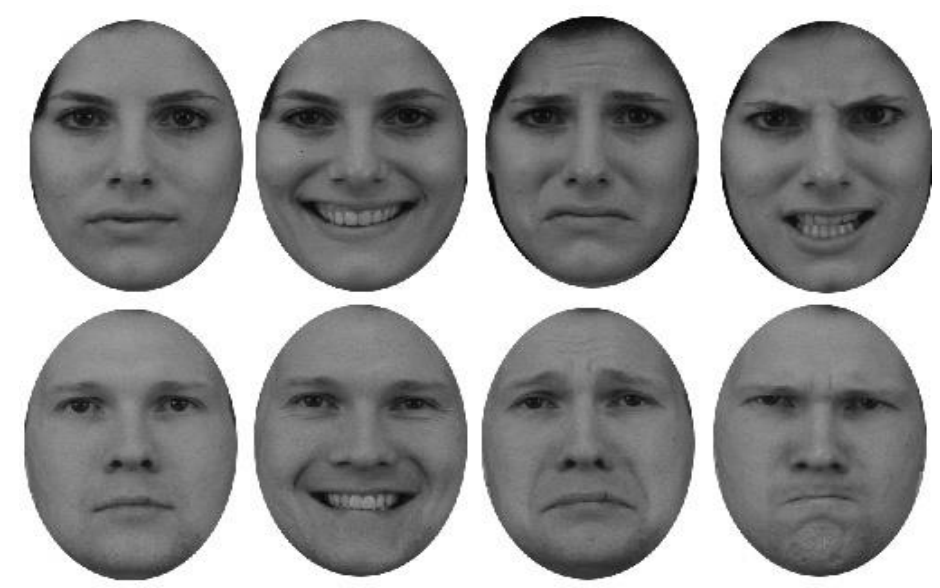

Fonte: Adaptado de Banco de Faces do Karolinska Institute

Figura 18: Ilustração das imagens utilizadas no experimento deste projeto. Imagens de faces femininas (fotos superiores) e masculinas (fotos inferiores) com 4 diferentes expressões, da esquerda para direita: neutra, alegria, tristeza e raiva. 
III.3.3 Procedimento Julgamento de Emoções

- A tarefa do participante foi a de julgar o sexo e a emoção de cada imagem apresentada.

- Testamos 5 níveis de contraste distribuídos logaritmicamente entre $2,5 \%$ e $15 \%(2,5 ; 3,4 ; 5,2 ; 8,5 ; 15$; ex. figura 19$)$.

- O limiar de contraste para julgamento de cada emoção em cada sexo foi obtido por meio de uma medida psicofísica de Estímulos Constantes.

- Cada um dos níveis de contraste foi apresentado 3 vezes para cada uma das 4 expressões faciais.

- A imagem de cada face/expressão apareceu na tela do computador por um tempo de 2 segundos.

- O sujeito realizou um total de 120 julgamentos (60 faces masculinas +60 faces femininas).

- Uma função psicométrica determinou o limiar de contraste correspondente a $75 \%$ de julgamentos corretos.
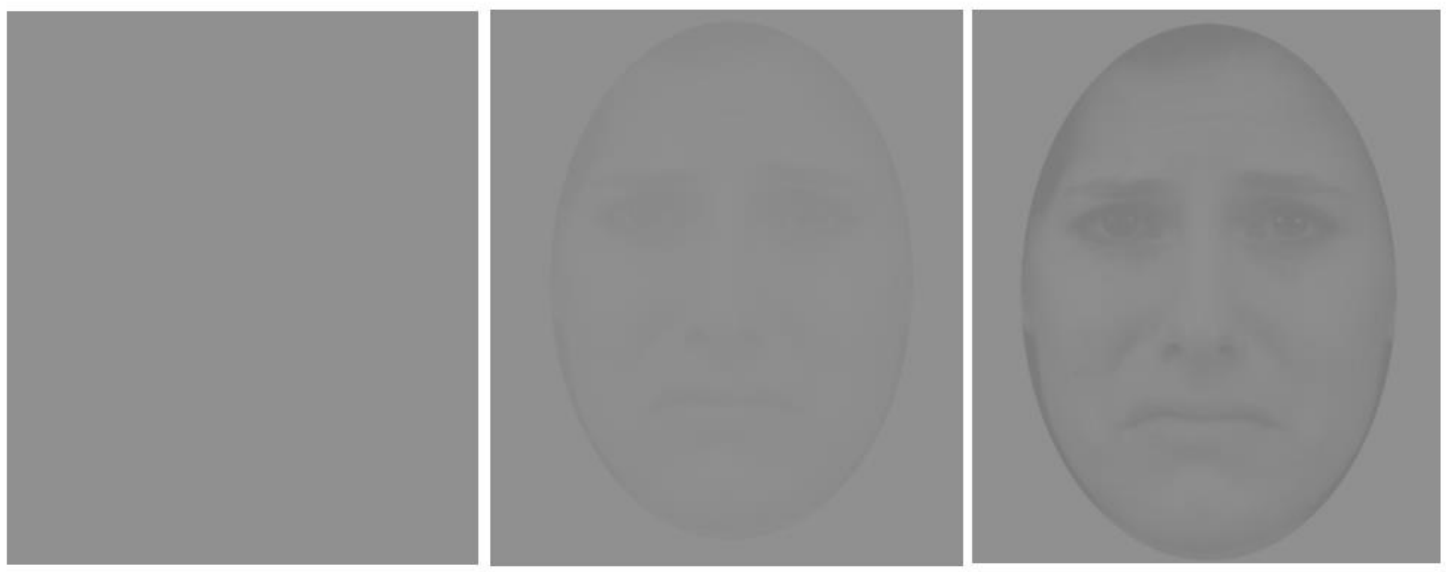

Fonte: Adaptado de Banco de Faces do Karolinska Institute

Figura 19: Imagens utilizadas no experimento deste projeto. Imagens de faces femininas com expressão emocional de tristeza, variando em nível de contraste, da esquerda para direita em: 2,5\%, $3,4 \%$ e $15 \%$. 


\section{ANÁLISE DOS RESULTADOS}

Medidas estatísticas descritivas completas foram realizadas em todos os dados obtidos. Adesão à curva normal foi testada. A comparação entre os diferentes grupos infanto-juvenis e adulto foi feito por meio de estatística comparativa de médias por análise de variância (ANOVA). Correlações e análises de subgrupos como sexo também foram realizadas.

\section{RESULTADOS}

Os resultados deste experimento são divididos pelas categorias de sexo e emoção (face), e apontaremos em seguida quais subgrupos de sujeitos (1) Adulto Masculino, (2) Adulto Feminino, (3) Criança Feminino e (4) Criança Masculino apresentaram diferenças de limiar de contraste, entre si. Os valores médios dos limiares de contraste para cada face, de cada subgrupo, são apresentados na tabela 1.

\begin{tabular}{ccccccccc}
\hline & $\begin{array}{c}\text { Homem } \\
\text { Neutro }\end{array}$ & $\begin{array}{c}\text { Homem } \\
\text { Alegre }\end{array}$ & $\begin{array}{c}\text { Homem } \\
\text { Raiva }\end{array}$ & $\begin{array}{c}\text { Homem } \\
\text { Triste }\end{array}$ & $\begin{array}{c}\text { Mulher } \\
\text { Neutro }\end{array}$ & $\begin{array}{c}\text { Mulher } \\
\text { Alegre }\end{array}$ & $\begin{array}{c}\text { Mulher } \\
\text { Raiva }\end{array}$ & $\begin{array}{c}\text { Mulher } \\
\text { Triste }\end{array}$ \\
\hline $\begin{array}{c}\text { Adulto Masculino } \\
\text { (Subgrupo 1) }\end{array}$ & $2,7(1,7)$ & $4,6(3,2)$ & $5,2(2,8)$ & $4,3(1,6)$ & $5,3(3,5)$ & $4,7(1,7)$ & $5,2(3,2)$ & $5,1(3,1)$ \\
$\begin{array}{c}\text { Adulto Feminino } \\
\text { (Subgrupo 2) }\end{array}$ & $5,8(4,7)$ & $8,0(5,0)$ & $6,8(5,2)$ & $4,2(3,8)$ & $6,3(2,4)$ & $5,9(4,6)$ & $5,9(4,8)$ & $5,2(3,6)$ \\
$\begin{array}{c}\text { Criança Feminino } \\
\text { (Subgrupo 3) }\end{array}$ & $9,9(3,8)$ & $9,3(7,5)$ & $7,7(4,0)$ & $7,8(3,6)$ & $8,3(3,9)$ & $9,3(3,4)$ & $9,8(3,8)$ & $7,6(3,1)$ \\
$\begin{array}{c}\text { Criança Masculino } \\
\text { (Subgrupo 4) }\end{array}$ & $7,2(6,2)$ & $9,8(5,25)$ & $7,1(5,0)$ & $6,7(3,5)$ & $7,3(3,7)$ & $7,2(6,5)$ & $7,2(8,9)$ & $7,6(5,8)$ \\
\hline
\end{tabular}

Tabela 1. Valores Médios (desvio padrão) de Limiares de Contraste.

Para a face Masculina Neutra houveram diferenças estatisticamente significantes $(F=8,63 ; p<0,001)$ entre os subgrupos: Adulto Masculino (1) e Adulto Feminino (2), onde o subgrupo 1 foi melhor no desempenho da atividade do que o subgrupo 2; entre os subgrupos Adulto Masculino (1) e Criança Masculino (4), os adultos necessitaram de menos contraste para o reconhecimento do sexo e emoção das faces apresentadas; entre os subgrupos Criança Feminino (3) e Criança Masculino (4), os meninos apresentaram desempenho superior às meninas; entre os 
subgrupos Adulto Feminino (2) e Criança Feminino (3), as mulheres necessitaram de um menor limiar de contraste.

Para a face Masculina Alegre $(F=3,08 ; p=0,032)$ o subgrupo Adulto Masculino (1) apresentou menor limiar de contraste do que o subgrupo Criança Masculino (4). Para a face Masculina Raiva não encontramos diferenças estatísticas entre os subgrupos para os valores de limiar de contraste. Os julgamentos para a face Masculina Triste $(F=6,50 ; p=0,002)$, mantiveram a diferença entre Adulto Masculino (1) e Criança Masculino (4); e entre os subgrupos Adulto Feminino (2) e Criança Feminino (3), sendo os subgrupos dos adultos melhores no desempenho da atividade.

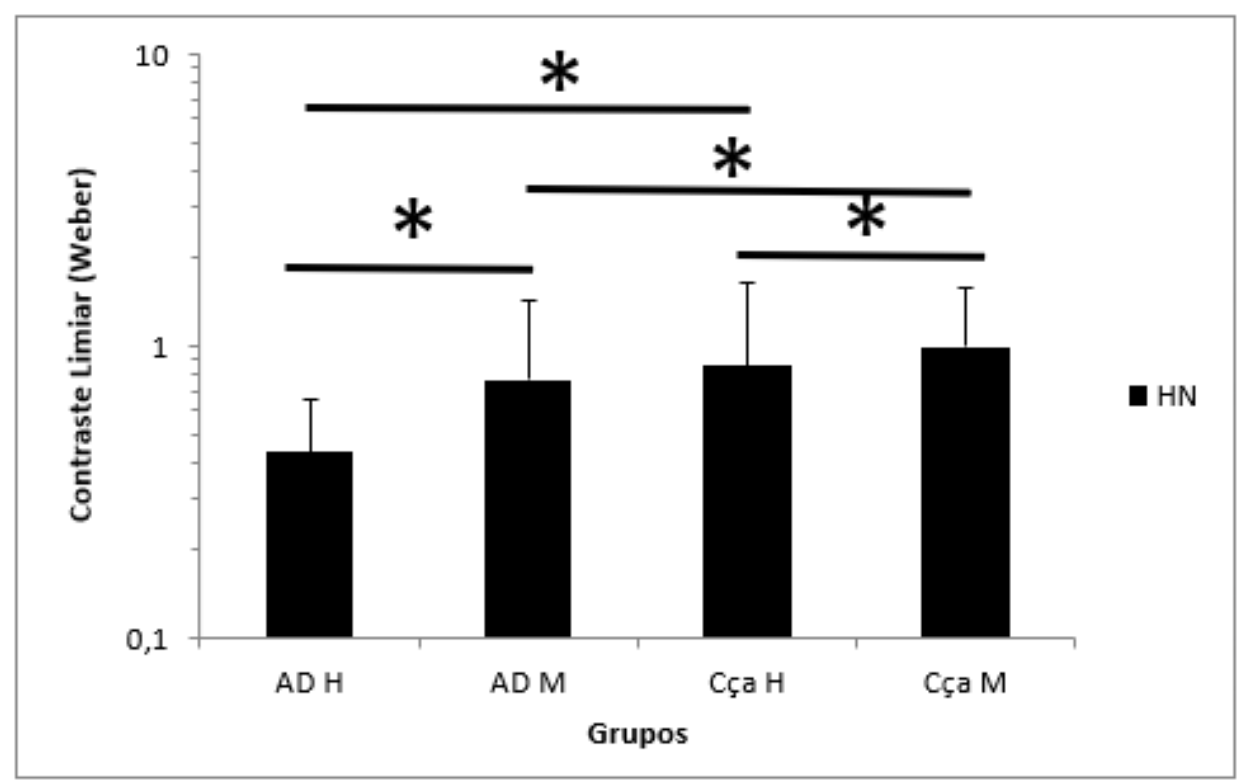

Gráfico 1. Face do Homem com expressão Neutra. Legendas: HN - Homem Neutro; $A D$ $\mathrm{H}$ - Adulto Homem; AD M - Adulto Mulher; Cça H - Criança Homem; Cça M - Criança Mulher. 


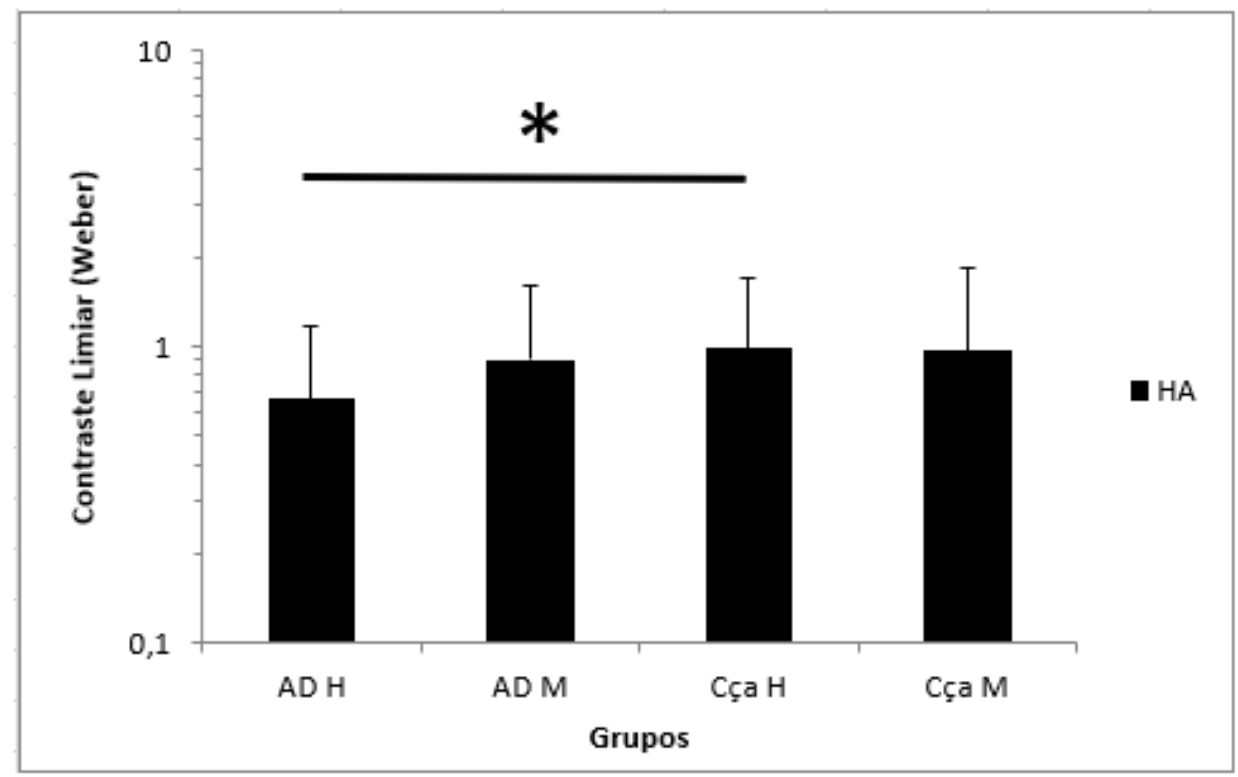

Gráfico 2. Face do Homem com expressão Alegre. Legendas: HA - Homem Alegre; AD H - Adulto Homem; AD M - Adulto Mulher; Cça H - Criança Homem; Cça M - Criança Mulher.

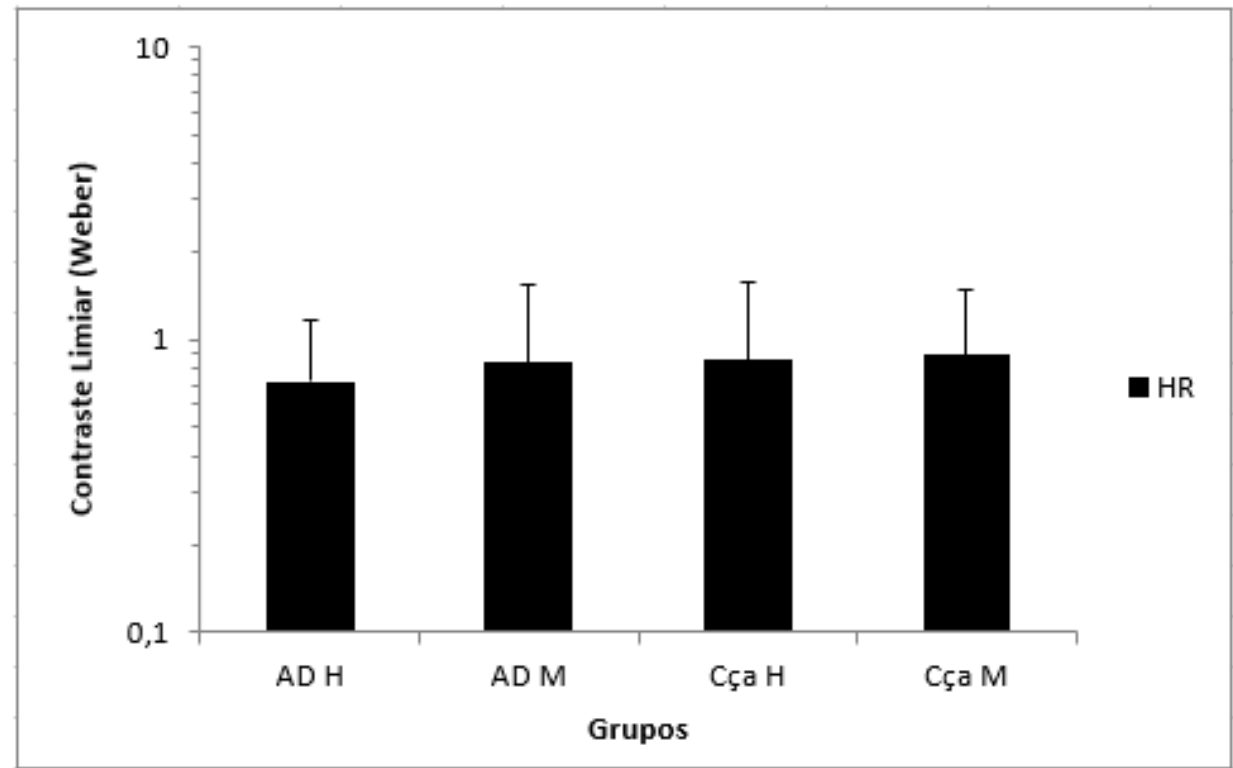

Gráfico 3. Face do Homem com expressão Raiva. Legendas: HR - Homem Raiva; AD H - Adulto Homem; AD M - Adulto Mulher; Cça H - Criança Homem; Cça M - Criança Mulher. 


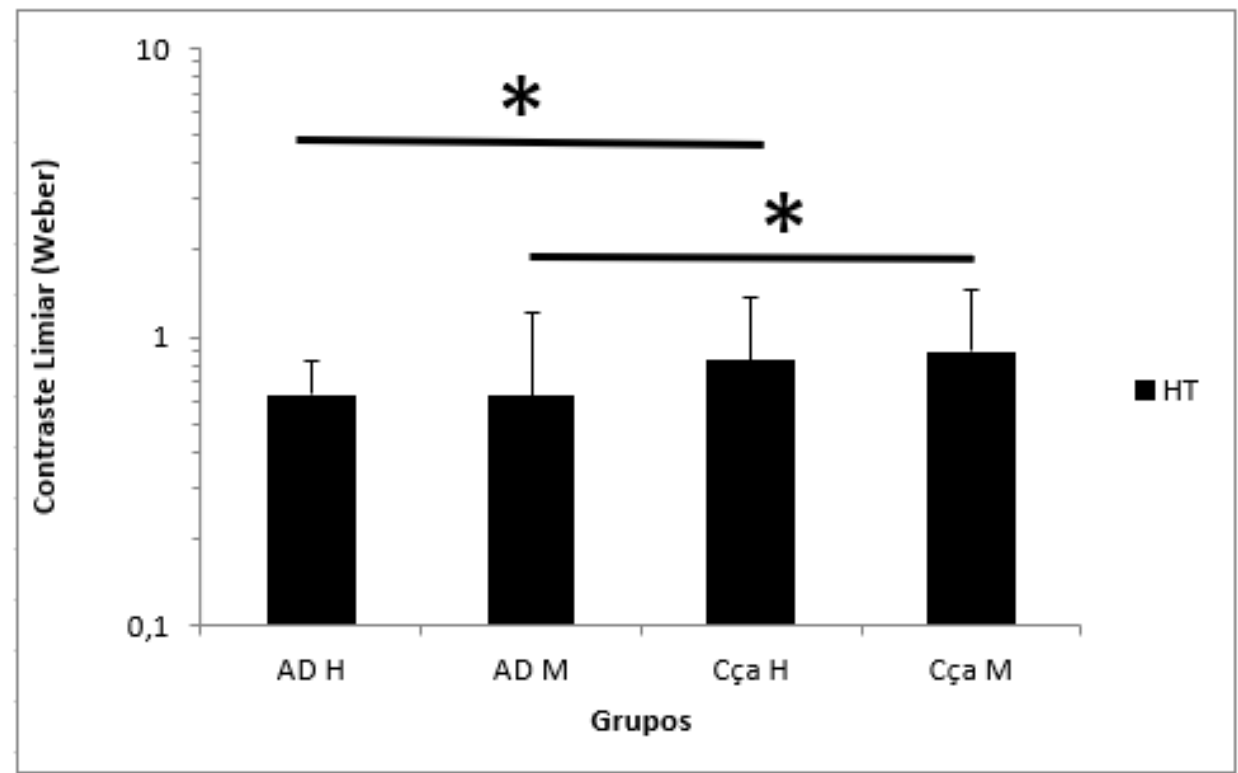

Gráfico 4. Face do Homem com expressão Triste. Legendas: HT - Homem Triste; AD H Adulto Homem; AD M - Adulto Mulher; Cça H - Criança Homem; Cça M - Criança Mulher.

Nas faces Femininas tivemos na Neutra $(F=5,13 ; p=0,003)$, a diferença entre os subgrupos Adulto Masculino (1) e Criança Masculino (4), tendo os adultos menor limiar de contraste. Na face Alegre $(F=5,57 ; p=0,002)$ o subgrupo Adulto Feminino (2) foi melhor que o subgrupo Criança Feminino (3) em seu desempenho na atividade. A face feminina, com a expressão de Raiva também não apresentou diferenças estatísticas entre os grupos para os valores de limiar de contraste. A Feminina Triste $(F=4,04 ; p=0,011)$ mostrou diferença entre Adulto Masculino (1) e Criança Masculino (4); e entre os subgrupos Adulto Feminino (2) e Criança Feminino (3), permanecendo a superioridade dos adultos. 


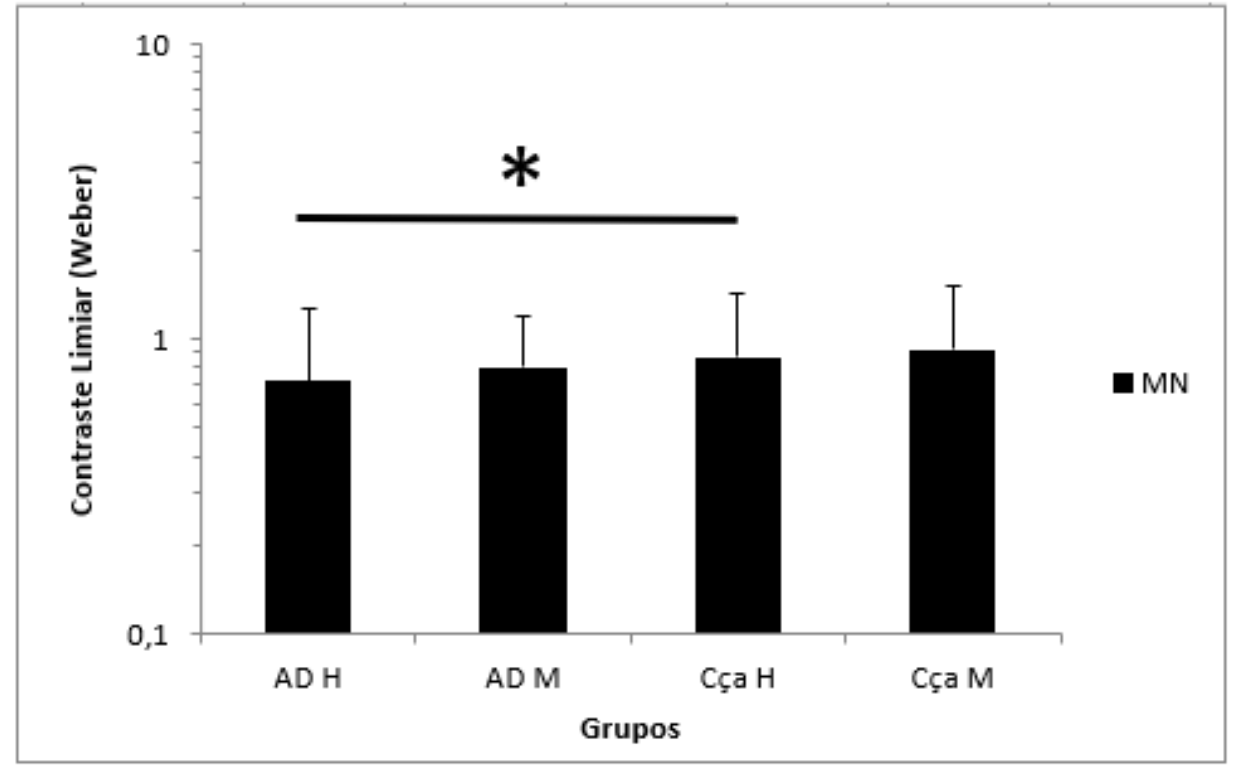

Gráfico 5. Face da Mulher com expressão Neutra. Legendas: MN - Mulher Neutra; AD H - Adulto Homem; AD M - Adulto Mulher; Cça H - Criança Homem; Cça M - Criança Mulher.

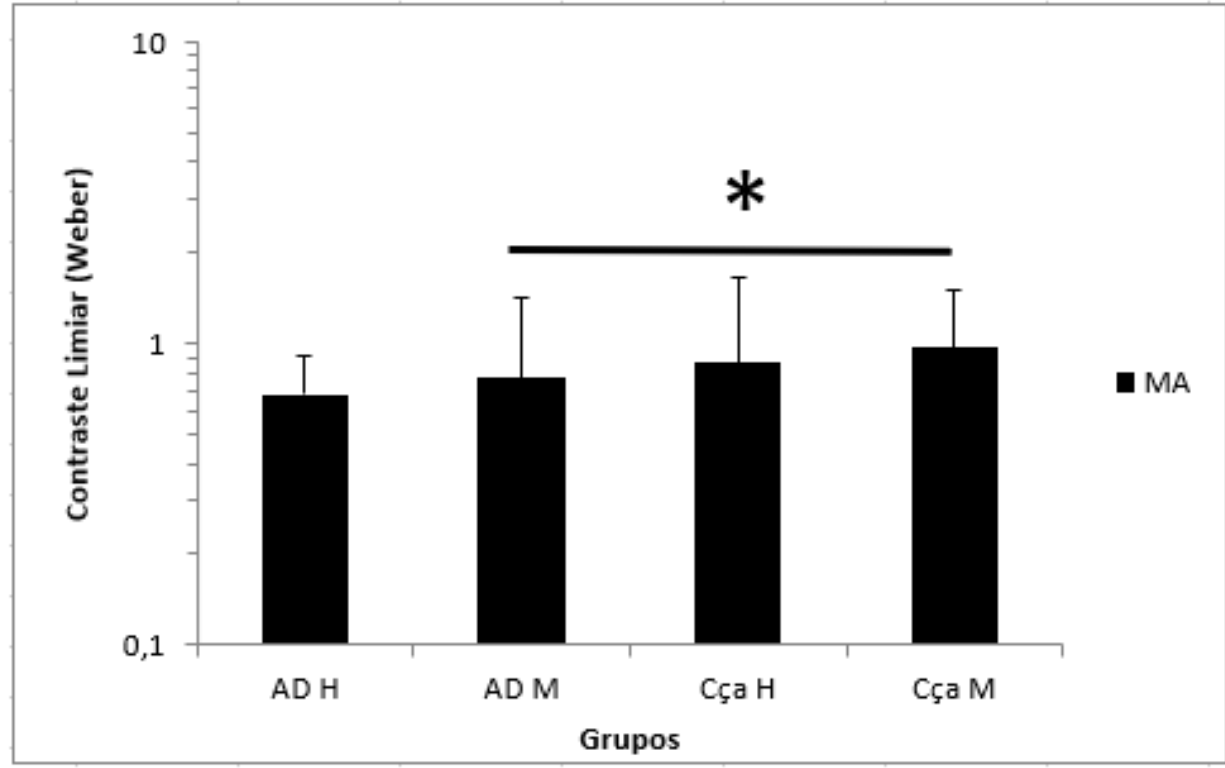

Gráfico 6. Face da Mulher com expressão Alegre. Legendas: MA - Mulher Alegre; AD H Adulto Homem; AD M - Adulto Mulher; Cça H - Criança Homem; Cça M - Criança Mulher. 


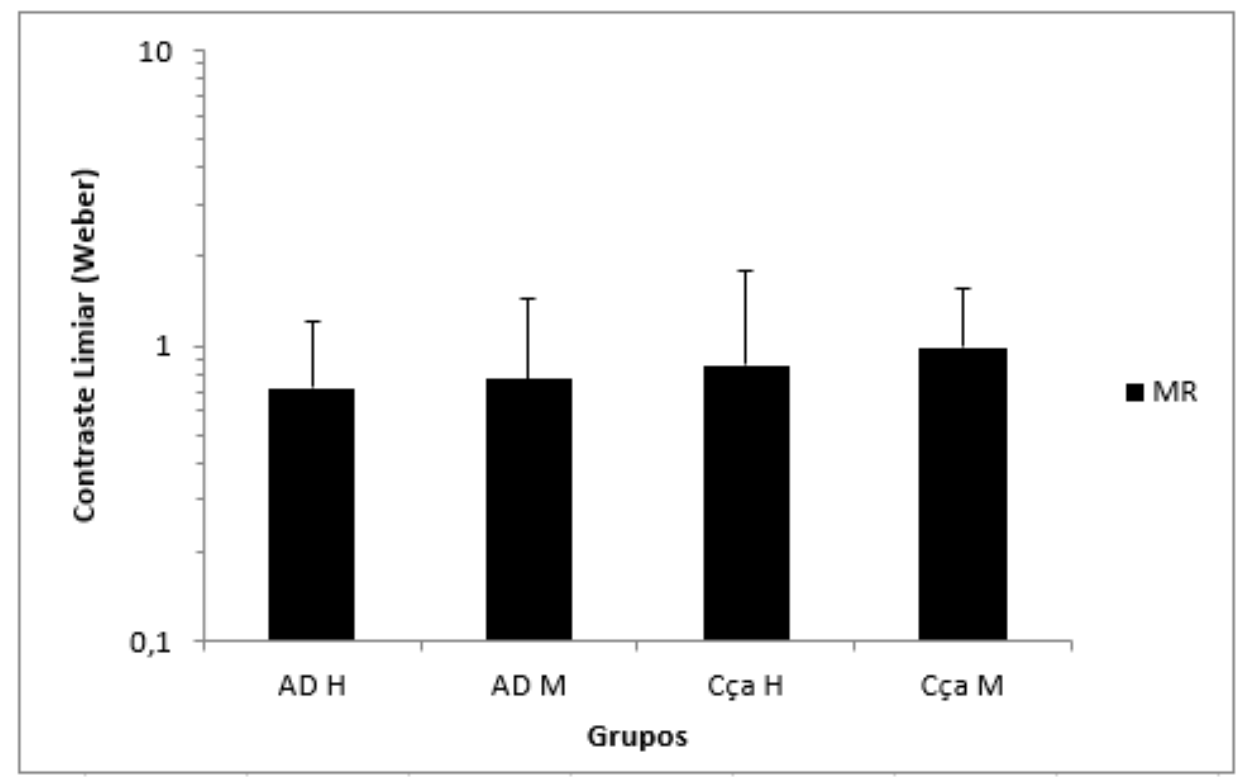

Gráfico 7. Face da Mulher com expressão Raiva. Legendas: MR - Mulher Raiva; AD H Adulto Homem; AD M - Adulto Mulher; Cça H - Criança Homem; Cça M - Criança Mulher.

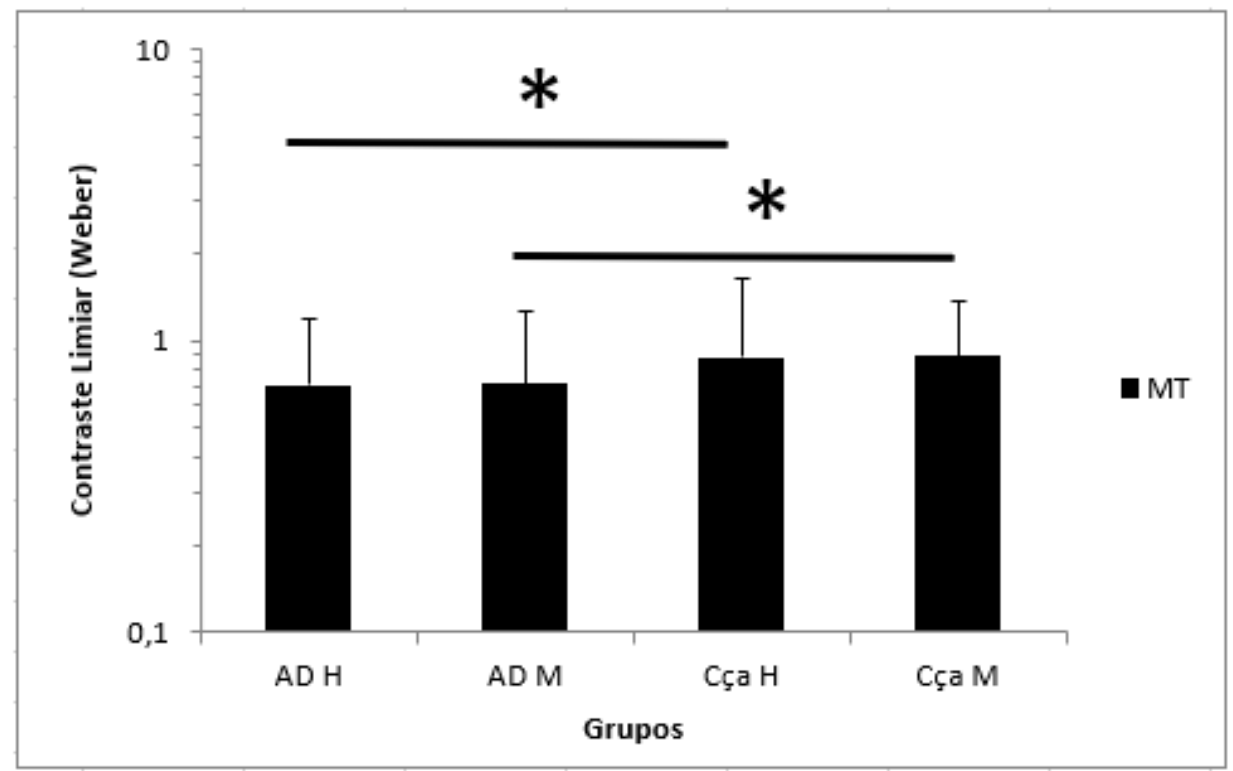

Gráfico 8. Face da Mulher com expressão Triste. Legendas: MT - Mulher Triste; AD H Adulto Homem; AD M - Adulto Mulher; Cça H - Criança Homem; Cça M - Criança Mulher.

Análise Intragrupo resultou que entre todas as emoções e os sexos, apenas o julgamento para faces Neutras de Homem foi estatisticamente significante $(F=2,84$; $p=0,012$ ), quando comparado ao julgamento de faces Neutras de Mulher, pelo subgrupo Adulto Masculino. 


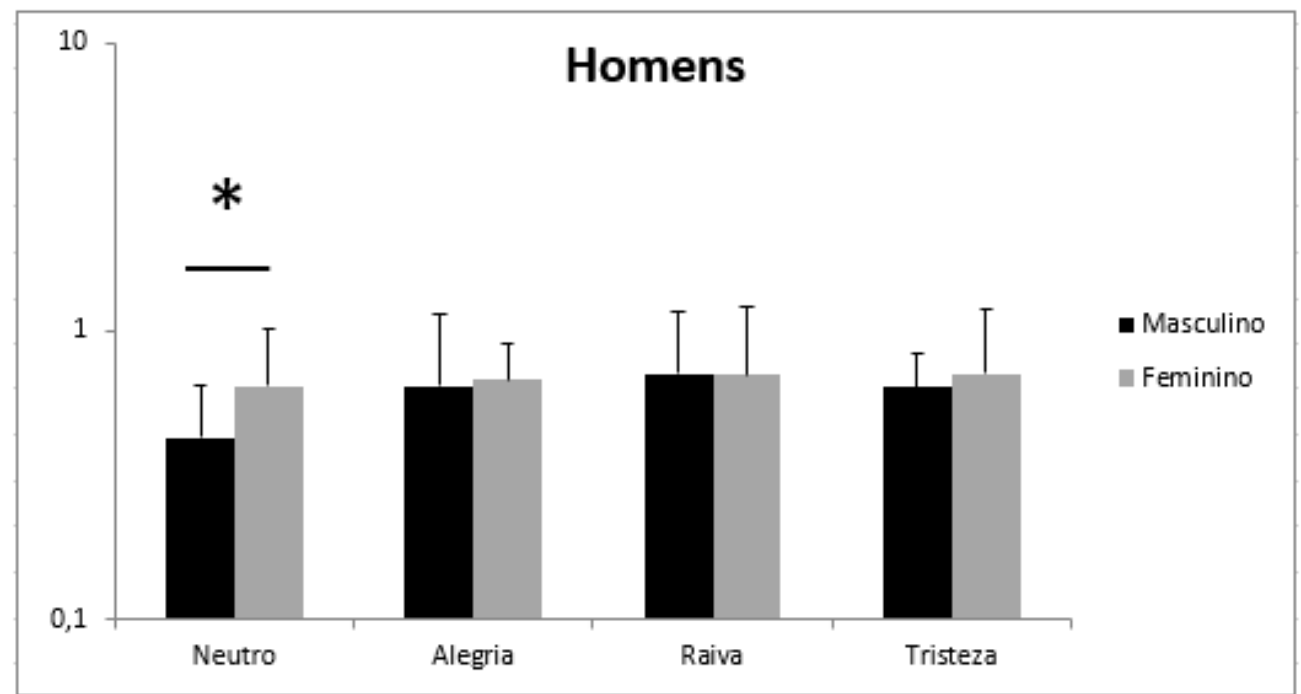

Gráfico 9. Análise Intragrupo de expressões faciais de emoções, do subgrupo Adulto Homem.

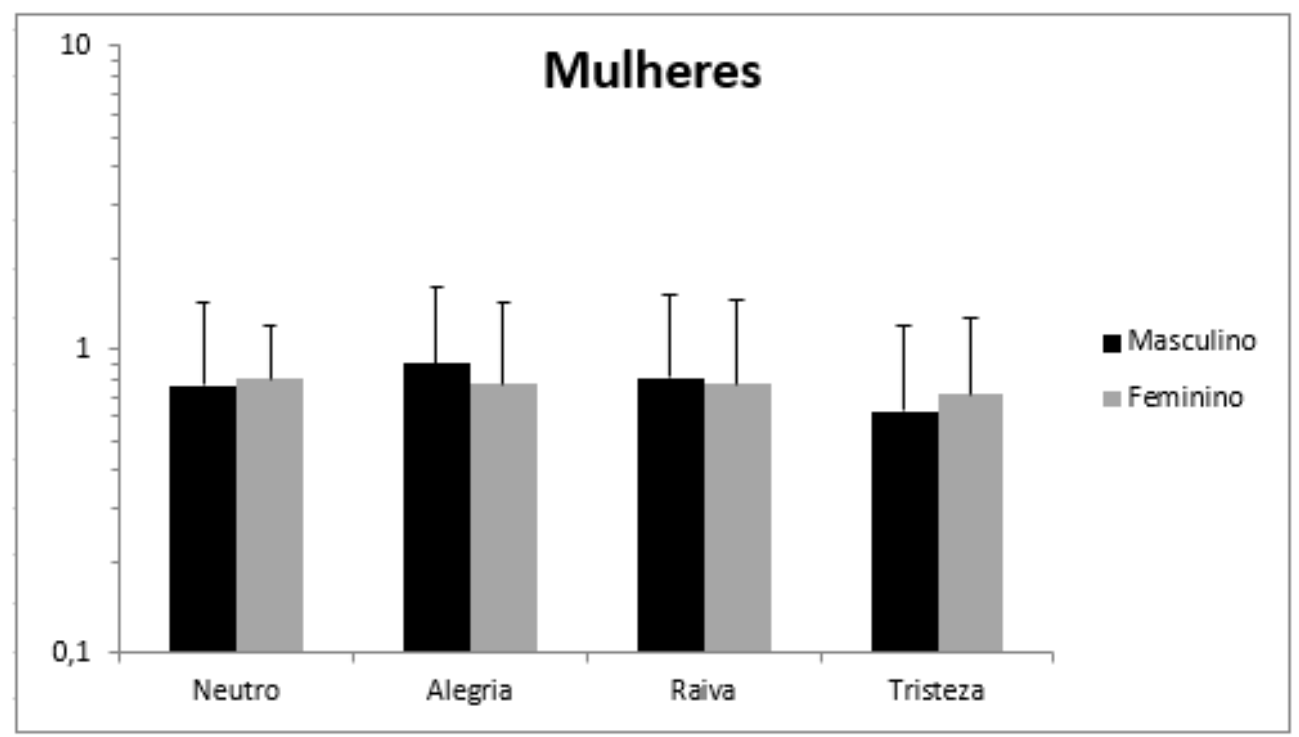

Gráfico 10. Análise Intragrupo de expressões faciais de emoções, do subgrupo Adulto Mulher. 


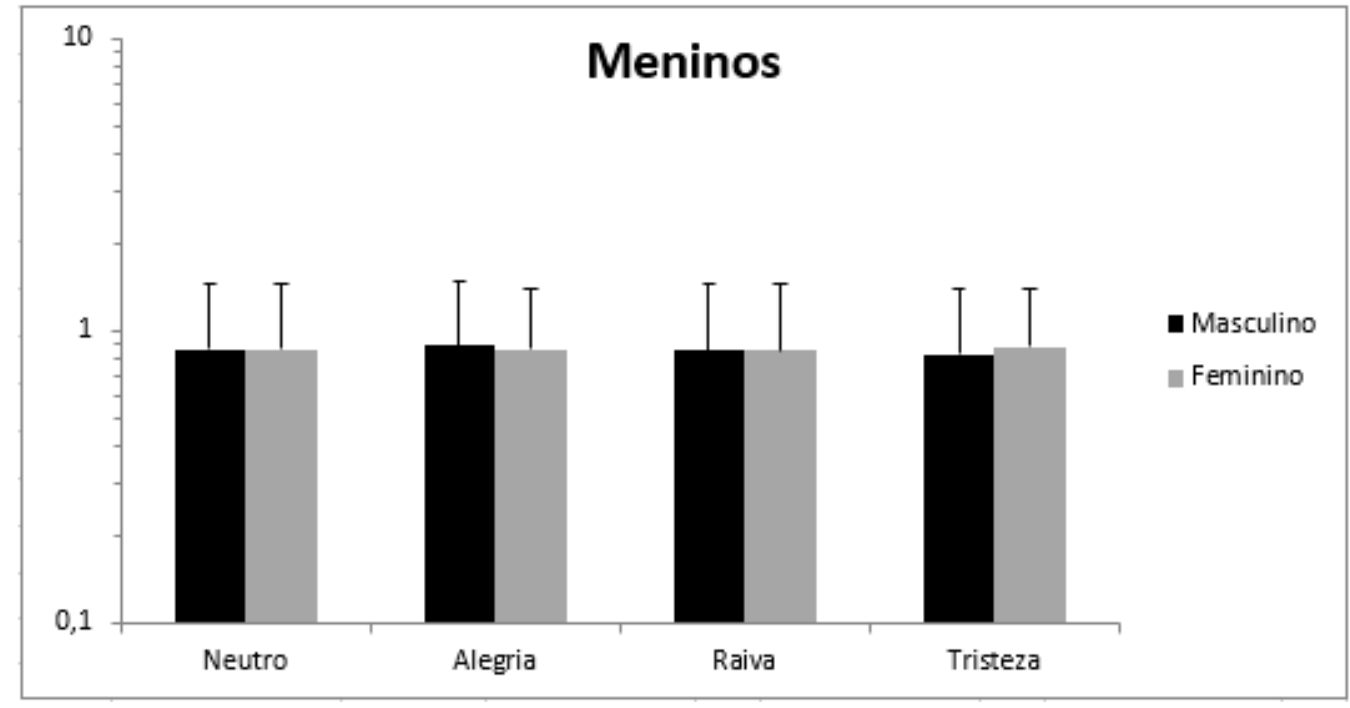

Gráfico 11. Análise Intragrupo de expressões faciais de emoções, do subgrupo Criança Homem (Meninos).

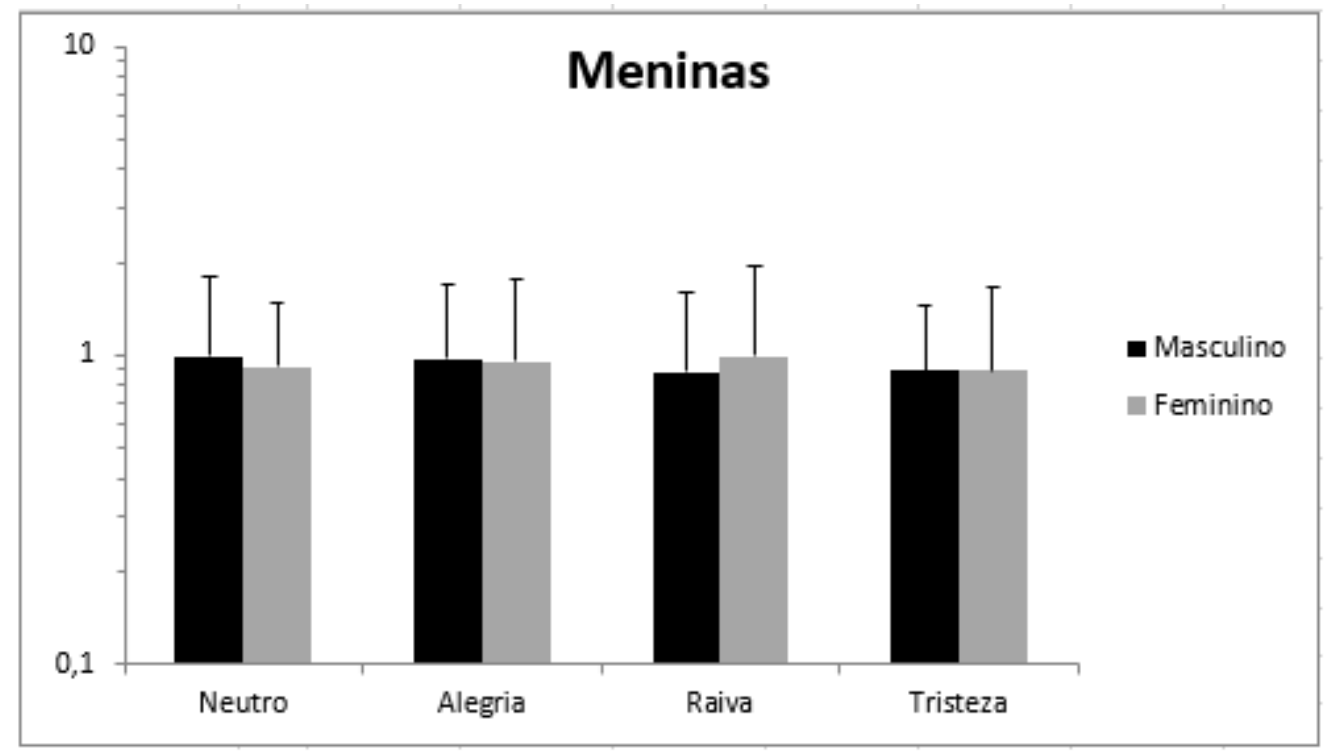

Gráfico 12. Análise Intragrupo de expressões faciais de emoções, do subgrupo Criança Mulher (Meninas). 


\begin{tabular}{llllllllll}
\hline \multicolumn{2}{c}{ Adulto Homem } & \multicolumn{2}{c}{ Adulto Mulher } & \multicolumn{2}{c}{ Criança Mulher } & \multicolumn{2}{c}{ Criança Homem } \\
\hline 0,425265628 & HN & 0,625554533 & HT & 0,885243394 & HR & 0,827601869 & HT \\
0,635483747 & HT & 0,712501149 & MT & 0,888594561 & MT & 0,853628023 & HR \\
0,643712344 & HA & 0,762678564 & HN & 0,889593976 & HT & 0,857564429 & MR \\
0,646864822 & MN & 0,768289795 & MA & 0,918881831 & MN & 0,858791611 & HN \\
0,675006091 & MA & 0,769007871 & MR & 0,957524005 & MA & 0,859258417 & MA \\
0,703788981 & MR & 0,802169839 & MN & 0,969071355 & HA & 0,864784825 & MN \\
0,707868119 & MT & 0,809896247 & HR & 0,989097404 & MR & 0,878843376 & MT \\
0,712383834 & HR & 0,902354897 & HA & 0,994592075 & HN & 0,891582056 & HA \\
\hline
\end{tabular}

Tabela 2. Análises Intragrupos, em ordem crescente de sexo/expressões emocionais com menor limiar de contraste necessário para serem reconhecidas por cada subgrupo. Legendas: $\mathrm{HN}-$ Homem Neutro; HA - Homem Alegre; HR - Homem Raiva; HT - Homem Triste; MN - Mulher Neutro; MA - Mulher Alegre; MR - Mulher Raiva; MT - Mulher Triste. 


\section{DISCUSSÃO}

Nosso trabalho conseguiu realizar medidas de julgamento de gênero e emoção em faces moduladas por contraste em adultos e crianças. Até onde sabemos este é o primeiro estudo que analisa reconhecimento de emoções em faces com variações de contraste, sendo, portanto, uma importante contribuição para a área. As pesquisas encontradas na literatura investigam apenas as variações de frequências espaciais e como elas afetam o reconhecimento de faces e emoções (Fiorentini et al.,1983; Costen et al., 1996; Hayes et al., 1986; Sergent, 1985; Schyns et al., 1999; Nasanen, 1999; Liu et al., 2000; Calder et al., 2000; Tieger et al., 1979; Norman et al., 1987).

Diferentemente dos estudos de julgamento de emoções onde manipulações experimentais ocorreram para as frequências espaciais das imagens de faces, cujos resultados mostraram que faixas de frequência espacial distintas tem diferentes papéis no processamento de faces (Sergent, 1985; Costen et al., 1996; Schyns et al., 1999; Nasanen, 1999; Liu et al., 2000; Calder et al., 2000; Tieger et al., 1979; Fiorentini et al., 1983; Hayes et al., 1986; Norman et al., 1987), nosso trabalho mostrou que para a dimensão visual de contraste, esta diferença entre reconhecimento de faces e o aprimoramento para uma análise mais detalhada para o julgamento de emoções não ocorreu com diferenças significantes entre homens e mulheres. Porém, quando comparamos os adultos com o grupo de crianças, ou seja, os homens com os meninos e as mulheres com as meninas, diferenças foram encontradas para as expressões faciais Neutra, Alegre e Triste.

Ewing et al., (2017) apontaram uma consistência de categorização mais forte para as faces felizes, seguidos de medo, tristeza e raiva, utilizando um paradigma da técnica de Bubbles que consiste em uma técnica computadorizada que permite identificar quais os estímulos estão sendo utilizados por nosso sistema visual para identificação e categorização de determinada figura. Nosso estudo não teve uma diferença significante entre os subgrupos para os sexos/expressões. Esta diferença pode se dar por conta da estimulação, que em nosso caso modulou o contraste da imagem, ou pela própria tarefa que está relacionada à discriminação e não à categorização. Esta diferença metodológica pode ter impacto como demonstrado em estudos de categorização e nomeação de cores. 
Estes resultados, mostrando a necessidade de maior contraste para a identificação de emoções e gêneros em faces para o grupo de crianças, sugere fortemente que até a idade das crianças que avaliamos, ou seja, entre 6 e 14 anos, ainda não se concluiu o processo de desenvolvimento para a percepção de faces, ao menos, com base no contraste da imagem.

Embora o reconhecimento de face em comparação com outro estímulo qualquer ocorra desde muito cedo no desenvolvimento, a discriminação de emoções está relacionada à pequenas modificações espaciais de seus elementos, como boca, olhos e sobrancelhas. Sabemos que o desenvolvimento da acuidade visual ocorre de maneira intensa nos primeiros anos de vida e atinge o ápice do desenvolvimento entre 7 e 10 anos de idade (Teller, 1997). No entanto, nossa capacidade de discriminar contrastes apresenta um desenvolvimento mais lento, com término ao final da adolescência. Nossos dados acompanham os achados desta literatura, uma vez que mostramos um desempenho inferior no julgamento de expressões emocionais para crianças, quando comparadas com adultos, quando modulamos o contraste espacial da imagem. Assim, o pleno desenvolvimento da percepção de faces ocorre mais tardiamente, o que não pode ser evidenciados pelas metodologias classicamente empregadas para o estudo de componentes espectrais das faces.

As condições de realização de nossa pesquisa se deram pelas possibilidades tecnológicas de utilizarmos para estímulos não periódicos, alterações de contraste, as quais reduziam os níveis de contraste da imagem de forma a gerar uma redução equilibrada para estímulos complexos. A modulação de contraste por meio do contraste de Weber permitiu que alcançássemos reduções de contraste para valores específicos, considerando a entrada não linear do perfil de contraste da imagem. Isto quer dizer que, pelo uso do contraste de Weber, a não periodicidade das frequências espaciais existentes nas faces não se configurou um problema metodológico. Desta forma, as imagens eram moduladas em contraste de maneira a permitir uma modulação assimétrica fazendo com que cada ponto da imagem alcançasse o valor de contraste a ser medido.

Durante a realização deste trabalho de pesquisa, nos deparamos com algumas dificuldades que acabaram por gerar limitações no alcance deste estudo. Devemos considerar tais limitações o número de sujeitos coletados, que devido ao período curto de coleta, ocorrido por tempo de desenvolvimento e implementação 
metodológica, assim como houve períodos de greve na escola cujos dados estavam sendo coletados. Outro limite evidente é a idade dos sujeitos que poderia ser ampliada, tanto para crianças com menor idade, quanto para adolescentes de mais idade, aumentando assim a perspectiva de se entender o percurso do desenvolvimento com maior resolução e, portanto, de forma mais precisa. Ainda, o grupo de adultos poderia ser avaliado com uma faixa etária mais abrangente, incluindo idosos, por exemplo, o que levaria à uma melhor análise das mudanças geradas pelo desenvolvimento da percepção de contraste e reconhecimento de expressões faciais de emoções.

Um outro ponto a ser considerado tem relação com as faces utilizadas em nosso estudo. As faces utilizadas no experimento são do banco de faces do Karolinska Institute da Suécia. Embora seja um banco de faces para estudos científicos validado, há notavelmente diferenças nos traços das faces quando comparadas às presentes na nossa população. Esta diferença pode ter contribuído negativamente para o estudo.

Para estudos futuros, sugerimos uma ampliação dos níveis de contraste a serem testados, isto permitiria um desenho de função psicométrica mais ajustado e consequentemente com menor variabilidade, pois apresentaria um maior número de pontos. O uso de medidas psicofísicas de estímulos constantes foi uma determinação metodológica derivada das características de geração do estímulo e de computação gráfica apresentados pelo sistema Psykinematix. Outros métodos psicofísicos mais adaptativos como o método da escada, poderão ser também testados em estudos futuros.

As emoções neste estudo tratadas, foram escolhidas entre as emoções básicas pontuadas por Ekman (1992), mas pesquisas futuras poderiam abranger emoções não inseridas neste experimento, como medo, ou emoções secundárias, que fazem parte do nosso dia-a-dia, como culpa ou a vergonha.

\section{VI.1 Percepção Face, Emoção e Contraste}

Em uma inspeção qualitativa visual, os valores de limiar de contraste para as emoções foram, em sua quase totalidade, menores para os homens do que para as mulheres, embora não fosse possível encontrarmos significância estatística para estas diferenças. Esses dados corroboram os dados encontrados no trabalho de 
Caramaschi (1997) que também encontrou melhor desempenho em julgamento de emoções em faces para homens do que para mulheres. No entanto, este trabalho não modulou o contraste das imagens. Encontramos resultado semelhante para os meninos, quando comparados com as meninas.

Não foi possível identificar uma emoção padrão comum entre todos os subgrupos, que necessitasse de um menor nível de contraste para ser reconhecida com maior facilidade. Notamos que nos subgrupos Femininos, Adulto e Criança, as expressões de tristeza foram reconhecidas com mais facilidade que as outras. No subgrupo Adulto Homem as expressões de alegria apareceram entre as primeiras identificadas, e no subgrupo Criança Homem a expressão de Raiva ficou em evidência. 


\section{CONCLUSÃO}

Foi possível comprovar a melhora da percepção de contraste e do reconhecimento de expressões faciais de emoções durante o aumento das idades, assim como pudemos notar um melhor desempenho dos sujeitos do sexo masculino na realização da tarefa.

Entre todas as emoções e os sexos, apenas o julgamento para faces de Homem Neutro foi estatisticamente significante, quando comparado ao julgamento de faces de Mulher Neutro, pelo subgrupo Adulto Masculino. 


\section{BIBLIOGRAFIA}

Adolphs, R., Gosselin, F., Buchanan, T. W., Tranel, D., Schyns, P., \& Damasio, A. R. (2005). A mechanism for impaired fear recognition after amygdala damage. Nature, 433 (7021), 68-72

Albert, J., et al., (2008). Alteraciones emocionales en el trastorno por déficit de atención/hiperactividad: datos existentes y cuestiones abiertas. Revista de Neurología, 47 (1), 39-45.

Anstis, S. M., (1998). Picturing peripheral acuity. Perception, 27, 817-825

Bal, E., et al., (2010). Emotion recognition in children with autism spectrum disorders: relations to eye gaze and autonomic state. Journal of Autism and Developmental Disorders, 40 (3), 358370.

Baron-Cohen, Simon, Ring, Howard, A., Wheelwright, Sally, Steve, C. R. (1999). Social intelligence in the normal and autistic brain: an fmri study. European Journal of Neuroscience, 11 (6), 1891-1898.

Bate, S. et al., (2010). Socio-emotional functioning and face recognition ability in the normal population. Personality and Individual Differences, 48 (2), 239-242.

Berenbaum, H. \& Rotter, A. (1992). The relationship between spontaneous facial expressions of emotion and voluntary control of facial muscles. Journal of Nonverbal Behaviour, 16 (3): 179-190.

Bretherton, I., et al., (1986). Learning to talk about emotions: a functionalist perspective. Child Development, 57, 529-548.

Brody, L. R. \& Harrison, R. H. (1987). Developmental changes in children's abilities to match and label emotionally laden situations. Motivation and Emotion, 11 (4), 347-365.

Brotman, M. A., et al., (2008). Risk for bipolar disorder is associated with face processing deficits across emotions. Journal of the American Academy of Child and Adolescent Psychiatry, 47 (12), $1455-1461$.

Bruce, V. \& Young, A.W. (2012). Face perception. Psychology Press: London.

Buitelaar, J. K., et al., (1999). Theory of mind and emotion-recognition functioning in autistic spectrum disorders and in psychiatric control and normal children. Development and Psychopathology, 11 (1), 39-58.

Burns, J. (1999). La hipótesis del cerebro social en la esquizofrenia. World Psychiatry, 4 (2), 77-81.

Burton, A. M. (2013). Why has research in face recognition progressed so slowly? The importance of variability. The Quarterly Journal of Experimental Psychology, 66 (8), 1467-1485.

Calder, A. J., Keane, J., Lawrence, A. D., \& Manes, F. (2004). Impaired recognition of anger following damage to the ventral striatum. Brain, 127 (9), 1958-1969.

Calder, A.J., Young, A.W., Keane, J. \& Dean, M. (2000). Configural information in facial expression perception. J. Exp. Psychol. Hum. Percept. Perform. 26, 527-551.

Calvo, M. G. \& Lundqvist, D. (2008). Facial expressions of emotion (kdef): identification under different display-duration conditions. Behavior Research Methods, 40 (1), 109-115. 
Campbell, F. W. \& Maffei, L. (1974). Contrast and spatial frequency. Scientific American, 231, 106-114.

Campos, J. J., Campos, R., G., \& Barrett, K. C. (1989). Emergent themes in the study of emotional development and emotion regulation. Development Psychology, 25(3), 394-402.

Caramaschi, S. (1997). O conhecimento das expressões faciais de emoções: tarefas de julgamento, reconhecimento de descrições, descrição e produção. Tese (Doutorado em Psicologia) Universidade de São Paulo, São Paulo.

Carrera-Levillain, P. \& Fernandez-Dols, J. M. (1994). Neutral faces in context: Their Emotional Meaning and Their Function. Journal of Nonverbal Behavior, 18(4): 281-299.

Chen, J. (2014). Face recognition as a predictor of social cognitive ability: effects of emotion and race on face processing. Asian J. Soc. Psychol., 17, pp. 61-69.

Collin, L., et al., (2013). Facial emotion recognition in child psychiatry: a systematic review. Research in Developmental Disabilities, 34, 1505-1520.

Colwell, M. J., \& Hart, S. (2006). Emotion framing: does it relate to children's emotion knowledge and social behavior?. Early Child Development, 176(6), 591-603.

Cornsweet, T. N. (1970). Vision perception. New York: Academic Press.

Costen, N. P., Parker, D. M., \& Craw, I. (1996). Effects of high-pass and low-pass spatial filtering on face identification. Perception and Psychophysics, 58, 602-612.

Cruz, A. A. V., \& Salomão, S. R (1998). Acuidade visual. Arquivos Brasileiros de Psicologia, 50, 9-26.

D'Argembeau, A. et al., (2003). The effects of happy and angry expressions on identity and expression memory for unfamiliar faces. Cognition and Emotion, 17, 609-622.

Dalgleish, T., Dunn, B. D., \& Mobbs, D. (2009). Affective neuroscience: past, present, and future. Emotion Review, 1 (4), 355-368.

Davis, F. (1979). A comunicação não verbal. São Paulo, Summus Editorial.

De Sonneville, L. et al., (2002). Facial identity and facial emotions: Speed, accuracy, and processing strategies in children and adults. Journal of Clinicaland Experimental Neuropsychology, 24(2), 200-213.

Denham, S. A. (1998). Emotional development in young children. New York: Guilford Press.

Denham, S. A., et al., (1994). Socialization of preschooler's emotion understanding. Developmental Psychology, 30(6), 928-936.

Desimone, R., et al., (1984). Stimulus-selective properties of inferior temporal neurons in the macaque. Journal of Neuroscience, 4, 2051-2062.

Desimone, R. (1991). Face-selective cells in the temporal córtex of monkeys. Journal of Cognitive Neuroscience, 3, 1-8.

Dias, É. B. \& Minervino, C. A. S. M. (2009). Competência emocional em crianças portadoras de transtorno do déficit de atenção/hiperatividade e outras patologias. Pediatria Moderna, 49 (6), 240-244. 
do Valle, J. (2008). A divisão sensorial do sistema nervoso. Fisiologia Humana e Biofísica.

Ekman P. (1978). Facial Signs: Facts, Fantasies, and Possibilities. In Sebeok, T. (Ed.), Sight, Sound, and Sense (pp. 124-156). Bloomington, IN: Indiana University Press.

Ekman, P. \& Friesen, W. V. (1969) The repertoire of nonverbal behavior: categories, origins, usage and coding. Semiotica, 1, 49-98.

Ekman, P. \& Friesen, W. V. (2003). Umasking the Face: a guide to recognizing emotions from facial expressions. Cambridge: This Malor Edition.

Ekman, P. (1992). An argument for basic emotions. Cognition and Emotion, 169-200.

Ekman, P. (2003). Darwin, deception, and facial expression.

Ekman, P. (2011). A linguagem das emoções. São Paulo: Lua de Papel

Ewing, L., et al., (2017). Developmental changes in the critical information used for facial expression processing. Cognition, 166, 56-66

Fasel, B. \& Luettin, J. (2003). Automatic facial expression analysis: a survey. Pattern Recognition, 36 (1), 259-275.

Feitosa, M. A. G. (1999). Resenha: Darwin, o comportamento humano e as emoções. Psicologia: Teoria e Pesquisa, 15 (3), 265-267.

Fiorentini, A., Maffei, L., \&Sandini, G. (1983). The role of high spatial frequencies in face perception. Perception, 12, 195-201.

Freitag, C. \& Schwarzer, G. (2009). Influence of emotional facial expressions on 3-5yearolds' face recognition. Cognitive Development, 26 (3), 230-247.

Gao, X., \& Maurer, D. (2009). Influence of intensity on children's sensitivity to happy, sad, and fearful facial expressions. Journal of Experimental Child Psychology, 102(4), 503-521.

Garner, P. W., Jones, D. C., \& Miner, J. L. (1994). Social competence among low-income preschoolers: emotion socialization practices and social cognitive correlates. Child Development, 65 (2), $622-637$.

Gauthier, I., Tarr, M. J., Anderson, A. W., Skudlarski, P., \& Gore, J. C. (1999). Activation of the middle fusiform'face area'increases with expertise in recognizing novel objects. Nature Neuroscience, 2 (6), 568-573.

Gomes, J. S. (2013). Protocolo de avaliação psiconeurofisiológica em crianças entre 9 e 13 anos durante a apresentação de imagens de filmes de animação.

Gosselin, F., \& Schyns, P. (2001). Bubbles: A technique to reveal the use of information in recognition tasks. Vision Research, 41(17), 2261-2271.

Gross, C. G., Rocha-Miranda, C. E., \& Bender, D. B. (1972). Visual properties of neurons in inferotemporal cortex of the macaque. Journal of Neurophysiology, 35, 96-111.

Haan, M., et al., (2004). Maternal personality and infants' neural and visual responsivity to facial expressions of emotion. Journal of Child Psychology and Psychiatry, 45 (7), 1209-1218.

Halberstadt, A. G., Denham, S. A., Dunsmore, J. C. (2001). Affective Social Competence. Social Development, 10(1), 79-119. 
Hamer, R. D., Mayer, D. L. (1994). The development of spatial vision. In D. M. Albert \& F. A. Jakobiec (Eds.), Principles and practice of ophthalmology: Basic sciences ( $p$ p. 578- 608). Philadelphia: WB Saunders.

Hansen, C. H. \& Hansen, R. D. (1988). Finding the face in the crowd: An anger superiority effect. Journal of Personality and Social Psychology, 54 (6), 917-924.

Haxby, J. V., Hoffman, E. A., \& Gobbini, M. I. (2000). The distributed human neural system for face perception. Trends in Cognitive Sciences, 4 (6), 223-233.

Hayes, T., Morrone, M. C., \& Burr, D. C. (1986). Recognition of positive and negative bandpass-filtered images. Perception, 15, 595-602.

Herba, C., \& Phillips, M. (2004). Annotation: Development of facial expression recognition from childhood to adolescence: Behavioral and neurological perspectives. Journal of Child Psychology and Psychiatry, 45(7), 1185-1198.

Hess, U., Adams, R. B., Jr., \& Kleck, R. E. (2004). Facial Appearance, Gender, and Emotion Expression. Emotion, 4(4), 378-388.

Huang, C. L. C., Hsiao, S., Hwu, H. G., \& Howng, S. L. (2012). The chinese facial emotion recognition database (cferd): a computer-generated 3-d paradigm to measure the recognition of facial emotional expressions at different intensities. Psychiatry Research, 200 (2), 928-932.

Hubel, D. H., \& Wiesel, T. N. (1962). Receptive fields binocular interaction and functional architecture in the cat's visual cortex. Journal of Physiology, 160, 106-154.

Hubel, D. H., \& Wiesel, T. N. (1977). Functional Architecture of macaque monkey visual cortex. Proceedings of the Royal Society of London, 198, Series B, 1-59.

Hurvich, L. M., \& Jameson, D. (1955). A quantitative theoretical account of color vision. Transactions of the New York Academy of Sciences, 18, 33-38.

Hurvich, L. M., \& Jameson, D. (1957). An opponent-processes theory of color vision. Psychological Review, 64, 384-404.

Hurvich, L. M., \& Jameson, D. (1974). Opponent process as a model of neural organization. America Psychologist, 29, 88-102.

Izard, C., et al., (2001). Emotion knowledge as a predictor of social behavior and academic competence in children at risk. Psychological Science, 12 (1), 18-23.

Jack, R. E., Garrod, O. G., \& Schyns, P. G. (2014). Dynamic facial expressions of emotion transmit an evolving hierarchy of signals over time. Current Biology, 24 (2), 187- 192.

Johnston, A., Hill, H., \& Carman, N. (2013). Recognising faces: effects of lighting direction, inversion, and brightness reversal. Perception, 42 (11), 1227-1237.

Johnston, P., Kaufman, J., Bajic, J., \& Sercombe, A. (2011). Facial emotion and identity processing development in 5- to 15-year-old children. Frontiers in Pschology, 2, 1-9.

Kandel, E. R. \& Schwartz, J. H. (1985.). Princípios de Neurociências (5ª ed. 2014), Porto Alegre: AMGH. 
Kawasaki, H., Tsuchiya, N., Kovach, C. K., Nourski, K. V., Oya, H., Howard, M. A., \& Adolphs, R. (2011). Processing of facial emotion in the human fusiform gyrus. Journal of Cognitive Neuroscience, 24 (6), 1358-1370.

Keltner, D., et al., (2003). Facial expression of emotion. In: R. J. Davidson, K. R. Scherer \& H. H. Goldsmith, eds. Handbook of Affective. Sciences, pp. 415-432. Oxford: Oxford. University Press.

Kesler, M. L., Andersen, A. H., Smith, C. D., Avison, M. J., Davis, C. E., Keslerand, R. J. K., \& Blonder, L. X. (2001). Neural substrates of facial emotion processing using fmri. Cognitive Brain Research, 11 (2), 213-226.

Kolb, H. (2011). Simple Anatomy of the Retina by Helga Kolb, https://webvision.med.utah.edu/book/part-i-foundations/simple-anatomy-of-the-retina/ acessado em (18 março 2019).

Ku, J., Jang, H. J., Kim, K., Kim, J.-H., Park, S. H., Lee, J.-H., Kim, S. I. (2005). Experimental results of affective valence and arousal to avatar's facial expressions. Cyberpsy., Behavior, and Soc. Networking, 8, 493-503.

LaBarbera, J. D., et al., (1976). Four- and six-month-old infants' visual responses to joy, anger, and neutral expressions. Child Development, 47, 535-538.

Lane, R. D., Reiman, E. M., Ahern, G. L., Schwartz, G. E., \& Davidson, R. J. (1997). Neuroanatomical correlates of happiness, sadness, and disgust. American Journal of Psychiatry, 154, 926-933.

Lawrence, K., Campbell, R., \&Skuse, D. (2015). Age, gender and puberty influence the development of facial emotion recognition. Frontiers in Psychology, 6, 1-14.

LeDoux, J. (2003). The emotional brain, fear, and the amygdala. Cellular and Molecular Neurobiology, 23 (4-5), 727-738.

Lee, H. J., Youn, J. M., O, M. J., Gallagher, M., \& Holland, P. C. (2006). Role of substantia nigra-amigdala connections in surprise-induced enhancement of attention. Journal Neuroscience, 26 (22), 6077-6081.

Leitzke, B. T. \& Pollak, S. D. (2016). Developmental changes in the primacy of facial cues for emotion recognition. Developmental Psychology, 52 (4), 572-581.

Lewis, Gary J.; Lefevre, Carmen E.; Young, Andrew W. (2016). Functional architecture of visual emotion recognition ability: A latent variable approach. Journal of Experimental Psychology: General, Vol 145(5), 589-602.

Liu, C.H., Collin, C.A., Rainville, S.J. \& Chaudhuri, A. (2000). The effects of spatial frequency overlap on face recognition. J. Exp. Psychol. Hum. Percept. Perform. 26, 956-979.

Livingstone, M. S., \& Hubel, D. H. (1987). Psychophysical evidence for separate channels for the perception of form, color, movement, and depth. Journal of Neuroscience, 7, 3416-3468.

Lundqvist, D., et al., (1998). The Karolinska Directed Emotional Faces-KDEF [CD-ROM]. Department of Clinical Neuroscience, Psychology section, Karolinska Institutet, Stockholm. 
Machado, P., et al., (2008). Relações entre o conhecimento das emoções, as competências acadêmicas, as competências sociais e a aceitação entre pares. Análise Psicológica, 3 (26), 463-478.

Malatesta, C. Z. \& Haviland, J. M. (1982). Learning display rules: the socialization of emotion expression in infancy. Child Development, 53 (4), 991-1003.

Matsumoto, D. (2009). Culture and emotional expression. Problems and solutions in crosscultural theory, 263-280.

Matsumoto, D., \& Ekman, P. (1988). Japanese and Caucasian Facial Expressions of Emotion (JACFEE) and Neutral Faces (JACNeuF). [Slides]: Dr. Paul Ekman, Department of Psychiatry, University of California, San Francisco.

Maxim, L. A. \& Nowicki, S. J. (2003). Developmental associations between nonverbal ability and social competence. Facta Universitatis-Series Philosophy, Sociology, Psychology and History, 10, 745-758.

Mayberg, H. S., Liotti, M., Brannan, S. K., McGinnis, S., Mahurin, R. K., Jerabek, P. A., Fox, P. T. (2014). Reciprocal limbic-cortical function and negative mood: converging pet findings in depression and normal sadness. The American Journal of Psychiatry, 156 (5), 675-682.

McCarthy, G., Puce, A., Gore, J. C., \& Allison, T. (1997). Face-specific processing in the human fusiform gyrus. J. Cognitive Neuroscience, 9 (5), 605-610.

Meletti, S. (2016). Emotion recognition. Neuropsychiatric Symptoms of Epilepsy, 177- 193.

Mendes, A. I. F., Arrais, K. C., \& Fukusima, S. S. (2009). Faces prototípicas provenientes de amostras populacionais de uma região brasileira. Psicologia: Reflexão e Crítica, 22 (2), 261-268.

Miller, G. A. (1962). Psychology: the science of mental life. Nova York: Harper \& Row.

Mishkin, M., et al., (1983). Object vision and spatial vision: two cortical pathways. Trends in Neuroscience, 1983, 6, 414-417.

Nasanen, R. (1999). Spatial frequency bandwidth used in the recognition of facial images. Vision Res. 39, 3824-3833.

Nelson, C. A. (2001). The development and neural bases of face recognition. Infant and Child Development, 10 (1-2), 3-18.

Norman, J. \& Ehrlich, S. (1987). Spatial frequency filtering and target identification. Vision Res. 27, 87-96.

Palma, B. \& Aboitiz, F. (2012). Procesamiento de expresiones faciales: una pro-puesta para el estudio del comportamiento social en el trastorno por déficit atencional e hiperactividad. Revista Chilena de Neurologia de la Infancia y Adolescencia, 2 (23), 119.

Pelli, D. G. \& Zang, L. (1991). Accurate control of contrast on microcomputer displays. Vision Research, 31, 1337-1350,

Pelphrey, K., et al., (2007). Perception of dynamics changes in facial affect and identity in autism. Scan, 2, 140-149. 
Perilla, L. M. (2008). Efeitos de bandas de frequência espacial alta e baixa no reconhecimento de faces em campo visual lateralizado. 2008. 65 f. Dissertação (Mestrado) - Faculdade de Filosofia, Ciências e Letras de Ribeirão Preto, Universidade de São Paulo, Ribeirão Preto, 2008.

Phillips, M. L., Drevets, W. C., Rauch, S. L., \& Lane, R. (2003). Neurobiology of emotion perception I: the neural basis of normal emotion perception. Biological Psychiatry, 54 (3), 504-514.

Reynolds, C., \& Kamphaus, R. W. (1992). Behavior Assessment System for Children. Circle Pines, MN: American Guidance Services.

Rivers, S. E., et al., (2010). Emotional intelligence in early adolescence: Its relation to academic performance and psychosocial functioning. Manuscript submitted for publication.

Rocca, C. C. A., et al., (2009). Facial emotion recognition in bipolar disorder: a critical review. Revista Brasileira de Psiquiatria, 31, 171-180.

Rocca, C. C. A., van den Heuvel, E., Caetano, S. C., \& Lafer, B. (2009, June). Facial emotion recognition in bipolar disorder: a critical review. Revista Brasileira de Psiquiatria, 31, 171-180.

Rodger H., et al., (2015). Mapping the development of facial expression recognition. Dev. Sci. $10.1111 /$ desc. 12281

Rodrigues, H. \& Rocha, F. L. (2016). Uma definição constitutiva de emoções: a constitutive definition of emotions. Revista Húmus, 5 (15), 18-32.

Rolls, E. T. (2000). On the brain and emotion. Behavioral and Brain Sciences, 23 (02), 219-228.

Rolls, E. T., \& Tovee, M. J. (1995). Sparseness of neuronal representation of stimuli in the primate temporal visual cortex. Journal of Neurophysiology, 73, 713-726.

Russell, J. A. \& Fernández-Dols, J. M. (1997). A what does a facial expression mean? The Psychology of Facial Expression, 1, 10-30.

Salomão, S. R. (2007). Desenvolvimento da acuidade visual de grades. Psicol. USP, São Paulo, v. 18, n. 2, p. 63-81.

Salovey, P., \& Mayer, J. D. (1990). Emotional intelligence. Imagination, Cognition and Personality, 9, 185-211.

Santana, C. C. D., de Souza, W. C., \& Feitosa, M. A. G. (2014). Recognition of facial emotional expressions and its correlation with cognitive abilities in children with down syndrome. Psychology \& Neuroscience, 7 (2), 73.

Schiffman, H. R. (2005). Sensação e percepção (L. A. F. Pontes \& S. Machado, Trad.). Rio de Janeiro: LTC.

Schwartz, S.H. (2009). Visual Perception: a Clinical Orientation. McGraw-Hill, New York.

Schyns, P.G. \& Oliva, A. (1999). Dr. Angry and Mr. Smile: when categorization flexibly modifies the perception of faces in rapid visual presentations. Cognition 69, 243-265.

Sergent, J. (1985). Influence of task and input factors on hemispheric involvement in face processing. J. Exp. Psychol. Hum. Percept. Perform. 11, 846-861.

Shankman, S. A., et al., (2013). Deficits in emotion recognition in pediatric bipolar disorder: the mediating effects of irritability. Journal of Affective Disorders, 144 (1), 134-140. 
Simões, E. A. Q.; Tiedemann, K. B. (1985). Psicologia da Percepção. São Paulo: EPU. Temas básicos de psicologia; v. 10 p. I, II

Schiller, P. H. (1992) The ON and OFF channels of the visual system. Trends in neuroscience, 15, 86-92.

Smith, M. L. , Cottrell, G. W. , Gosselin, F. \& Schyns, P. G. (2005).Transmitting and decoding facial expressions of emotion. Psychol. Sci.

Souza, G. S., et al., (2013). A visão através dos contrastes. Estud. Av. São Paulo, v. 27, n. 77, p.45-60.

Streit, M., loannides, A., Liu, L., Wölwer, W., Dammers, J., Gross, J., \& Müller-Gärtner, H. W. (1999). Neurophysiological correlates of the recognition of facial expressions of emotion as revealed by magnetoencephalography. Cognitive Brain Research, 7 (4), 481-491.

Teller, D. First Glance: (1997) The vision of Infants. Investigative ophthalmology and Visual Science, 38 (11): 2183-2203

Tettamanti, M., Rognoni, E., Cafiero, R., Costa, T., Galati, D., \& Perani, D. (2012). Distinct pathways of neural coupling for different basic emotions. Neuroimage, 59 (2), 1804-1817.

Tieger, T. \& Ganz, L. (1979). Recognition of faces in the presence of two-dimensional sinusoidal masks. Percept. Psychophys. 26, 163-167.

Tucker, J. S. \& Riggio, R. E. (1988). The role of social skills in encoding posed and spontaneous facial expressions. 87-97.

Tyler, C. W. (1997). Colour bit-stealing to enhance the luminance resolution of digital displays on a single pixel basis. Spatial Vision 10, 369-377

Vuilleumier et al., (2003). Distinct spatial frequency sensitivities for processing faces and emotional expressions. Nat. Neurosci., 6, pp. 624-631

Vuilleumier, P. \& Pourtois, G. (2007). Distributed and interactive brain mechanisms during emotion face perception: evidence from functional neuroimaging. Neuropsychologia, 45 (1), 174-194.

Waiden, T. A. \& Field, T. M. (1990). Preschool children's social competence and production and discrimination of affective expressions. British Journal of Developmental Psychology, 8 (1), 65-76.

Weiner, K. S. \& Zilles, K. (2015). The anatomical and functional specialization of the fusiform gyrus. Neuropsychologia, 83, 48-62.

Wilhelm, O., et al., (2010). Individual differences in perceiving and recognizing faces - one element of social cognition. Journal of Personality and Social Psychology, 99 (3), 530-548.

Young, M. P., \& Yamane, S. (1992). Sparse population coding of faces in the inferotemporal cortex. Science, 256, 1327-1331. 